\title{
SEPARATING EARTHWORMS FROM ORGANIC MEDIA USING AN ELECTRIC FIELD
}

\author{
DISSERTATION \\ Presented in Partial Fulfillment of the Requirements for \\ the Degree Doctor of Philosophy in the Graduate \\ School of the Ohio State University
}

By

Hala I. Chaoui, M.S.

The Ohio State University

2005

Dissertation Committee

Professor Harold Keener, Adviser

Approved by

Associate Professor Ann Christy

Professor Mark Bennett

Professor Deborah Stinner

Adviser

Food, Agricultural and Biological

Engineering Graduate Program 



\begin{abstract}
Earthworms have been shown to effectively process biodegradable organic waste and increase the availability of nutrients to plants in the final product, earthworm casts (or vermicompost), compared to the raw material. After processing earthworms are typically mechanically separated from the vermicompost and used for processing more waste or sold. This study investigated whether an electric field could be used to separate earthworms from vermicompost. Results showed that electric current does repel earthworms, at levels as low as $3 \mathrm{~mA}$. Results also showed that an electric field generated across electrodes inserted in a medium (such as soil) inhibits earthworm migration along a nitrate gradient. The effectiveness with which an electric field repels earthworms is a function of the voltage created across earthworms which in turn is a function of electrode depth, spacing, earthworm species (and resulting diameter and resistance) and electric current level. Each factor was shown to significantly affect the effectiveness with which earthworm were repelled. This was concluded through a set of experiments where earthworms were placed in a $2.8 \times 2.8 \times 7.5 \mathrm{~cm}$ soil slab at a density corresponding to 150 earthworms per liter, and effectiveness of the electric field was calculated as a function of the number of earthworms that exited the soil slab. Spatial voltage values were evaluated in each replicate in order to identify the voltage drops in the soil slab and derive the corresponding threshold electric current (current at the edge of the soil slab).
\end{abstract}


Results showed that the effectiveness of the electric field was logarithmically proportional to the voltage generated across earthworms, at a given electrode spacing, up to the point where earthworm mortality started to occur. At higher voltages the electric field effectiveness decreased exponentially due to mortality. The time where all potential earthworms exited a soil slab increased exponentially up to peak effectiveness, and decreased exponentially after that. Testing the derived model on different soil types showed that soil properties including salinity, moisture content and porosity are accounted for in the model by soil resistance that is indirectly expressed in the electric current term, and that the results apply to any soil type. A comparison between alternating and direct current showed an increased effectiveness of the model when alternating current was used, which suggests that an $\mathrm{AC}$ voltage source would increase the effectiveness with which an electric field repels earthworms. A model of electric current diffusion in earthworm casts suggested that as increasing voltage levels are used, the distance from the electric field at which an optimal electric current level can be found converges to a single value. The mathematical models derived from this study can be used for the preliminary design of an electric earthworm separator consisting of an array of current-conducting rods connected to a power or voltage source. 
Dedicated to my mother Mona 


\section{ACKNOWLEDGMENTS}

I would like to thank my adviser, Harold Keener, for his support, his very helpful attention to details, and his high expectations from me. I would also thank my initial advisor, Dr. Reza Ehsani, for his support and the freedom of action he gave me in my work, before he resigned from OSU. I also thank my graduate committee members Dr. Mark Bennett and Dr. Deborah Stinner for their support.

I thank the department of Food, Agricultural and Biological Engineering for funding me in my research, and giving me the technical and personal assistance I needed. I also thank the American Society of Agricultural and Biological Engineers for giving me the opportunity to present my work and interact with other professionals in my field; their welcoming attitude towards beginning professionals is very encouraging.

I thank my mother for bearing my absence from home during my $\mathrm{PhD}$ studies.

I also thank all my friends in the graduate student room 250 for their help and support, and my friends and roommates as well. 


\title{
VITA
}

\author{
September 27, $1973 \ldots \ldots \ldots \ldots \ldots \ldots \ldots \ldots \ldots$ Born - Beirut, Lebanon

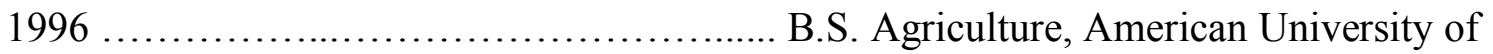 \\ Beirut

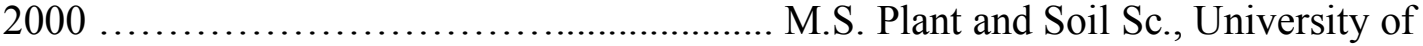 \\ Maine \\ $2000-2001 \ldots \ldots \ldots \ldots \ldots \ldots \ldots \ldots \ldots \ldots \ldots$ Researcher, \\ Entomology and Horticulture departments \\ at The Ohio State University \\ 2000 - present ......................... Graduate Research Associate, Department \\ of Food Agricultural and Biological \\ Engineering at The Ohio State University
}

\section{PUBLICATIONS}

\section{Research Publications}

Chaoui, H.I., Zibilske, L.M., Ohno, T. 2003. Effect of Earthworm Casts and Compost on Soil Microbial Activity and Plant Nutrient Availability. Soil Biology and Biochemistry, 35, 295-302.

\section{FIELDS OF STUDY}

MAJOR FIELD: Agricultural and Biological Engineering / Bioprocessing

Soil Science

Plant Science 


\section{TABLE OF CONTENTS}

ABSTRACT .2.

\section{CHAPTERS:}

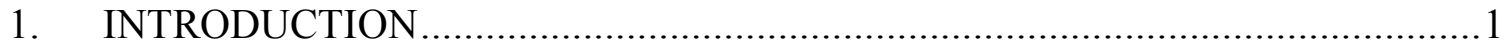

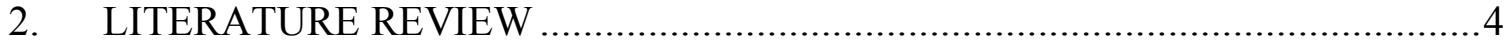

2.1. Current problems in organic farming....................................................... 4

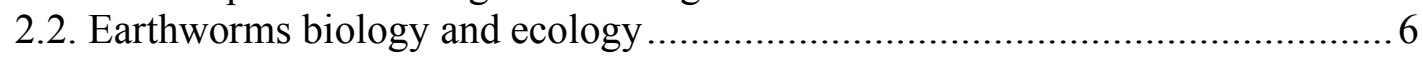

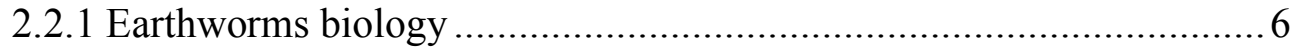

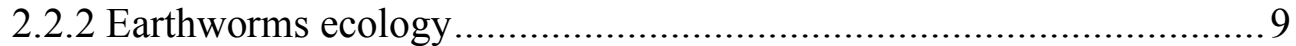

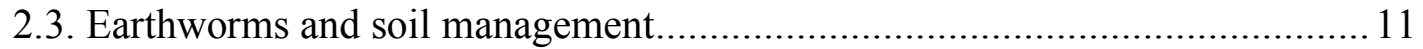

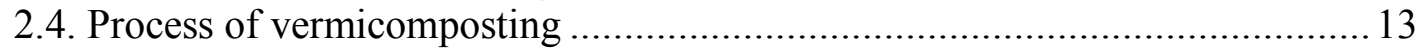

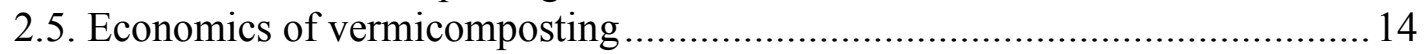

2.6. Earthworm separation techniques.............................................................. 14

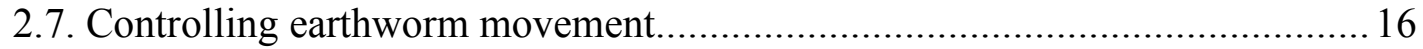

2.8. Effect of alternating and direct current on animals ......................................... 17

2.9. Effect of electric current on plant nutrient availability on soils ....................... 19

2.10. Mathematical models of the electric field effect on earthworms ...................20

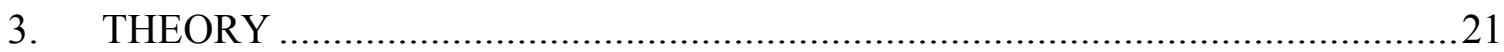

3.1. Variables affecting the voltage across earthworms ........................................2

3.2. Modeling electrical potential across earthworms ........................................2 23

3.3. Modeling the effectiveness of an electric field at repelling earthworms..........26

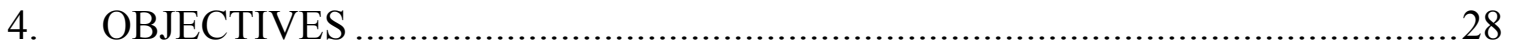

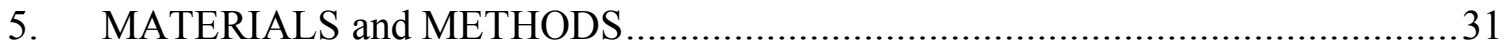

5.1. Mobility studies, no electric field ................................................................. 31

5.2. Mobility studies, with electric field .............................................................. 33

5.3. Testing and developing the theoretical model for effectiveness of an electric

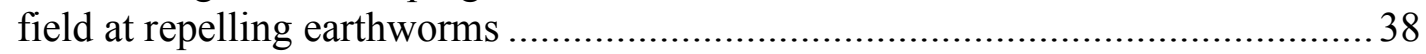

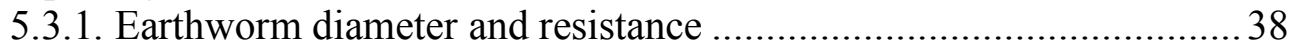

5.3.2. Electric field effectiveness at repelling earthworms ......................... 38

5.3.3. Deriving threshold electric current and soil slab resistance ............... 44

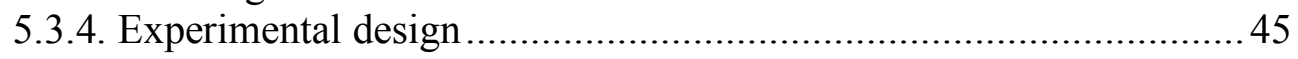


5.4. Testing the model for electric field effectiveness in media with different levels of soil salinity, moisture content or bulk density levels .................................. 48

5.5. The effect of direct or alternating current on the effectiveness of an electric field at repelling earthworms .................................................................... 50

5.6. The effect of current level on the location of threshold current in earthworm

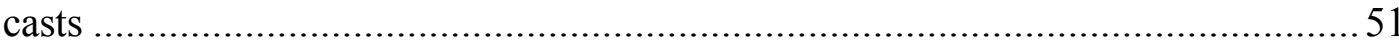

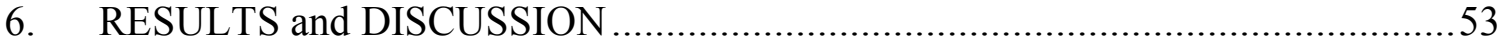

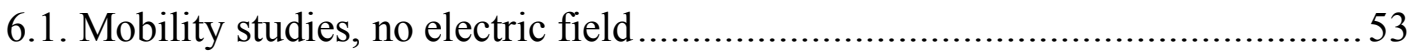

6.2. Mobility studies, with electric field .................................................. 54

6.3. Testing and developing the theoretical model for effectiveness of an electric

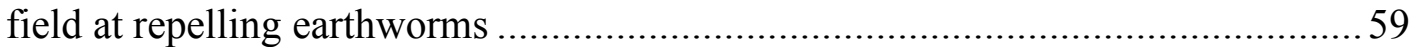

6.3.1. Earthworm diameter and resistance .......................................55

6.3.2. Deriving threshold resistance and electric current ........................59

6.3.3. Evaluating the effect of each variable on electric field effectiveness 63

6.3.4. Developing the model for electric field effectiveness at repelling

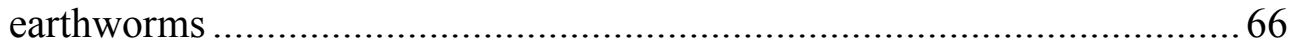

6.3.5. $\mathrm{t}_{100 \%}$ : Time required to repel all potential earthworms.....................6 68

6.3.6 Earthworm mortality ......................................................... 71

6.3.7. Replicability of the soil slab preparation technique ...................... 73

6.4. Test the model for electric field effectiveness in media with different levels of soil salinity, moisture content or bulk density levels .................................... 75

6.5. The effect of direct or alternating current on the effectiveness of an electric field at repelling earthworms ................................................................... 80

6.6. The effect of current level on the location of threshold current in earthworm

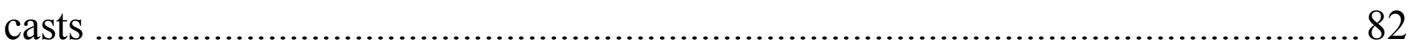

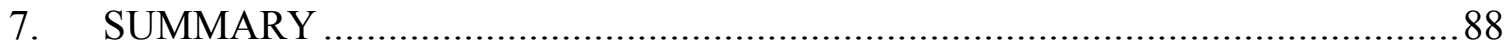

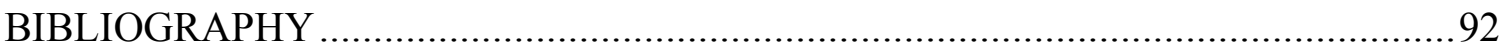

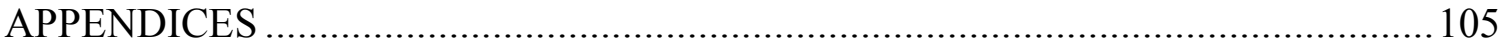

APPENDIX A: The effect of aeration on feed ingestion by earthworms............. 105

APPENDIX B: The effect of species distribution on the rate of feed ingestion by earthworms 


\section{LIST OF FIGURES}

Figure 2.1. Flowchart of processes involved in vermicomposting. Adapted from Fieldson, 1988.

Figure 3.1. The components of a soil slab; earthworms, soil and two electrodes, and location where voltage $(\mathrm{V})$ and resistance $(\mathrm{R})$ are measured. V drop threshold and $\mathrm{R}$ threshold were measured at the edge of the soil slab as shown.

Figure 5.1. Test setup 1 for study on electric field repelling earthworms. 34

Figure 5.2. Top view of the miniature field plot and the attached earthworm traps, raised on wooden pillars.

Figure 5.3. Method by which electrodes and a power supply were used to create an electric field.

Figure 5.4. a) Plastic dividers used as a mold to build a soil slab, a $2.8 \mathrm{~cm}$ electrode spacing is shown. b) Adding individually weighed soil layer followed by of earthworms each, a $1.4 \mathrm{~cm}$ electrodes spacing is shown. c) Once the soil and earthworms are stacked and compacted 2 of the 4 dividers are removed leaving the sides of the soil slab that are parallel to the electric field (generated across the electrodes) un-obstructed, to facilitate the exit of earthworms.

Figure 5.5. Top view of a soil slab; layout of the voltage drop measurements (represented by the labeled segments) at the surface of the soil slabs used to evaluate voltage diffusion. The large dots represent the soil electrodes (cathode and anode) across which the electric field is generated. The small dots represent the surface locations, in addition to the cathodes, where voltage was measured in reference to the anode. The two figures represent a) voltage drop measurements in treatments where the electrode spacing was $2.8 \mathrm{~cm}$ and $\mathrm{b}$ ) voltage drop measurements in treatments where the electrode spacing was $1.4 \mathrm{~cm}$.... 
Figure 5.6. Earthworm exiting the soil slab under the effect of the electric field generated

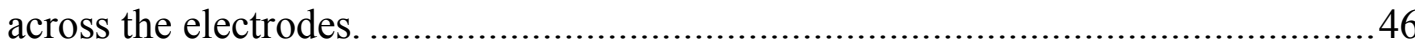

Figure 5.7. Top view of the rectangular soil slab used to measured voltage diffusion; layout of the voltage drop measurements (represented by the labeled segments) at the surface of the soil slabs used to evaluate voltage diffusion. The large dots red represent the two soil electrodes (cathode and anode) across which the electric current is generated. The small dots represent the surface locations where voltage was measured in reference to the anode.

Figure 6.1. Earthworm migration in the absence of containment is expressed in percentage weight of earthworms which exited a nutrient-rich container. Significant treatment differences at the 5\% level using Tukey's test between treatment means are indicated by differing letters

Figure 6.2. Earthworm displacement due to an electric field. The treatments were $0,3,5$, 7 , and $10 \mathrm{~mA}$. Significant treatment difference $(\mathrm{p}<0.05)$ was found between $0 \mathrm{~mA}$ current and all the other treatments, but not among the other treatments.

Figure 6.3. Earthworm migration across an electric field generated on one side of a 1x1 $\mathrm{m}$ surface area container is expressed in earthworm count. Significant treatment differences at the $5 \%$ level using Tukey's test between treatment means are indicated by differing letters.

Figure 6.4. Earthworm migration across an electric field generated at the border of a 37 $\mathrm{cm}$ diameter container is expressed in earthworm count. Significant treatment differences at the 5\% level using Tukey's test between treatment means are indicated by differing letters.

Figure 6.5. Voltage vs. electric current at the edge of the soil slabs with 7.5, 7.5, and 5 $\mathrm{cm}$ depth and $2.8,1.4$, and $1.4 \mathrm{~cm}$ electrode spacing respectively. The voltage drop across the corresponding spacing values was used to derive the threshold current in subsequent calculations. At the 24 volts level all treatments were significantly different at the 5\% level using Tukey's test

Figure 6.6. The ratio [electric current between electrodes/threshold electric current of the soil slab] vs. different treatments. Significant treatment differences at the $5 \%$ level are indicated by differing letters. 
Figure 6.7. Electric field effectiveness at repelling earthworms a) in all treatments and b) in treatments where one factor was varied between each treatment pair. Significant treatment differences at the 5\% level using Tukey's test between treatment means are indicated by differing letters.

Figure 6.8. Electric field effectiveness at repelling earthworms vs. a value proportional to the voltage created across earthworms $\left(\mathrm{V}_{\mathrm{w}} / \mathrm{k}\right)$.

Figure 6.9. a) Time elapsed in minutes before the maximum potential number of earthworms exiting the soil slab is reached $\left(\mathrm{t}_{100 \%}\right)$, in each treatment. Significant treatment differences at the 5\% level using Tukey's test between treatment means are indicated by differing letters. b) $\mathrm{t}_{100 \%}$ vs. a value proportional to the voltage created across earthworms $\left(\mathrm{V}_{\mathrm{w}} / \mathrm{k}\right)$.

Figure 6.10. a) Percentage earthworm mortality in each treatment. Significant treatment differences at the 5\% level using Tukey's test between treatment means are indicated by differing letters. b) Percentage earthworm survival vs. a value proportional to the voltage created across earthworms.

Figure 6.11. Soil resistance at the center of the soil slab, based on resistance measured between electrodes. Significant treatment differences at the 5\% level using Tukey's test between treatment means are indicated by differing letters.

Figure 6.12. Testing the model for electric field effectiveness by plotting against it field effectiveness values derived from four soil mixes as described in Table 6.2 ..........77

Figure 6.13. The $\mathrm{R}^{2}$ values indicate the fit of the electric field effectiveness recorded in four soil mixes, to the theoretical model. It is shown here in relation to the moisture level of used mixes. In this completely random blocked design, one of the blocks (mix 4) included a treatment with an $\mathrm{x}$ value beyond the range of the theoretical model. The trend line shown here excludes this mix (mix 4).

Figure 6.14. The $\mathrm{R}^{2}$ values indicate the fit of the electric field effectiveness recorded in four soil mixes, to the theoretical model. It is shown here in relation to the conductivity (salinity) level of used mixes. In this completely random blocked design, one of the blocks (mix 4) included a treatment with an x value beyond the range of the theoretical model. The trend line shown here excludes this mix (mix 4). 
Figure 6.15. The $\mathrm{R}^{2}$ values indicate the fit of the electric field effectiveness recorded in four soil mixes, to the theoretical model. It is shown here in relation to the $\%$ porosity of used mixes. In this completely random blocked design, one of the blocks (mix 4) included a treatment with an $x$ value beyond the range of the theoretical model. The trend line shown here excludes this mix (mix 4).

Figure 6.16. Electric field effectiveness at repelling earthworms when alternating or direct current is used, and also in comparison to the theoretical effectiveness value predicted by the model. Significant treatment differences at the 5\% level using Tukey's test between treatment means are indicated by differing letters. .81

Figure 6.17. Models of electric current values in function of the voltage created across an electric field and the distance of the current from the electric field (within $3 \mathrm{~cm}$ from the field). These values apply to a slab of earthworm casts that is $7.5 \mathrm{~cm}$ deep, with a porosity of $75.3 \%$ and a moisture level of $159 \%(\mathrm{db})$ .83

Figure 6.18. Distance from an electric field at which a targeted current of $2.2 \mathrm{~mA}$ is found, plotted against the voltage across the electric field.

Figure A.1. a) Trial 1 and b) Trial 2 of a study showing the effect of mechanical aeration on earthworm feeding rate, shown in hours until full incorporation of feed into the soil (Significant treatment differences at the 5\% level using Tukey's test between treatment means are indicated by differing letters).

Figure B.1. Elapsed time for feed incorporation in hours vs. the percentage of E. foetida in the distribution of endogeic and epigeic species. Each trial was analyzed for significant treatment differences separately and significant treatment differences at the 5\% level using Tukey's test are indicated by differing letters. 


\section{LIST OF TABLES}

Table 5.1. Treatments and the analyses used in studies on effectiveness of electric field at repelling earthworms ( ${ }^{*}$ see Table 5.2 for explanation of numbered treatments)....43

Table 5.2. Pairs of Set 2 treatments used to identify treatment effect of each factor.......43

Table 5.3. Soil mixes created to evaluate the effect of soil properties on the effectiveness of the electric field at containing earthworms. The percentages are by volume......50

Table 6.1. Diameter (D) and resistance (R) of two earthworm species, the corresponding standard error and the $\mathrm{RD}^{2}$ term to be used in modeling electric field effectiveness. Significant treatment differences at the 5\% level using Tukey's test between treatment means are indicated by differing letters

Table 6.2. Properties of the four soil mixes used in testing the model for electric field effectiveness at repelling earthworms, and the $\mathrm{R}^{2}$ values of showing the fit of each soil mix to the model. Significant treatment differences at the 5\% level using Tukey's test between treatment means are indicated by differing letters.

Table 6.3. The mean electric current values at increasing distances from an electric field generated between two electrodes, in a $7.5 \mathrm{~cm}$ deep soil slab, with a $2.8 \times 24 \mathrm{~cm}$ surface area. Significant treatment differences at the 5\% level using Tukey's test between treatment means are indicated by differing letters. Shown in bold are the significantly different values used to model the electric field's diffusion (in Figure 6.17 ), all within a $3 \mathrm{~cm}$ range from the electric field. Values beyond this range we not significantly different from those at $+/-3 \mathrm{~cm}$ from the electric field.

Table 6.4. Based on Figure 6.17, the following models express electric current in function of distance from an electric field and voltage, in an earthworm casts slab as described in (Figure 3.1), for each voltage level across the field. Models shown also express the distance at which a given current level is found from an electric field.. 86 


\section{CHAPTER 1}

\section{INTRODUCTION}

Effectively separating earthworms from organic media after completing a vermicomposting batch process could increase the rate of waste bioprocessing by earthworms and protect the monetary investment in earthworms for such operations. The technique developed to separate earthworms from organic media can also be used to contain them in agricultural plots and protect neighboring earthworm-susceptible ecosystems from earthworm invasions. High earthworm count in the soil could also enhance soil fertility since earthworms increase the rate of plant-available nutrient release from organic amendments (Pashanasi, 1992; Parmelee, 1988; Ruz-Jerez, 1992) and also increase soil aeration. There is also evidence that earthworms increase disease suppression in soil (Finola et al., 1995). A technique developed to effectively and quickly separate earthworms from the waste that they processed would allow streamlining the waste processing by earthworms. This in turn would allow more widespread implementation of this waste processing system and reduce the price of the byproduct: earthworm casts.

Earthworm-processed waste (earthworm casts) can be a valuable amendment in organic farming systems. Organic agriculture is a management system that enhances the agroecosystem's function through agronomic, biological, and mechanical practices, and 
is considered less resource-intensive than traditional agriculture (FAO, 1999). As a result, soil biological activity is sustained and the non-target effects of pesticide use are eliminated. Sustained microbial activity results in nutrient mineralization and disease suppression, which enhances soil fertility in an ecologically sustainable manner.

While organic agriculture has many positive production and ecological attributes, few studies have investigated ways to increase their economic efficiency. In particular, there are key questions concerning the management of nutrients in terms of supplying sufficient quantities during times of crop demand, while reducing the potential for losses of nutrients to the environment. This is where earthworm-processed waste could be an improved alternative to organic amendments with high nutrient immobilization levels.

A study started in 2001 by the North-East Organic Farming Network (NEON) at Cornell University targets organic farming knowledge gaps such as soil nutrient balances, possible over-application of nutrients, cover crops, crop rotation and its effect on disease and weed stress. In the Netherlands, emphasis is placed on improving manual weed control for use in organic farming by developing torsion and finger weeders, and sensoraided weeding (Kurstjens et al., 2000). The Organic Agriculture Consortium, led by the Ohio State University, has worked since 2000 to define biological and economic factors involved in successfully transitioning from conventional to organic production of grain, vegetable and fruit crops. A website developed by the Consortium provides researchbased information on transitional and certified organic production of these crops (organicaginfo.org). Organic farming needs more efficient ways to increase yield in order to meet the customer demand while maintaining organic standards (USDA Economic Research Service, 2000), and also while avoiding nutrient leaching from the soil. There 
are today 300,000 fewer small farms than in 1979, a trend that may be reversed by more economically sustainable organic farming (USDA, 1998).

On an economic level, high managerial costs are discouraging conversion to organic systems (USDA, 2001), even though organic produce is one of the fastest growing segments of the food industry, with sales totaling $\$ 7.8$ billion in 2000 (USDA, 2001).

The long-term goal of this study is to increase the efficiency of the process by which organic waste is processed by earthworms into a nutrient-rich product, which could potentially be used as an organic soil amendment. The immediate goal is to evaluate an electric field as a means of controlling earthworm movement in a media such as soil or waste. This would allow separating earthworms from organic media in a waste processing facility or containing earthworms at high densities in a field situation. 


\section{CHAPTER 2}

\section{LITERATURE REVIEW}

Vermicomposting is a mesophilic process that does not require the processed waste to reach elevated temperatures, which would actually be detrimental to earthworms, and is driven by the activity of earthworms and not that of bacteria and fungi. The result is an organic soil amendment that can be used in organic systems. The reviewed literature focuses on problems in organic farming, earthworm biology and ecology, the role of earthworms in soil fertility, the process and economics of recycling waste through earthworms, the known earthworm separation techniques, studies where earthworm movement was controlled, the role of electricity in repelling earthworms, and modeling the effect of an electric field on repelling earthworms.

\subsection{Current problems in organic farming}

Low fertilizer efficiency, nutrient leaching, and high labor and managerial costs prevent organic farming from being more profitable. Pang and Letey (2000) showed the low nitrate-efficiency of organic fertilizers in corn. In an experiment by Cavero et al. (1996) organic tomatoes fertilized with vetch and turkey manure showed nitrate $(\mathrm{N})$ deficiency compared to conventionally grown tomatoes. More nutrient leaching occurs 
from soil receiving composted or anaerobically stored manure than one amended with NPK (Bergstrom and Kirchmann, 1999). The suggested remedy was to use countermeasures to leaching rather than avoiding organic fertilizers. Green manuring, which is the application of legume mulches, is a common practice in organic farming and can also cause nitrate leaching (Cameron and Wild, 1984).

Farmers who convert to organic farming should expect losses in yield, particularly in the presence of low soil fertility and disrupted biological processes (FAO press release, 1999). In 1990, organically grown corn, soybean and wheat yields in Ohio were lower than state averages for these crops (Batte et al., 1993). Currently, organic farming needs more efficient ways to increase yield in order to meet the demand while maintaining organic standards (USDA Economic Research Service, 2000). Batte et al. (1993) also concluded that high managerial costs are discouraging farmers from adopting organic systems, since labor costs per acre were 6 percent higher for Ohio organic producers than for conventional farmers.

While disease suppression has been reported in organic systems in relation to compost and/or manure amendments, foliar and fruit diseases caused by bacterial, fungal and oomycete pathogens frequently occur in organic farming systems despite long crop rotations and other cultural practices. Numerous products approved by the Organic Materials Research Institute (OMRI, New Brunswick, NJ), plant extracts, compost teas, biological control agents and other materials are being marketed as foliar sprays and drenches, but few are highly effective on a consistent basis (Al Dahmani et al., 2003; McSpadden-Gardener and Fravel, 2002). OMRI-approved copper-based fungicides are most effective in managing foliar and fruit diseases of tomatoes (Wszelaki et al., 2002). 
However, copper compounds are well known to be toxic to earthworms (Reinecke et al., 2002; Burrows and Edwards, 2002; Jongmans et al., 2003; Spurgeon et al., 2004; Friis et al., 2004).

Foodborne disease outbreaks traced to fresh fruits and vegetables are increasingly recognized in the US. For example, a recent literature review cites twice as many produce-related foodborne disease outbreaks between 1988-1992 as in the five year period prior to 1988 (Buck et al., 2003). The risk of product contamination with foodborne pathogens is a concern for farmers whether using organic or conventional methods of agriculture. The primary source of produce contamination in the field is believed to be either the irrigation water or a soil (amended with manure) reservoir.

\subsection{Earthworms biology and ecology}

\subsubsection{Earthworms biology}

Earthworms belong to the order Oligochaeta, class Chaetopoda and phylum Annelida. Earthworms are classified into three ecological groups: epigeic, endogeic, and anecic. Epigeic worms burrow close to the surface. Endogeic worms burrow at approximately $15 \mathrm{~cm}$ depth. Anecic worms have vertical burrows reaching a depth of 1 $\mathrm{m}$ in the soil. Epigeic species increase the mineralization rate of surface litter and anecic species incorporate litter deeper into the soil profile and enhance aeration and water infiltration (Edwards and Bohlen, 1996).

The following information on earthworm biology is from Edwards and Lofty (1972). Earthworms have nervous, circulatory, digestive, excretory, muscular, and reproductive systems, and a segmented body. The circulatory system is closed and consists of a ventral 
and a dorsal blood vessel, that lead blood towards the posterior and anterior end respectively. The blood in pumped by a series of hearts at the anterior end. Earthworms have a nervous system consisting of a nerve bundle (brain) and a nerve cord. It is the earthworm nervous system, consisting of a nerve bundle (brain) and a nerve cord, which is affected by the passage of electric current through the earthworm. Each body segment is covered with bristles (setae) that are extended and retracted to facilitate movement. The locomotion of earthworms is due to muscular contractions which shorten and lengthen the body, alternately. The earthworm's skin includes eye cells, which cause earthworms to be sensitive to light, and skin glands which secrete mucus and facilitate burrowing. Oxygen uptake also occurs through the skin. Earthworms swallow the soil through which they burrow, and derive their nutrients from the organic residues in the soil. Earthworms are hermaphroditic but not self mating; after a mutual exchange of sperm a cocoon is produced by the clitellum near the anterior end of the body and sperm, and egg cells are deposited in it. Fertilization happens within the cocoon, which is deposited in the soil and hatches in about 3 weeks.

Earthworm-processed soil has a more water-stable structure than non-ingested material (Marininssen and Hillenaar, 1997). Earthworm casts have a composite structure made of 210-500 $\mu \mathrm{m}$ diameter units composed of very densely packed clay/silt size particles. Scanning electron microscopy suggests the high aggregate stability is due to the presence of cements (Chan and Heenan, 1995). This stability increases with aging of the casts (Shipitalo, 1987; Decaens, 1999). Earthworm casts also reduce soil salinity due to ammonium (Borowski, 1995). Less dissolved organic C, nitrate and ammonium leach from earthworm casts as compared to undigested soil, a difference which decreases after 
several wetting/drying cycles (McInerney and Bolger, 2000). Buckerfield et al. (1997) found that high numbers of earthworms in the soil may be indicators of sustainable crop production. Orozco (1996) found that coffee pulp processed by the epigeic earthworm Eisenia foetida with no initial available carbon (C) or nitrate (N) had $178 \mathrm{mg} / \mathrm{kg}$ of available $\mathrm{N}$ and $8600 \mathrm{mg} / \mathrm{kg}$ of extractable $\mathrm{C}$ after ingestion. In addition, the earthworm casts contained higher concentrations of $\mathrm{P}, \mathrm{Ca}$ and $\mathrm{Mg}$ than the initial material. Earthworms have an optimal soil pH range of 7-8 (Ndegwa and Thompson, 2000) and they suffer toxicity at high salinity levels (Santamaria-Romero et al., 2001).

A study by Schonholzer et al. (1999) showed that earthworms feed on fungi. The content of an earthworm's fore, mid and hindgut in filamentous fungi and bacterial cells was analyzed. It was reported that most of fungi hyphae was disrupted before arriving in the foregut (intestine), and the remaining hyphae were completely digested during passage through the gut. Bacterial cells were higher in number in the gut than in the soil, which was partially due to a multiplication of the cells. Also bacterial cell counts increased from fore- to hindgut (Schonholzer et al., 1999). Some studies investigated the mutualism between earthworms and microbes. In vitro tissue culture of different earthworm species gut walls showed that $P$. elongata synthesizes all of its own extra and intracellular enzymes, and that $P$. corethrurus requires soil microflora to hydrolyze cellulose and mannan (Lattaud et al., 1997). Barois, (1992) found that epigeic species have less microbial activity in their gut than endogeic species, which suggests less intense relationship between epigeic species and soil microflora.

Pathogen suppression in the presence of earthworms has also been investigated. Previous studies show that Enterobacteriacea including Salmonella are not isolated from 
the gastrointestinal tract of earthworms, even when worms are raised in heavily contaminated environments (Finola et al., 1995). These data would suggest that many Gram negative bacteria, such as those responsible for many of the foodborne diseases, do not survive passage through the gastrointestinal tract of the earthworm. Since high temperatures are not part of organic matter processing by earthworms, casts may inherently contain the microorganisms necessary for disease suppression. Only a few studies have tested for disease suppression in the presence of earthworm casts (Szczech et al., 1993) or earthworms - (Aporrectodea spp.) (Stephens and Davoren, 1997; Stephens et al., 1994). Szczech and Smolinska (2001) showed a suppression of the plant pathogen Phytophthora spp. by earthworm casts.

\subsubsection{Earthworms ecology}

In the field, earthworms at a density of 40 to $80 \mathrm{~g} / \mathrm{m}^{2}$ increased the efficiency of organic fertilizers by increasing the $\mathrm{N}$ mineralization rate of the ingested material (Pashanasi, 1992). Binet (1992) estimated $\mathrm{N}$ release from rye grass processed by earthworms at $0.13 \mathrm{mg}$ of $\mathrm{N}$ per gram earthworm per day. Birch seedlings planted in soil with earthworms had more leaf and stem biomass than those grown in pots without earthworms (Haimi, 1992). Nitrogen uptake increases in the presence of earthworms (Ruz-Jerez, 1992, Edwards, 1998), and so does soil porosity (Edwards, 1998). Earthworm casts applied to soybean plots increased plant dry weight by 40 to $70 \%$ (Lui et al., 1991) and plant yield was increased by $36 \%$ in the presence of earthworms (Pashanasi et al., 1996). Increased nitrogen uptake in the presence of earthworm casts was also reported by Zhao et al. (1988) and Tomati (1994). 
Earthworm population level is related to the level of organic matter in sandy savanna soils, and adding earthworms to the soil could increase agro-ecological sustainability (Araujo and Lopez-Hernandez, 1999). Earthworm spatial distribution was found not to be affected by topography (Rossi et al., 1997) but it is affected by the $\mathrm{C}$ to $\mathrm{N}$ ratio in plant residues and by tillage (Hubbard et al., 1999). As to the horizontal spatial redistribution of organic matter due to earthworms, anecic earthworms cause organic $\mathrm{C}$ to be distributed vertically in the soil while endogenous species caused higher organic $\mathrm{C}$ levels at or near the soil surface (Tomlin et al., 1992). This suggests that inoculating the soil with endogeic species would make organic matter available where it can be used by the plant.

Non-indigenous earthworms can also cause negative changes in the native vegetation of an ecosystem. The earthworm Lumbricus rubellus has colonized forests that did not originally contain earthworms and their presence was correlated with the extinction of the rare goblin fern Botrychium mormo and a reduction in the $\mathrm{O}_{1}$ and $\mathrm{O}_{2}$ soil horizons, and a significant increase in the thickness of the A horizon (Gundale, 2002). Earthworms can also have other undesired effects including burying of surface residues that protect soil surfaces from erosion, increase erosion and surface sealing due to fresh casts, dispersing weed seeds, and transmitting plant or animal pathogens (Hendrix and Bohlen, 2002). The positive or negative effect of earthworms on an ecosystem depends on the net result of all of its effects (Hendrix and Bohlen, 2002), and the potential side effects of earthworms suggest that an earthworm field containment technique would maintain earthworms at high counts and also protect neighboring susceptible ecosystems form earthworm invasions. 


\subsection{Earthworms and soil management}

Uncomposted animal manure can be used as a fertilizer for certified organic farmers only if incorporated into the soil at least 90-120 days before harvest time (USDA Economic Research Service, 2000). Although this may be manageable, there are problems due to the level of available nutrients in manure, and the odor caused by the release of ammonia and other compounds (Riskowski et al., 1991). Applying earthworm-processed residues instead or inoculating the soil with earthworms to increase mineralization could result in a product high in nutrients (Pashanasi, 1992; Parmelee, 1988; Ruz-Jerez, 1992) and with a lower rate of $\mathrm{N}_{2} \mathrm{O}$ production (Knight, 1992).

Intercropping wheat with the clover legume increases the number of earthworms to an average of 548 individuals per $\mathrm{m}^{2}$ as compared to wheat monocropping with 194 individuals per $\mathrm{m}^{2}$ (Schmidt et al., 2001). Intercropping with clover also increased the number of earthworm species as compared to the wheat system and favored the epigeic and epigeic/anecic types of earthworms (Schmidt et al., 2001).

In an experiment by Picek et al. (2000) it was shown that supplying the soil with air after it had been supplied with oxygen-free nitrogen gas significantly increased both $\mathrm{CO}_{2}$ evolution and microbial consumption of glucose, and also accelerated $\mathrm{C}$ mineralization. This indicates that increased aeration of the soil increases microbial activity and thus nutrient mineralization. Freijer (1996) modeled the rate of hydrocarbon mineralization and found oxygen and microbial biomass concentration to be the controlling variables, showing the relevance of increasing soil aeration to achieve faster mineralization. A synergy is expected to occur between the increased aeration in the 
presence of earthworms (due to their burrows) and the resulting increase in nutrient mineralization and microbial biomass. The reason is that earthworms feed on microbial biomass. A preliminary study (Appendix A) showed that mechanical aeration of the soil increases the rate at which earthworm incorporate feed into the soil.

Earthworms improve soil aeration and could reduce dependence on tillage if present in high numbers. Farm machinery, whether used for tillage or other tasks, affects pore space in the soil (Binet et al., 1997) and also leads to compaction, which affects root growth (Garcia et al., 1988). Tillage was also found to increase denitrification and $\mathrm{CO}_{2}$ efflux in a tilled fallow silt loam (Calderon et al., 2001). In corn production, soil sampled at a depth of $150 \mathrm{~cm}$ showed less residual $\mathrm{NO}_{3}-\mathrm{N}$ in a no-till system (Varshney et al., 1993). In addition, significantly more endogeic earthworms at depth of 5 to $15 \mathrm{~cm}$ are present under no-till conditions than under conventional tillage (Clapperton et al., 1997). Epi-endogeic earthworms incorporate surface applied residues in a no-till system which leads to yield increase (Brown et al., 1998; Tebrugge et al., 1999). Earthworm containment could therefore replace tillage for incorporation purposes. In turn no-till results in larger earthworm counts in an organic farming system (Hendrix, 1998), which implies a synergy between no-till and high earthworm counts.

Earthworm species distribution does affect the rate at which feed is incorporated into the soil. The effect of different earthworm species distribution on the rate of feed incorporation was tested (Appendix B) using a species mix made of an epigeic worm ( $E$. foetida) and an endogeic worm (E. hortensis) to represent species that allow adequate nutrient distribution across the root zone. Results showed that a $100 \%$ to $66 \%$ E. foetida species distribution resulted in the highest feed incorporation rate. 
Earthworms can be sampled by hand sorting $25 \times 25$ x $40 \mathrm{~cm}$ soil blocks (RodriguezAragones et al., 2001). Dickey and Kladivko (1989) found that the most efficient sample size for counting earthworms in-situ was a rectangle $10 \mathrm{~cm}$ along the row by half of the row spacing (45 $\mathrm{cm}$ across).

\subsection{Process of vermicomposting}

Vermicomposting is a mesophilic process that is driven by the activity of earthworms and not that of bacteria and fungi. It consists of feeding organic materials to earthworms. Vermicomposting does not require the processed waste to reach elevated temperatures, which would actually be detrimental to earthworms.

Earthworms have an optimal $\mathrm{pH}$ range of 7-8 (Ndegwa and Thompson, 2000) and they suffer toxicity at high salinity levels (Santamaria-Romero et al., 2001), therefore ammonia-rich material such as poultry manure may need to be buffered with other materials. The threshold ammonia level for waste to be processed by earthworms is 0.5 $\mathrm{mg} / \mathrm{g}$ waste on a wet basis, and $0.5 \%$ salt (Fieldson, 1988). Increased aeration accelerates the rate of waste processing by earthworms. Earthworms also have an ideal stocking density of 150 earthworms / liter in the case of Eisenia foetida (Frederickson and Howell, 2004) at which the rate of waste processing in maximized. The latter is the most efficient at consuming feed and the most commonly used species in commercial vermicomposting. Earthworms can ingest $75 \%$ of their weight daily (Ndegwa, 1999). The optimal moisture content in their feed is $75 \%$ (Ndegwa and Thompson, 2000).

The types of vermicomposting methods were summarized by Beetz (1999) to include windrow systems (labor intensive), stacked bins or containers (difficult to add feedstuff), 
batch reactors (one cycle at a time), and continuous flow reactors (capital intensive).

Earthworms migrate towards fresh feed, so in windrows and bins, 1 foot thick feed layers are added one at a time to draw earthworms away from the lower processed material, which is then collected. Thin feed layer additions prevent fermentation and the resulting heat build up which is lethal to earthworms.

\subsection{Economics of vermicomposting}

There are environmental benefits to processing organic waste into an environmentally friendly byproduct and to averting/reducing environmental costs (such as avoiding fines due to ground water pollution caused by organic waste disposal).

Waste can be processed through earthworms and sold at high profit depending on the effectiveness of the vermicomposting operation. Small-scale systems for vermicomposting are less capital intensive and can offer more economic flexibility, as more of these systems can be incrementally added as an operation grows. Earthworms produced in such operations can also be sold as bait or worm meal (protein source), however most of the revenue is expected to be from vermicompost since the earthworm market is limited (Fieldson, 1988).

\subsection{Earthworm separation techniques}

Up to the point where earthworms and waste must be separated, vermicomposting can be done using common horticultural equipment (Fieldson, 1988). Earthworms and processed waste must be separated before earthworm casts are sold in the market in order to preserve the investment in earthworms. The methods currently available for earthworm 
separation are time consuming, and some are energy consuming too. As summarized by Beetz (1999) and Fieldson (1988), these include mechanical separation and heating or drying the waste material.

Mechanical separation includes using a trammel-type screen separator made of an inclined rotating cylinder with a woven wire mesh wall. This type of separation is labor intensive and doesn't fit the high throughput in commercial vermicomposting (Fieldson, 1988). A modified separator without a screen wall gave improved results but it required that the vermicompost be at an $80 \%$ moisture level or less.

Gently heating the waste does drive earthworms out without harm, but this procedure is also costly (Fieldson, 1988). Drying the waste to repel earthworms from it is another option, but it is space and time consuming. Figure 2.1, as adapted from Fieldson (1988), is a flowchart of the vermicomposting process and its varied outputs. 


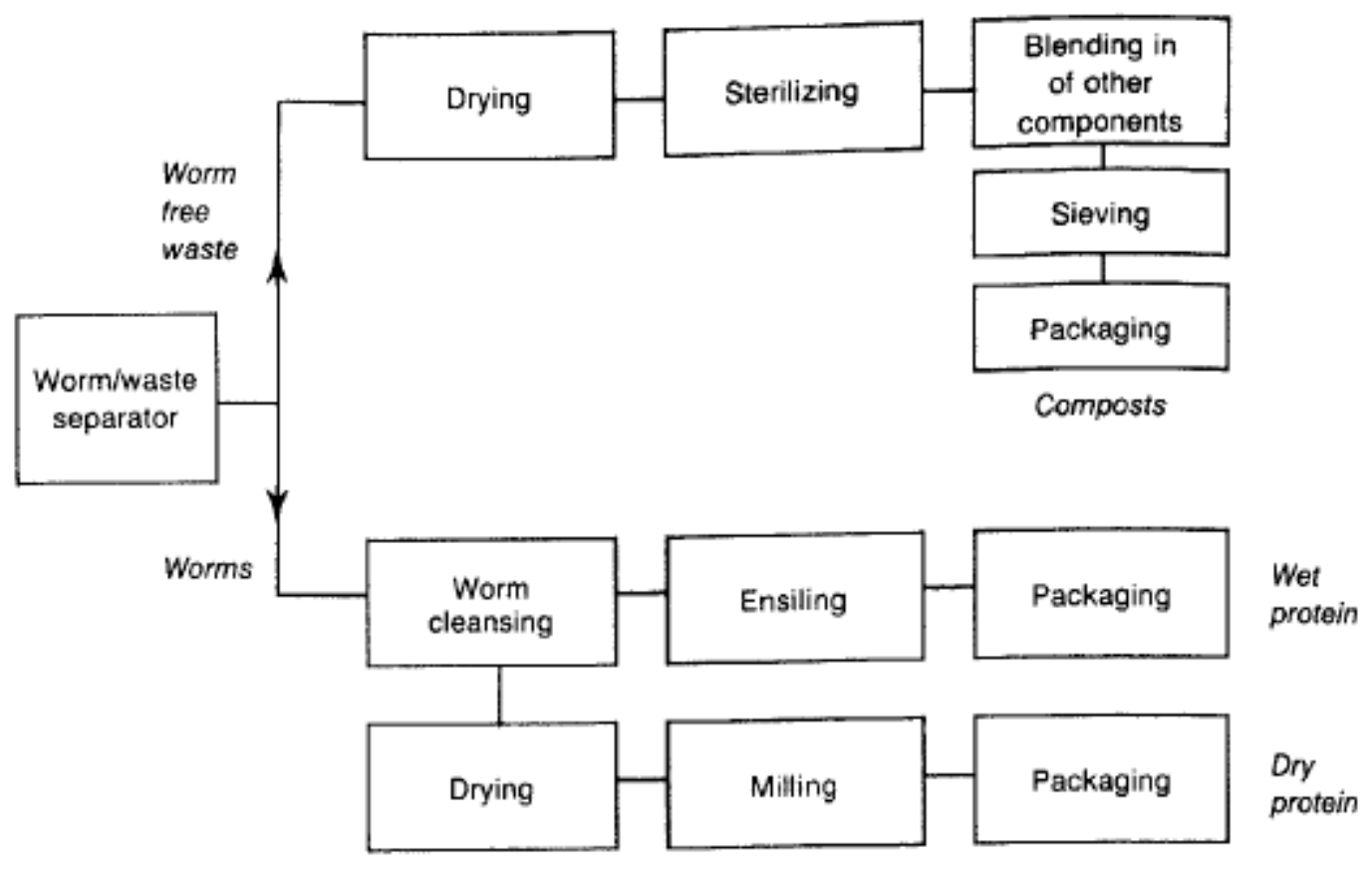

Figure 2.1. Flowchart of processes involved in vermicomposting. Adapted from Fieldson, 1988.

\subsection{Controlling earthworm movement}

Controlling earthworm movement can include repelling them from a media or containing them. Repelling earthworms accelerates the separation of earthworms and feed in a waste processing facility, and it can also be used as a mean of sampling earthworms. Rushton and Luff (1984) developed an electrical method for sampling earthworms; they inserted a circular array of electrodes in the soil and then passed current through pairs of diametrically opposing electrodes. As a result the soil within the electrode array behaved as a capacitor and earthworms were repelled from it. Shallowburrowing and juvenile earthworms were the easiest to extract. 
An earthworm containing system can maintain them at high counts in plots and protect neighboring fragile ecosystems from earthworm invasions. Bohlen et al. (1995) attempted to maintain high earthworm counts by enclosing them with PVC barriers buried $45 \mathrm{~cm}$ deep and $15 \mathrm{~cm}$ above the surface. The dominant species were Lumbricus terrestris and Aporrectodea tuberculata and this increased earthworm count by a multiplier of 1.17 .

\subsection{Effect of alternating and direct current on animals}

The following information was collected from a fact sheet by Surbrook and Schrandt (2005). Direct current (DC) moves in one direction through a conductor (such as the body of an earthworm) and causes muscle tetanus ("muscle freezing"). Alternating current $(\mathrm{AC})$ reverses direction through a conductor at a given frequency, 60 times per second at a frequency of $60 \mathrm{~Hz}$, which give the muscle opportunities to relax. However since AC current alternates direction it causes fibrillation in the neurons of the heart's pace maker. A heart "frozen" by DC has a better chance of recovery after the current is switched off than a fibrillating heart.

In a study by Gregory et al. (1991) it was found that increasing the frequency of a square wave (DC) beyond $125 \mathrm{~Hz}$ did not increase the incidence of ventricular fibrillation in broilers and hens. Aternating current at $50 \mathrm{~Hz}$ frequency was found more efficient at killing birds than the same r.m.s. (root mean square) current at $1500 \mathrm{~Hz}$. In a study by Robb et al. (2002) it was found that once a threshold lethal AC current magnitude is applied to trout, increasing the frequency of the current reduces the time it takes to kill the animal. Accordingly, when the intent is to repel but not kill earthworms, 
a low frequency (either a square DC wave or sinusoidal AC wave) might be more appropriate. Slowik et al. (1996) found that when $0.83 \mathrm{~mA}$ or more current flowed through the body of the red imported fire ant, Solenopsis invicta Buren, derangement, incapacitation, and death occured.

Low voltage electric fences have also been investigated in previous studies. Kolz (1995) devised and patented an aquatic electric fence which repels aquatic warm blooded mammals without injuring them, by generating a current across an array of electrodes. The operator of the fence can determine the level of energy to be induced through the animal in the water, and accordingly the criteria of the electric field to be induced are determined based on a design model. Poole et al. (2004) used different voltages and conductivity levels in an electric fence designed to repel badgers (Meles meles). As voltage increased and conductivity increased (meaning AC current increased) the fence became more effective at repelling badgers. 


\subsection{Effect of electric current on plant nutrient availability on soils}

When an electric current is used to contain earthworms at high counts in the soil, plant nutrient availability in the vicinity of the electric field might be affected. In a greenhouse experiment by Kravcov (1962) electric current was applied through the rhizosphere of bean plants and also through fallow soil. The result was increased microbial activity, microbial biomass, and organic matter mineralization. Mineralization increase was documented through an increase in $\mathrm{CO}_{2}$ release and in nitrate, ammonium, free phosphoric acid and water-soluble humus concentration. The result was also an increase in plant yield. Given these reported facts, in addition to using electric current at relatively high (yet sub lethal) levels at the edge of a planted plot to contain earthworms, current might also be used at relatively low levels to enhance nutrient mineralization and increase plant yield. 


\subsection{Mathematical models of the electric field effect on earthworms}

Previous studies (Pozdnyakova, 1999) showed the relation between several soil properties (CEC, salinity, moisture content) and soil bulk resistivity. Resistivity would in turn affect the current level if a voltage source was used. In this planned experiment however a current source will be used. Its effect on individual earthworms will depend on the electric potential (voltage) created as the current flows through the earthworm. This voltage depends on the current level, the earthworm's lateral diameter and its resistance. The current is also dispersed vertically across the depth of the soil electrode and horizontally, in an ellipsoid shape determined by the spacing between soil electrodes. As a result, the electric potential across the earthworm is a function of current, earthworm diameter and resistance, soil electrode depth and spacing, and will be modeled accordingly. 


\section{CHAPTER 3}

\section{THEORY}

\subsection{Variables affecting the voltage across earthworms}

An electric field is created through current loops generated by a current source between soil electrodes at a given depth. The effectiveness of this field at repelling earthworms is calculated as the ratio of number of earthworms repelled in the treatment to the number repelled in the control. The treatment differs from the control in that an electric field will be generated in the center of the soil slab. The edges of the soil slab parallel to the electric field are in direct contact with the air, allowing an easy exit for the earthworms.

In theory the effectiveness of an electric field at repelling earthworms or in containing earthworms is expected to depend on electric potential $\left(\mathrm{V}_{\mathrm{w}}\right)$ across the earthworm. Now $\mathrm{V}_{\mathrm{w}}$ is dependent on current level, earthworm diameter and resistance, and electrode depth (along which the current is divided). $\mathrm{V}_{\mathrm{w}}$ also depends on electrode spacing since this affects the spatial distribution of voltage between the two electrodes. The electric current considered here is the one at the threshold of the soil slab (the point beyond which earthworms were to be repelled) on the two sides parallel to the slab's centerline across which the two electrodes are placed (Figure 3.1). The level of electric 
current in this area will determine whether a given earthworm will exit the soil slab or remain in the soil slab.

A functional mathematical model was derived to predict electric potential across the earthworms using dimensional analysis. This analysis is based on the fact that both sides of an equation must have the same units.

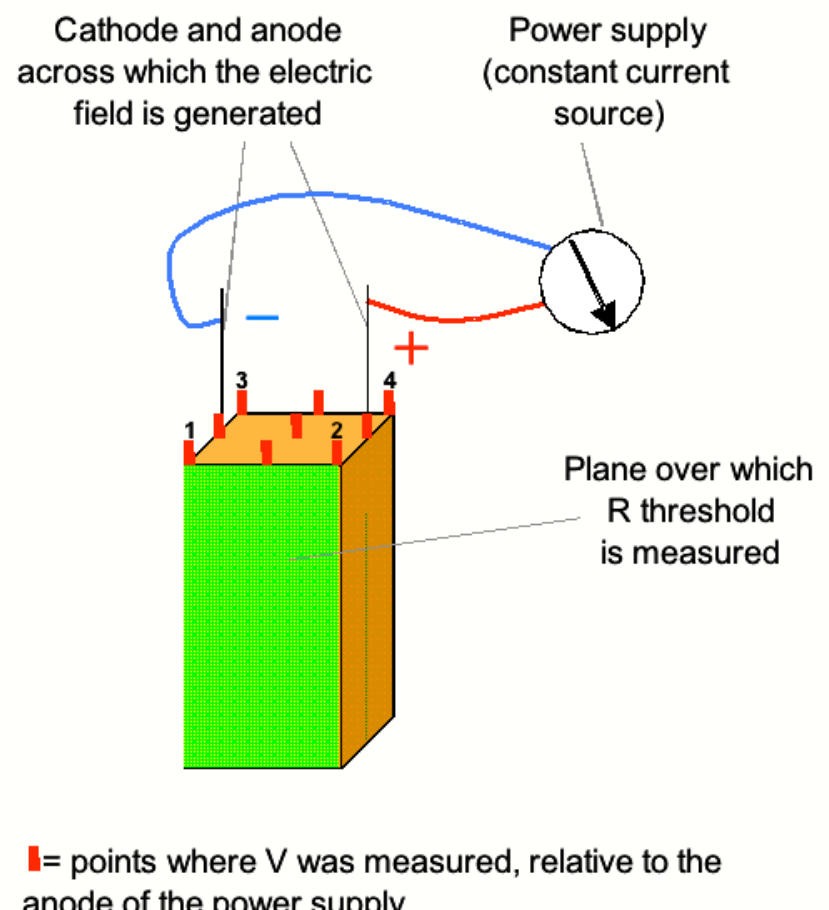
anode of the power supply

Voltages (1 -2) and (3 -4) are the voltage drop values at the soil thresholds parallel to the electric field

Figure 3.1. The components of a soil slab; earthworms, soil and two electrodes, and location where voltage $(\mathrm{V})$ and resistance $(\mathrm{R})$ are measured. V drop threshold and $\mathrm{R}$ threshold were measured at the edge of the soil slab as shown. 


\subsection{Modeling electrical potential across earthworms}

$$
V=f(i, D, d, s, R)
$$

where,

$\mathrm{V}=$ electrostatic potential across the earthworm, in Volts

$i=$ electrostatic current, in Amps

$\mathrm{R}=$ resistance across the earthworm's lateral diameter in Ohms

$\mathrm{D}=$ earthworm's lateral diameter, in $\mathrm{cm}$

$\mathrm{d}=$ depth of electrodes, in $\mathrm{cm}$

$\mathrm{s}=$ spacing between electrodes, in $\mathrm{cm}$

Since these variables have different units, they cannot be added. Therefore the function $\mathrm{f}$ takes the form,

$$
\mathrm{V}=\mathrm{k} \cdot \mathrm{i}^{\mathrm{a}} \cdot \mathrm{D}^{\mathrm{b}} \cdot \mathrm{d}^{\mathrm{c}} \cdot \mathrm{s}^{\mathrm{d}} \cdot \mathrm{R}^{\mathrm{e}}
$$

where $\mathrm{k}$ is proportionality constant.

Using length (L), mass (M), time (T) and permittivity $(\kappa)$ as the fundamental units we can perform a dimensional analysis to derive the component of each variable.

First the Raleigh method (Raleigh, 1915) is used to group the variables,

$$
\left(\mathrm{L}^{0.5} \mathrm{M}^{0.5} \mathrm{~T}^{-1} \kappa^{-0.5}\right)=\left(\mathrm{L}^{1.5} \mathrm{M}^{0.5} \mathrm{~T}^{-2} \kappa^{0.5}\right)^{\mathrm{a}} \cdot(\mathrm{L})^{\mathrm{b}} \cdot(\mathrm{L})^{\mathrm{c}} \cdot(\mathrm{L})^{\mathrm{d}} \cdot\left(\mathrm{L}^{-1} \mathrm{T \kappa}^{-1}\right)^{\mathrm{e}}
$$

L: $\quad 0.5=0.5 a+b+c+d-e$

$\mathrm{M}: \quad 0.5=0.5 \mathrm{a}$

$\mathrm{T}: \quad-1=-2 \mathrm{a}+\mathrm{e}$

$\kappa:-0.5=0.5 \mathrm{a}-\mathrm{e}$ 
Solving gives

$a=1$

$\mathrm{e}=1$

$b=-c-d$

$$
\mathrm{V}=\mathrm{k} \cdot \mathrm{i} \cdot \mathrm{D}^{-\mathrm{c}-\mathrm{d}} \cdot \mathrm{d}^{\mathrm{c}} \cdot \mathrm{s} \cdot \mathrm{d}
$$

After grouping the variables,

$$
\frac{V}{R}=k \cdot i \cdot\left(D^{-1} d\right)^{c} \cdot\left(D^{-1} s\right)^{d}
$$

Using the Buckingham method (Buckingham, 1931), each of the three variable groups can be analyzed as a dimensionless group to derive its components. Only one group can contain the dependent variable, the electric potential (V) in this case.

The variable groups are defined as:

$$
\begin{gathered}
\pi_{1}=\mathrm{V}^{\mathrm{a}} \cdot \mathrm{R}^{\mathrm{b}} \cdot \mathrm{i}^{\mathrm{c}} \\
\pi_{2}=\mathrm{D}^{\mathrm{d}} \cdot \mathrm{d}^{\mathrm{e}} \\
\partial_{3}=\mathrm{D}^{\mathrm{d}} \cdot \mathrm{d}^{\mathrm{f}}
\end{gathered}
$$

$\pi_{1}: \mathrm{L}^{0} \mathrm{M}^{0} \mathrm{~T}^{0} \kappa^{0}=\left(\mathrm{L}^{0.5} \mathrm{M}^{0.5} \mathrm{~T}^{-1} \kappa^{-0.5}\right)^{\mathrm{a}}\left(\mathrm{L}^{-1} \mathrm{T \kappa}^{-1}\right)^{\mathrm{b}}\left(\mathrm{L}^{1.5} \mathrm{M}^{0.5} \mathrm{~T}^{-2} \kappa^{0.5}\right)^{\mathrm{c}}$

$\mathrm{L}: \quad 0=0.5 \mathrm{a}+1.5 \mathrm{~b}-\mathrm{c}$

$\mathrm{M}: 0=0.5 \mathrm{a}-0.5 \mathrm{~b}$

$\mathrm{T}: 0=-\mathrm{a}-2 \mathrm{~b}+\mathrm{c}$

$\kappa: 0=-0.5 a+0.5 b-c$

Solving for a,

$b=-1$

$c=-a$ 


$$
\pi_{1}=\left(\mathrm{V} \cdot \mathrm{R}^{-1} \cdot \mathrm{i}^{-1}\right)^{\mathrm{a}}
$$

Since $(\text { dimensionless unit })^{\mathrm{n}}=(\text { dimensionless unit })^{1}$, we can chose $\mathrm{a}=1$

$$
\pi_{1}=\mathrm{V} /(\mathrm{Ri})
$$

$\pi_{2}: \mathrm{L}^{0} \mathrm{M}^{0} \mathrm{~T}^{0} \kappa^{0}=(\mathrm{L})^{\mathrm{d}} \cdot(\mathrm{L})^{\mathrm{e}}$

$\mathrm{L}: 0=\mathrm{d}+\mathrm{e}$

$\mathrm{M}: 0=0$

$\mathrm{T}: 0=0$

$\kappa: 0=0$

Solving for $\mathrm{d}$,

$e=-d$

$$
\pi_{2}=(D / d)^{d}
$$

Since $(\text { dimensionless unit })^{\mathrm{n}}=(\text { dimensionless unit })^{1}$, we can chose $\mathrm{d}=1$

$$
\pi_{2}=\mathrm{D} / \mathrm{d}
$$

This places electrode depth in the denominator, and the rationale is that the voltage generated across an earthworm is in inversely proportional to electrode depth, because with increasing electrode depth the electric current will be divided over a larger distance, which will reduce the electric current crossing an earthworm. 
$\pi_{3}: \mathrm{L}^{0} \mathrm{M}^{0} \mathrm{~T}^{0} \kappa^{0}=(\mathrm{L})^{\mathrm{d}} \cdot(\mathrm{L})^{\mathrm{f}}$

L: $\quad 0=d+f$

M: $0=0$

$\mathrm{T}: 0=0$

$\kappa: 0=0$

Solving for $\mathrm{d}$,

$f=-d$

$$
\pi_{3}=\mathrm{D} / \mathrm{s}
$$

This places electrode spacing in the nominator, and this maintains earthworm diameter as a variable in this function since in the previous variable group the same variable was also in the denominator.

The resulting model for electric potential (V) across an earthworm is,

$$
V_{w}=k \cdot i \cdot R \cdot D^{2} /(d \cdot s)
$$

3.3. Modeling the effectiveness of an electric field at repelling earthworms

$$
\varepsilon_{\mathrm{f}}=\frac{\mathrm{n}_{\mathrm{V}_{\mathrm{w}}}-\mathrm{n}_{0}}{\mathrm{n}_{\mathrm{T}}-\mathrm{n}_{0}}
$$

where

$$
\begin{aligned}
& \mathrm{n}_{\mathrm{T}}=\text { total worms in media } \\
& \mathrm{n}_{0}=\text { worms exiting at } 0 \text { voltage } \\
& \mathrm{n}_{\mathrm{V}_{\mathrm{w}}}=\text { worms exiting at } \mathrm{V}_{\mathrm{w}}
\end{aligned}
$$


The highest number of earthworms exiting the media (slab) is reached for different time periods, depending on the voltage generated across the slab, i.e. earthworms.

However, too high a voltage will kill the earthworms. Thus, $\varepsilon_{\mathrm{f}}$ is expected to increase with electric potential across earthworms (V) up to a peak value and then decrease due to earthworm mortality. The equation describing the curve was derived experimentally, based on a trend line between measured electric field effectiveness and the calculated value of $\mathrm{V}_{\mathrm{w}} / \mathrm{k}$.

$$
\begin{gathered}
\varepsilon_{f}=g\left(V_{w}\right) \\
\varepsilon_{f}=f\left(i \cdot R \cdot D^{2} /(d \cdot s)\right)
\end{gathered}
$$

where $f(x)=k \cdot g(x)$. 


\section{CHAPTER 4}

\section{OBJECTIVES}

The overall objective of this study was to develop and evaluate a mathematical model of the effectiveness of an electric field in repelling earthworms from an organic media or containing them at a high count in the soil. Specific objectives of the study were:

1. to determine the effect of population density on the movement of two major earthworm species in the soil without the presence of an electric field.

2. to identify design factors (electrode spacing, direct current level, earthworm size, ....) affecting earthworm movement in an electric field and to develop a theoretical model predicting voltage drop across an earthworm as a function of the design factors.

3. to derive from experimental data on two earthworm species mathematical models predicting the effectiveness of an electric field in repelling earthworms from the soil as a function of voltage drop across earthworms.

4. to derive from experimental data a model of earthworm mortality as a function of electric voltage drop across earthworms.

5. to derive from experimental data a model of the time required to repel all possible earthworms as a function of electric voltage drop across earthworms. 
6. to determine if the soil salinity, moisture content or bulk density levels were accounted for in model by the term soil resistance.

7. to determine if earthworm response in an electric field is affected by whether current was alternating or a direct current.

8. to determine the spatial distribution of current when a voltage, $\mathrm{V}$, I, is applied between two electrodes in earthworm casts.

To accomplish these objectives the following hypotheses were tested:

- At a given stocking density earthworms migrate unless contained.

- An electric field repels/limits earthworm migration across a nutrient gradient, relative to a control.

- Effectiveness of an electric field in repelling earthworms is affected by the current level, distance between electrodes, depth of electrodes, and earthworm diameter and resistance, i.e. voltage generated across earthworms.

- The mortality rate of earthworms exposed to an electric field is a function of the voltage generated across earthworms and the earthworm species.

- The time period required to repel all potential earthworms due to an electric field depends on the voltage generated across earthworms.

- The model expressing the effectiveness of an electric field in terms of voltage generated across earthworms is valid for a specific electric field, regardless of soil salinity, moisture content or bulk density. 
- Effectiveness of an electric field at repelling earthworms is dependent on whether direct or alternating current is used.

- The distance of a targeted threshold current from the electrodes is a function of the current level applied between electrodes, for a given electrode spacing, depth and media resistance level. 


\section{CHAPTER 5}

\section{MATERIALS and METHODS}

Earthworms used in all experiments were purchased from Connecticut Worm Valley (Connecticut Valley, Connecticut). They were kept in plastic cylinders containing a commercial compost/dairy manure mix. The containers were $18 \mathrm{~cm}$ diameter and $20 \mathrm{~cm}$ high with a plastic screen bottom for drainage. Moisture of the mix was maintained by watering regularly. For a particular study, earthworms were removed from the mix and placed immediately into the test apparatus. For studies requiring an electric field, a Hewlett Packard 6216B power source (Cambridge, USA) supplied a stable current source. All studies were carried out in Room 317 of the Ohio State University's Agricultural Engineering Building in Columbus, $\mathrm{OH}$.

\subsection{Mobility studies, no electric field}

Migration of the earthworms was evaluated for three different ratios of the worm species, Eisenia foetida $(E F)$ and E. hortensis (EH) and three incubation time periods of 2, 4 and 6 days. The mixes were $100 \% E F$ (two trials), 1:1 weight ratio of $E F$ and $E H$, and $100 \% \mathrm{EH}$. The test apparatus was a $7.6 \mathrm{~cm}$ diameter, $15 \mathrm{~cm}$ high cylinder placed in the center of an $18 \mathrm{~cm}$ diameter and $20 \mathrm{~cm}$ high cylinder. Both cylinders had screened 
bottoms. The outer cylinder was filled with a prepared soil mix of 55\% commercial compost (Green Thumb Composted Cow Manure, Green Thumb Organics Inc., LaPorte, IN), 30\% sandy loam and 15\% commercial fine white sand. The inner cylinder was filled with the potting mix up to a depth of $6 \mathrm{~cm}$. A quantity of mature earthworms equivalent to $28 \mathrm{~g}$ and an amount of compost calculated to sustain earthworms for seven days, based on the optimal feed to earthworm ratio of 0.75:1 (Ndegwa, 2000), were added on top of the soil in the center cylinder. This resulted in a $6 \mathrm{~cm}$ layer of soil and a 4 $\mathrm{cm}$ layer of compost $(150 \mathrm{~g})$ in each $7.6 \mathrm{~cm}$ diameter cylinder. The margin between the wall of the smaller and larger cylinder was entirely filled with the soil mix, as to reach the same soil line as in the smaller cylinder. The setup was designed to evaluate the migration level of earthworms from the inner cylinder to the outer one over a period of 6 days. The available nitrate content was $55.7 \mu \mathrm{g} / \mathrm{g}$ in the soil mix in the outer cylinder and $666.5 \mu \mathrm{g} / \mathrm{g}$ in the compost in the inner cylinder, which indicates a significantly higher nitrate level in the inner cylinder. Knowing that daylight prevents surface earthworm migration due to their sensitivity to light, a 10 hour dark period was used in conjunction with daylight-like conditions created with indoor lightning the rest of the time. The dark period was created using a black tarp strapped above each outer cylinder. Depending on the trial either perforated or non-perforated inner cylinders were used. In the case of nonperforated cylinders, only surface migration was possible during the dark hours. In the trials where perforated cylinders were used, both surface and subsurface migration was possible, as would be the case in soil in a field. In the first series of trials with $100 \% E F$, worms freshly arrived by mail were used and the inner cylinder was non-perforated. In the second trial, the same conditions were replicated but the $E F$ used had been living in a 
container in the lab for two weeks. In the trials with the mix of $E F: E H$ and $100 \% E H$, the worms were from the container in the lab and the test apparatus used a perforated inner cylinder. In each of the trials, after the 2,4 , or 6 days of incubation, the content of the outer cylinder was screened for earthworms. Each treatment was replicated three times. All replicates were watered up to field capacity at the onset of the experiment and were kept moist until collected.

\subsection{Mobility studies, with electric field}

Studies on repelling earthworms with an electric current were done in three phases. Phase 1. This phase involved inserting two electrodes vertically at the sidewalls of an open top plexiglass container; $1.3 \mathrm{~cm}$ deep, $2.5 \mathrm{~cm}$ wide and $30.5 \mathrm{~cm}$ long (Figure 5.1) filled with a soil mix composed of 55\% commercial compost, $30 \%$ sandy loam and $15 \%$ commercial fine white sand. Treatments consisted of the worm species $(E F)$ and current levels of 0 (control), 3, 5, 7 and $10 \mathrm{~mA}$ across the two electrodes. Each treatment was replicated three times. In each replicate the earthworm was placed across a distance of 0 to $2.5 \mathrm{~cm}$ from the electrodes (one tip of the earthworm at $0 \mathrm{~cm}$ and the other at $2.5 \mathrm{~cm}$ ), and about $1 \mathrm{~cm}$ depth. The position of the earthworm was recorded after 10 minutes of exposing the earthworm to the electric field. 


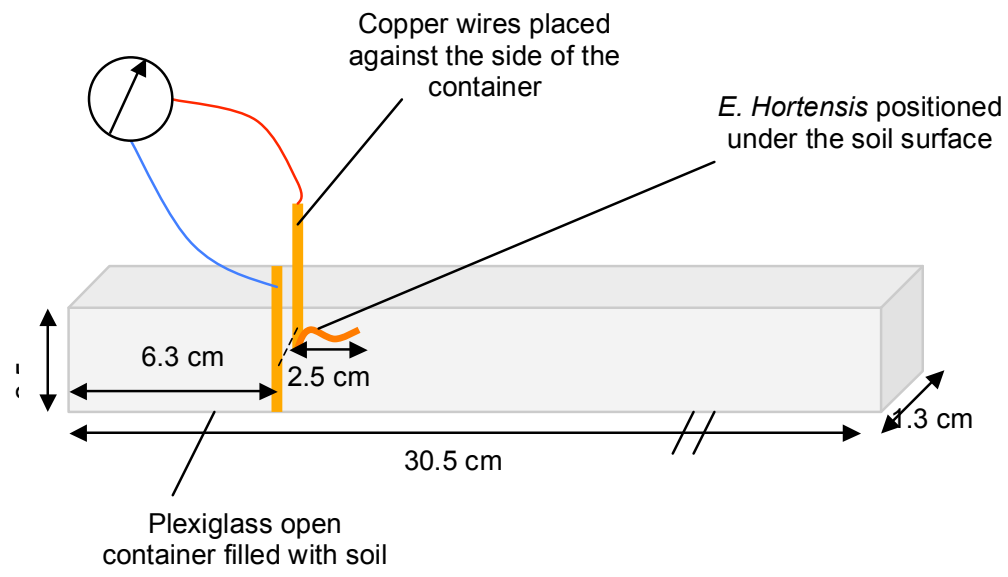

Figure 5.1. Test setup 1 for study on electric field repelling earthworms

Phase 2. The movement of both EH and EF away from an electric field in the presence and absence of light was investigated. A miniature field plot consisting of a $1 \mathrm{~m} \mathrm{x} 1 \mathrm{~m} \mathrm{x}$ $0.45 \mathrm{~m}$ box (Figure 5.2), made of expanded metal reinforced with screen, was filled with half a ton of soil mix composed of 55\% commercial compost, $30 \%$ sandy loam and $15 \%$ commercial fine white sand. The box was equipped with a $40 \mathrm{~cm}$ high wooden lid which when closed created totally dark conditions. Approximately 1000 earthworms of both species; $0.45 \mathrm{~kg}$ E. foetida $(E F)$ and $0.45 \mathrm{~kg}$ E. hortensis $(E H)$ were added to the box and evenly distributed over the surface and allowed four weeks to settle in before subjecting them to the electric field. 


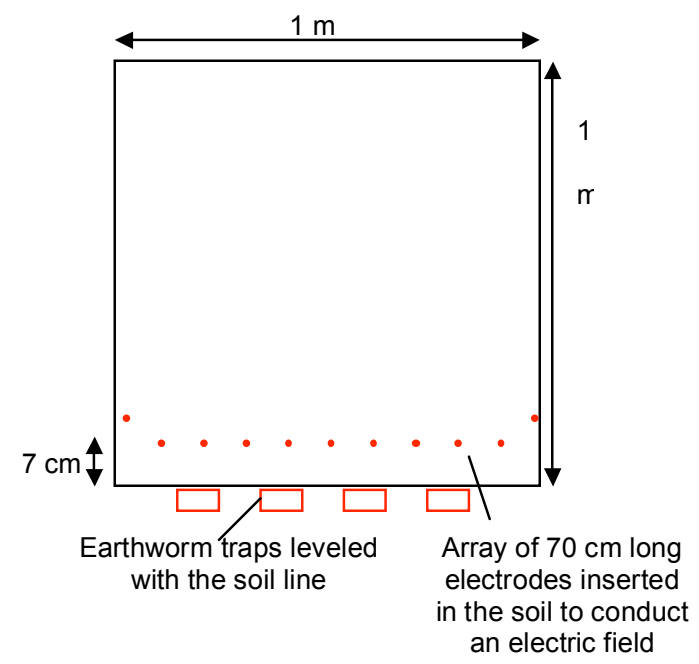

Figure 5.2. Top view of the miniature field plot and the attached earthworm traps, raised on wooden pillars.

Four earthworm traps were placed along one side of the box, towards the middle. These traps consisted of open top containers $(5 \times 10 \times 15 \mathrm{~cm})$ made of plastic canvas and filled with a compost mix with an average nitrate content of $485 \mu \mathrm{g} / \mathrm{g}$ dry material. Once in place, the traps were over-watered so as to leach nutrients into the box and create a chemical gradient to attract earthworms. At a $7 \mathrm{~cm}$ distance from the trap side of the box, a $1 \mathrm{~m}$ long array of electrodes made of copper-plated stainless steel rods were inserted into the soil at a $10 \mathrm{~cm}$ spacing. Measured resistance between electrodes was about $100 \mathrm{Ohms}$ for wet soil, which was the case during the electric field treatments. Alternate electrodes received a positive and negative current from a stable current source (Hewlett Packard 6216B power supply) as shown in Figure 5.3, which compensated for soil moisture variations and created a current loop between every two electrodes. The current used had an amplitude of $5 \mathrm{~mA}$. For treatments with light, one white light emitting diode was used per electrode. Treatments and control were run within a two- 
week period, to avoid bias due to changing soil conditions. The electric fence was evaluated based on the number of earthworms which migrated into the traps, relative to a control $(0 \mathrm{~mA})$. The control and $5 \mathrm{~mA}$ treatment were replicated three times, each replicate consisting of a 12 hour run. Also, in an attempt to empty the margin between the side of the box and the electric field from earthworms, a $5 \mathrm{~mA}$ electric field was created for about 12 hours before the first recorded $5 \mathrm{~mA}$ run.

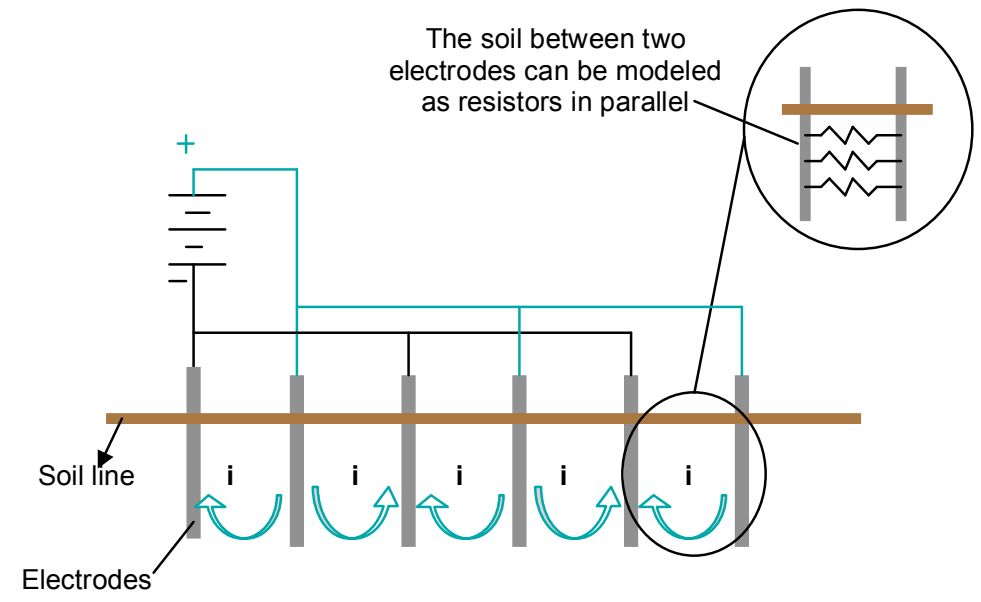

Figure 5.3. Method by which electrodes and a power supply were used to create an electric field.

Phase 3. The effect of electrode spacing and current levels on the repelling effect of an electric field on earthworms was investigated. The set up was a basket, $37 \mathrm{~cm}$ in diameter and $30 \mathrm{~cm}$ high filled with a soil mix composed of 55\% commercial compost, $30 \%$ sandy loam and 15\% commercial fine white sand, and inoculated with about $200 \mathrm{~g}$ of the $E F$ and $250 \mathrm{~g}$ of the $E H$ species (a total of approximately $450 \mathrm{~g}$ ). The surface area of the basket was $0.107 \mathrm{~m}^{2}$, which results in an earthworm stocking density of $4.2 \mathrm{~kg} / \mathrm{m}^{2}$ $\left(9 \mathrm{lb} / \mathrm{m}^{2}\right)$, approximately twice that of the second phase experiment. The basket was 
lined with black plastic screen and drainage holes were added at the bottom to ensure good drainage. Earthworm traps consisted of a black screen container, $4 \times 10 \times 27 \mathrm{~cm}$ in dimension when filled with compost. Three of these traps were strapped along the sides of the basket, evenly spaced. A tarp covered the sides of the basket to maintain dark conditions around the traps. A tarp covering the surface was used in treatments requiring dark conditions at the soil surface. The 5 treatments were $0 \mathrm{~mA}$ with a covered surface (control), $5.4 \mathrm{~mA}$ of current / $11 \mathrm{~cm}$ spacing between electrodes under dark or lit conditions, and $8 \mathrm{~mA}$ current / 21.5 spacing between electrodes under dark or lit conditions. Each treatment included three replicates in time (reusing the same set-up) and consisted of a four-hour run. Before starting a replicate, a nutrient gradient was created by drenching the basket with 3.6 liters of water between replicates and watering the traps with a hose for 5 seconds each to cause the nutrient rich solution to leach into the basket. Electrodes were connected to a stable current source (Hewlett Packard 6216B power supply).

In phases 2 and 3 treatments were evaluated based on the number of earthworms migrating into the traps relative to the control, analyzing each species separately. The electric field's effectiveness was calculated as the \% decrease in earthworm migration across the electric filed, relative to a control. A linear model of electric field effectiveness was derived by solving a matrix for each species for each of the lit or dark conditions at the soil surface. 


\subsection{Testing and developing the theoretical model for effectiveness of an electric field at repelling earthworms}

\subsubsection{Earthworm diameter and resistance}

According to theory developed for the effectiveness of the electric field at repelling earthworms, earthworm diameter and resistance are two of the controlling variables. Earthworm diameter and resistance were determined in four replicates of each of the $E F$ and $E H$ species. Electrical resistance was measured by connecting an Ohm meter to two copper leads. Each earthworm was placed so as to have the two leads touch the opposing sides of its diameter and resistance was recorded. The resulting data was analyzed for mean and variance.

\subsubsection{Electric field effectiveness at repelling earthworms}

The experiments for repelling earthworms used an electric field created through current loops generated between soil electrodes. The current source maintained a stable current level as soil resistance changed with the movement of earthworms. The soil electrodes were $20 \mathrm{~cm}$ long and $1.6 \mathrm{~mm}$ diameter stainless steel hypodermic needles, gage 18 and $15 \mathrm{~cm}$ long Spinal Needle (MWI Veterinary Supply Co., Meridian, Idaho) (Figure 5.4). They were placed along the centerline of a $2.8 \mathrm{~cm} \times 2.8 \mathrm{~cm} \times$ depth $(7.5$ or 5 $\mathrm{cm}$ ) soil slab containing the equivalent of 150 earthworms / liter medium (Figure 5.5). This density was reported as the optimal stocking density by Frederickson and Howell (2004). The $7.5 \mathrm{~cm}$ deep soil slab was constructed in the following manner. First a 1:6 water to soil mix ratio was prepared, where the soil mix was a 55\% commercial compost, $30 \%$ sandy loam and $15 \%$ commercial fine white sand, mixed and then screened through 
a $4 \mathrm{~mm}$ screen. Then three layers of the soil mix, $16 \mathrm{~g}$ each, were poured into a mold created by plastic dividers in a $25 \times 36.5 \times 14 \mathrm{~cm}$ plastic container (USA Plastic, Lima, Ohio), and where the soil electrodes were already in place (Figure 5.4). After addition of each layer, it was slightly compacted, followed with about $1.5 \mathrm{ml}$ water and three earthworms were added on top of the first three layers for the studies using $E F$. In the treatments using $E H$ earthworms, five $E H$ earthworms (1, 2, and 2 after each soil of the first three soil layers) were used). Then two more layers of soil were added, also slightly compacted and sprayed with about $1.5 \mathrm{ml}$ water, but without any added earthworms. For the case of the $5 \mathrm{~cm}$ deep soil slab, soil weight per layer was of 16,16 and $21 \mathrm{~g}$ and three $E F$ were added after each of the first two layers. This method of creating a soil/ earthworm slab allowed earthworms to be uniformly distributed along the soil profile and reduces the heterogeneity in the porosity of the soil. Soil resistances at either 5 or $7.5 \mathrm{~cm}$ soil depth (the soil depth used in the treatment) and along the center line of the $2.8 \times 2.8$ cm surface were derived using current level between electrodes and soil at various depths and spatial locations. 

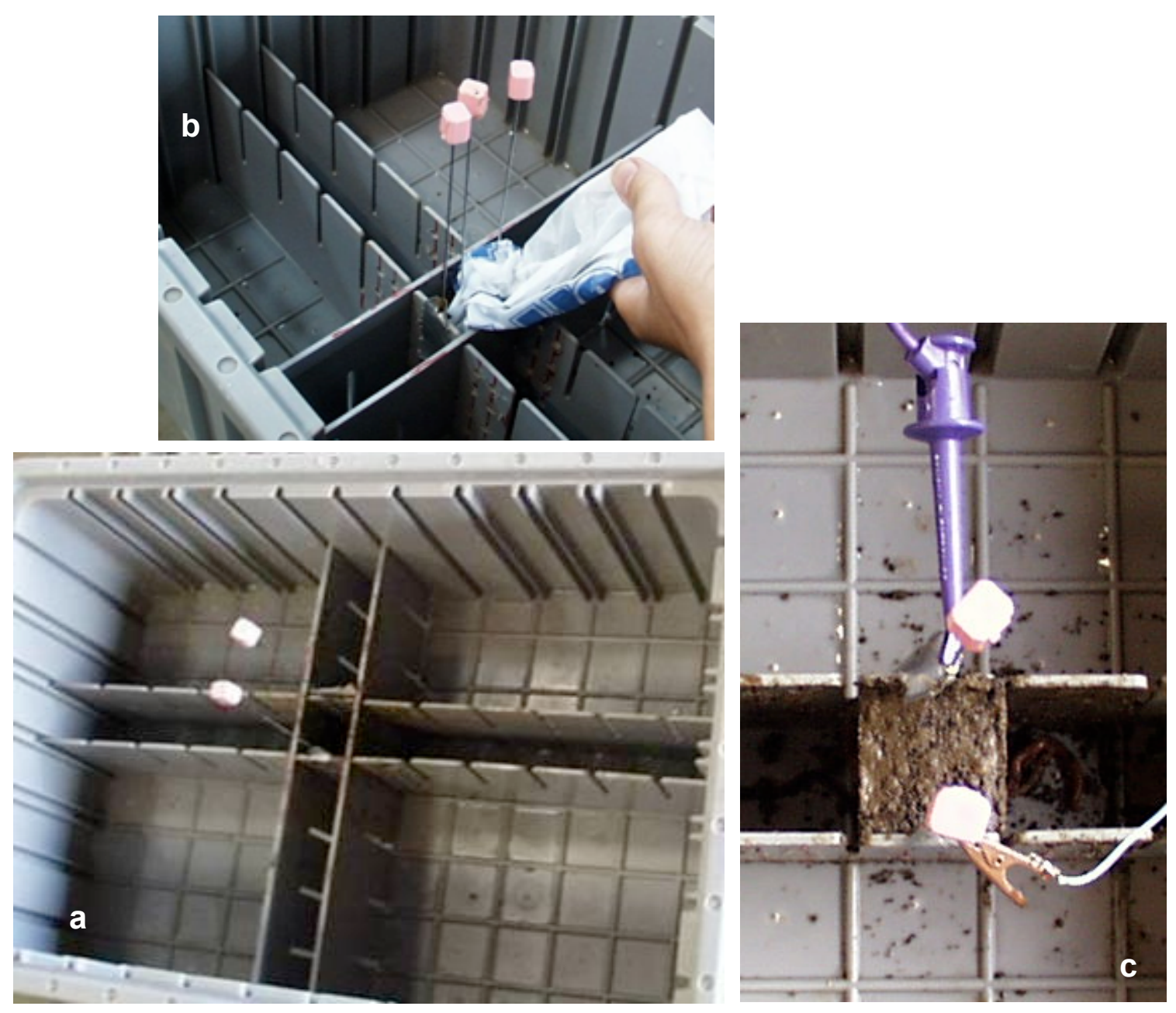

Figure 5.4. a) Plastic dividers used as a mold to build a soil slab, a $2.8 \mathrm{~cm}$ electrode spacing is shown. b) Adding individually weighed soil layer followed by of earthworms each, a $1.4 \mathrm{~cm}$ electrodes spacing is shown. c) Once the soil and earthworms are stacked and compacted 2 of the 4 dividers are removed leaving the sides of the soil slab that are parallel to the electric field (generated across the electrodes) un-obstructed, to facilitate the exit of earthworms. 

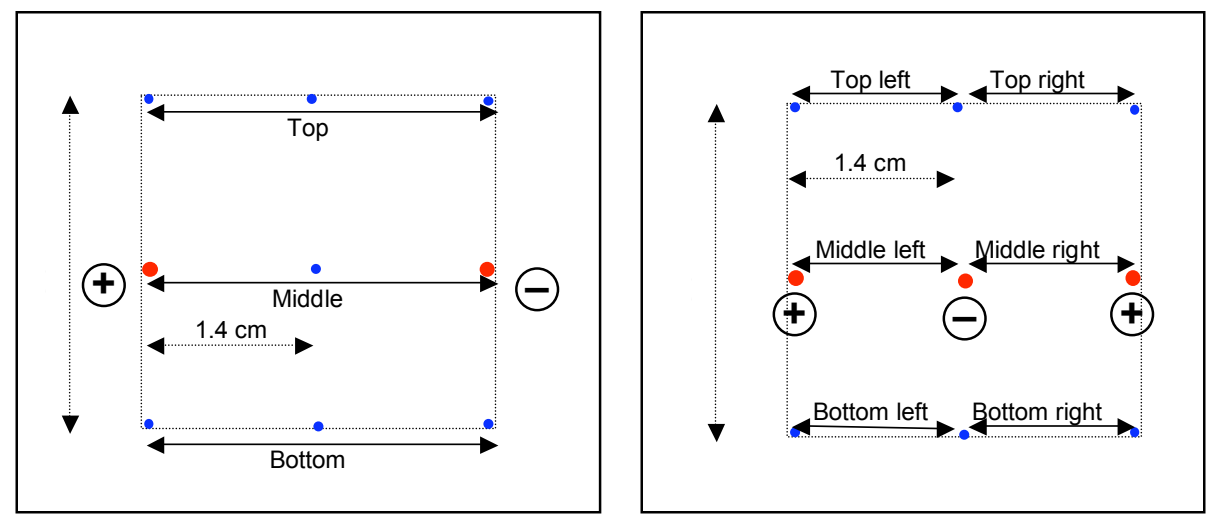

Figure 5.5. Top view of a soil slab; layout of the voltage drop measurements (represented by the labeled segments) at the surface of the soil slabs used to evaluate voltage diffusion. The large dots represent the soil electrodes (cathode and anode) across which the electric field is generated. The small dots represent the surface locations, in addition to the cathodes, where voltage was measured in reference to the anode. The two figures represent a) voltage drop measurements in treatments where the electrode spacing was $2.8 \mathrm{~cm}$ and b) voltage drop measurements in treatments where the electrode spacing was $1.4 \mathrm{~cm}$. 
Table 5.1 shows the experimental design and testing program followed. Each of the treatments described are defined by a set of conditions: electrode (and soil) depth, electrode spacing, earthworm species and level of electrical current between soil electrodes. The current levels between electrodes; 0 (control), 2, 5, 12, 24, and $35 \mathrm{~mA}$, were used in Set 1 of treatments with otherwise identical conditions. In another set of treatments each of the factors affecting the voltage created across earthworms was varied within pairs of treatments. Pairs of treatments where all but one variable are constant allow determining whether the differing variable has a significant effect. The pairs of treatments studied are identified in Set 2-Treatments in Table 5.1. Variables in this study were electrode and soil depth, electrode spacing, and earthworm species. Earthworm species controlled the earthworm diameter and resistance variables.

Treatments were pooled for most of the data analysis and were expressed in terms of a value proportional to the voltage created across the earthworms, $\mathrm{iRD}^{2} / \mathrm{ds}$, which is the value equal to $\mathrm{V}_{\mathrm{w}} / \mathrm{k}$ from eq. $1 \mathrm{a}$ (section 3.2$)$. 


\begin{tabular}{|c|c|c|c|c|c|c|c|c|c|}
\hline 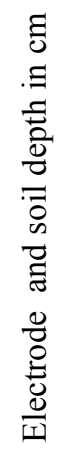 & 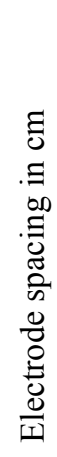 & 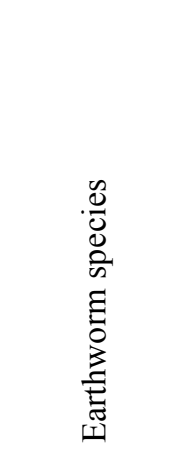 & 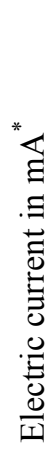 & 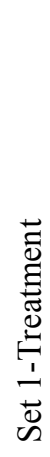 & 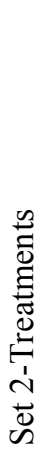 & 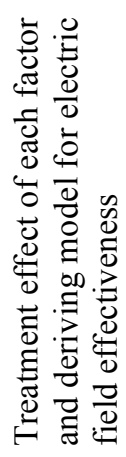 & 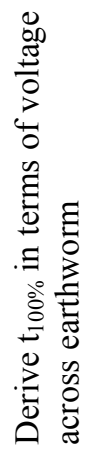 & 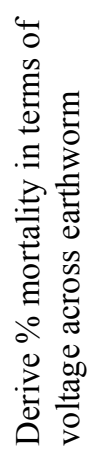 & 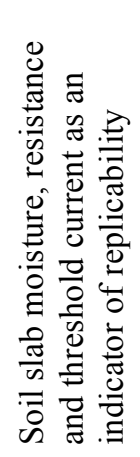 \\
\hline \multirow{6}{*}{7.5} & \multirow{6}{*}{2.8} & \multirow{6}{*}{ E. foetida } & 0 & $\mathrm{x}$ & $\mathrm{x}$ & $\mathrm{x}$ & $\mathrm{x}$ & $\mathrm{x}$ & $\mathrm{x}$ \\
\hline & & & 2 & $\mathrm{x}$ & & & $\mathrm{x}$ & $\mathrm{x}$ & $\mathrm{x}$ \\
\hline & & & 5 & $\mathrm{x}$ & 1 & $\mathrm{x}$ & $\mathrm{x}$ & $\mathrm{x}$ & $\mathrm{x}$ \\
\hline & & & 12 & $\mathrm{x}$ & 4 & $\mathrm{x}$ & $\mathrm{x}$ & $\mathrm{x}$ & $\mathrm{x}$ \\
\hline & & & 24 & $\mathrm{x}$ & & & $\mathrm{x}$ & $\mathrm{x}$ & $\mathrm{x}$ \\
\hline & & & 35 & $\mathrm{x}$ & & & $\mathrm{x}$ & $\mathrm{x}$ & $\mathrm{x}$ \\
\hline \multirow{2}{*}{7.5} & \multirow{2}{*}{1.4} & \multirow{2}{*}{ E. foetida } & 0 & & $\mathrm{x}$ & $\mathrm{x}$ & $\mathrm{x}$ & $\mathrm{x}$ & $\mathrm{x}$ \\
\hline & & & 5 & & 2 & $\mathrm{x}$ & $\mathrm{x}$ & $\mathrm{x}$ & $\mathrm{x}$ \\
\hline \multirow{2}{*}{5} & \multirow{2}{*}{1.4} & \multirow{2}{*}{ E. foetida } & 0 & & $\mathrm{x}$ & $\mathrm{x}$ & $\mathrm{x}$ & $\mathrm{x}$ & $\mathrm{x}$ \\
\hline & & & 5 & & 3 & $\mathrm{x}$ & $\mathrm{x}$ & $\mathrm{x}$ & $\mathrm{x}$ \\
\hline \multirow{2}{*}{7.5} & \multirow{2}{*}{2.8} & \multirow{2}{*}{ E. hortensis } & 0 & & $\mathrm{x}$ & $\mathrm{x}$ & & & $\mathrm{x}$ \\
\hline & & & 12 & & 5 & $\mathrm{x}$ & & & $\mathrm{x}$ \\
\hline
\end{tabular}

Table 5.1. Treatments and the analyses used in studies on effectiveness of electric field at repelling earthworms ( ${ }^{*}$ see Table 5.2 for explanation of numbered treatments).

\begin{tabular}{|c|c|}
\hline \multicolumn{1}{c}{ Treatments compared } & Question answered \\
\hline 1 and 2 & Does electrode spacing affect $\varepsilon_{\mathrm{f}}$ \\
\hline 1 and 3 & Does electrode depth affect $\varepsilon_{\mathrm{f}}$ \\
\hline 1 and 4 & Does electric current level affect $\varepsilon_{\mathrm{f}}$ \\
\hline 4 and 5 & Does earthworm diameter and resistance affect $\varepsilon_{\mathrm{f}}$ \\
\hline
\end{tabular}

Table 5.2. Pairs of Set 2 treatments used to identify treatment effect of each factor. 


\subsubsection{Deriving threshold electric current and soil slab resistance}

In treatments with the $2.8 \mathrm{~cm}$ electrode spacing, a current loop was generated across two electrodes, placed at centerline on opposite sides of the soil slab. In treatments with a $1.4 \mathrm{~cm}$ electrode spacing two parallel current loops (at the prescribed current level) were generated since a third electrode was added midpoint between the side electrodes and connected to ground. The side electrodes received a parallel voltage from the power supply. Spatial voltage distribution was measured in every replicate at the intersections of lines forming a grid with a cell size of $1.4 \times 1.4 \mathrm{~cm}$, the centerline of which overlapped with the imaginary line connecting both electrodes (Figure 5.5).

Soil resistance at the edge of the soil slab was averaged over four randomly selected replicates of each type of soil slabs: the $7.5 \mathrm{~cm} / 2.8 \mathrm{~cm}, 7.5 \mathrm{~cm} / 1.4 \mathrm{~cm}$ and $5 \mathrm{~cm} / 1.4$ $\mathrm{cm}$ combinations of soil slab depth and electrode spacing. Soil resistance was derived by applying a known current and measuring current, after all potential earthworms had exited the soil slab during a treatment. Two electrodes were placed at the edge of the soil slab, at either 1.4 or $2.8 \mathrm{~cm}$ depending on the electrode spacing used in the test. The electrodes found along the centerline were left in place, to maintain their effect on threshold current. After applying 12 or 24 volts, the electric current was measured at the edge of the soil slab (across the soil depth). To derive this value the average threshold voltage drop within each replication was divided by soil resistance. This value was used as the threshold current in the electric field model. 


\subsubsection{Experimental design}

All treatments were replicated four times. Replication was done in time since replicates were monitored individually. Replicates were randomized to eliminate nontreatment effects. In each replicate the prescribed current was applied and the number of earthworms that exited the soil slab into the larger container was recorded every minute for the first two minutes and then once every two minutes, for up to 14 minutes, or 20 minutes in case the number of exited earthworms had not stabilized after 10 minutes (Figure 5.6). The design was a randomized complete block design where treatments were blocked by the period for which earthworms were present in the soil slab before electric current was applied (incubation time). The effectiveness of the electrical field at containing earthworms was calculated using eq. 2 (section 3.3). The control was used to calculate the electric field effectiveness but it was not part of the analysis of variance between treatments. All treatment differences were detected through an ANOVA. A two-way blocked ANOVA determined whether the length of incubation time affected any of the dependent variables, possibly by affecting earthworm distribution. A one-way ANOVA was then conducted in case the blocking effect was null. Least significant differences were calculated using Tukey's test. One or more trend lines were to be derived from the resulting data and their equation represented the electric field effectiveness model. The nonlinear $\mathrm{R}^{2}$ value of these models was also computed using the following equation; 


$$
R^{2}=1-\frac{S S_{r e g}}{S S_{\text {tot }}}
$$

where,

$\mathrm{SS}_{\mathrm{reg}}$ is the sum of the squares of residuals between the given values and the trend line,

and

$\mathrm{SS}_{\text {tot }}$ is the sum of the squares of residuals between the given values and their overall mean.

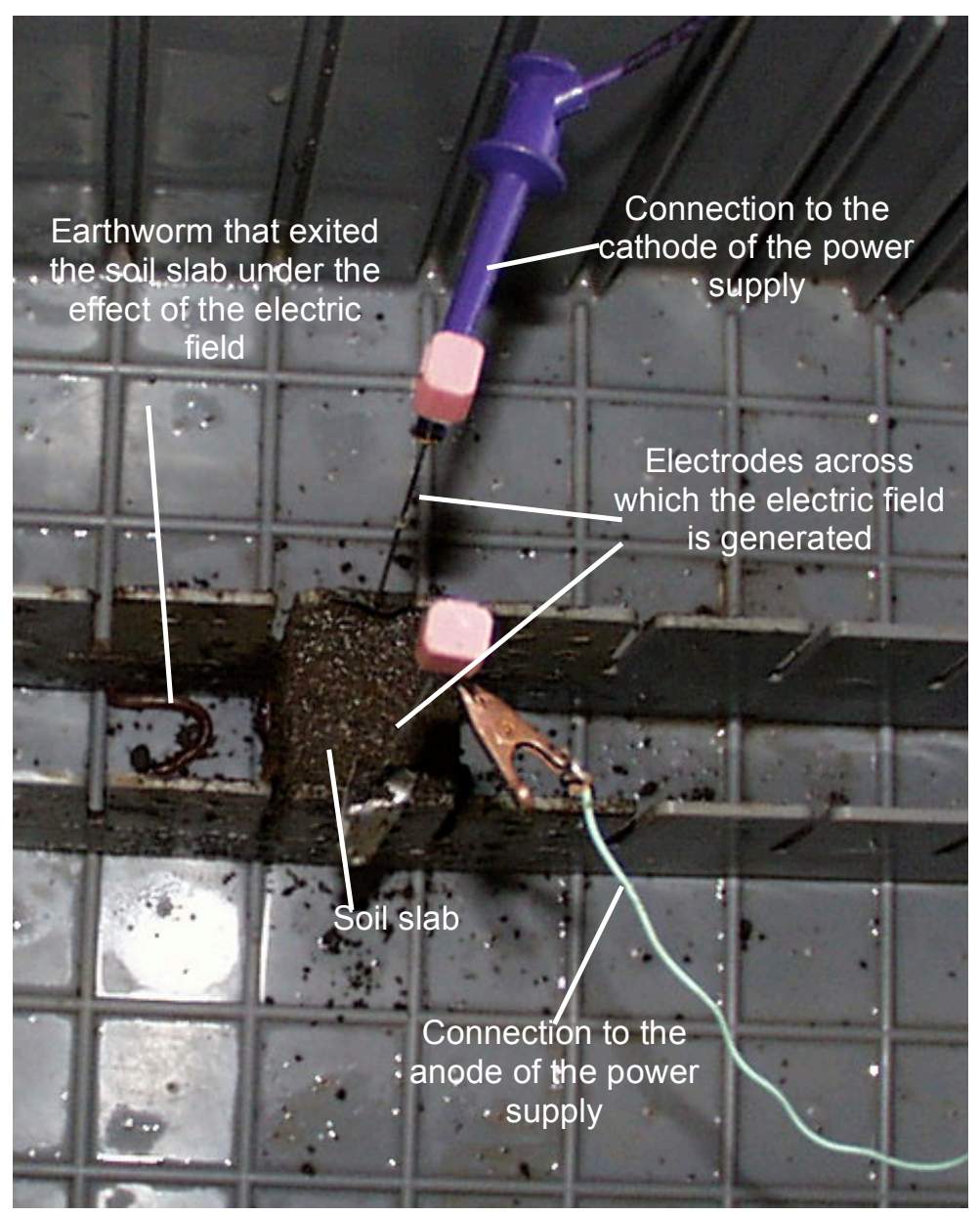

Figure 5.6. Earthworm exiting the soil slab under the effect of the electric field generated across the electrodes. 


\subsubsection{Recording $t_{100 \%}$, earthworm mortality and soil moisture}

The value of $\mathrm{t}_{100 \%}$ was recorded as the time when the cumulative number of exited earthworms reached a plateau, within the 14 or 20 minutes of data recording. At the conclusion of each experiment the soil slab was screened for earthworms and the rate of earthworm mortality was calculated as the number of dead earthworms divided by the initial number of earthworms. In the case of one pool of treatments (Table 5.1) the soil from the slab was also collected to be later analyzed for moisture content, in order to investigate the replicability of the technique used to build the soil / earthworm slabs. Gravimetric moisture analysis was conducted according to Black (1965). A 10 g soil sample was heated in an oven at $105 \mathrm{C}$ for 24 hours, in a closed pre-weighed metal container covered by a lid, also pre-weighed. 


\subsection{Testing the model for electric field effectiveness in media with different levels of soil salinity, moisture content or bulk density levels}

In this experiment the validity of the model describing the effectiveness of the electric field is tested while determining whether it is affected by soil porosity, moisture and salinity. The same experimental set up was used as for the experiment designed to derive the model for electric field effectiveness, with a $2.8 \mathrm{~cm}$ spacing and $7.5 \mathrm{~cm}$ depth for electrodes. Three treatments consisted of $5 \mathrm{~mA}, 5 \mathrm{~mA}$ and $12 \mathrm{~mA}$ with E. hortensis, $E$. foetida and E. foetida as the earthworm species used respectively. The control was $0 \mathrm{~mA}$ with either of the earthworm species and each treatment was replicated four times each. Each replicate consisted of a different type of soil mix. The experimental design was a randomized complete block design, and treatments were blocked by soil mix, resulting in four blocks. Four soil mixes were created as shown in Table 5.3. Each soil mix was analyzed for its porosity, moisture and salinity. Porosity was calculated using the equation;

$$
\text { Porosity } \%=\left(1-\frac{\text { bulk density }}{\text { particle density }}\right) \times 100
$$

Bulk density was calculated as the dry weight of soil mix divided by the known volume of the soil slab $(2.8 \times .2 .8 \times 7.5 \mathrm{~cm})$. The soil dry weight was derived by measuring the fresh weight of the soil used in the soil slab and dividing it by $(1+$ decimal moisture content). Moisture content was determined by gravimetric moisture analysis (Black, 1965). Particle density was estimated at $2.65 \mathrm{~g} / \mathrm{cm}^{3}$ for the mineral component of the soil mixes and soils and $2.27 \mathrm{~g} / \mathrm{cm}^{3}$ for the organic components (Weindorf and Wittie, 2003). Salinity was measured in term of electric conductivity (Rhoades, 1996). 
Since the components of each mixture are determined in terms of percentages by volume, the composite particle density for each mix was determined as,

$$
\begin{gathered}
\text { particle density } \rho=\frac{w t(g)}{\mathrm{cm}^{3}}=\frac{f_{1} \times w t(g)}{f_{1} \times \mathrm{cm}^{3}} \\
\text { composite particle density in } \mathrm{g} / \mathrm{cm}^{3}=\frac{\mathrm{f}_{1} \times \mathrm{wt}_{1}}{\mathrm{f}_{1} \times \mathrm{cm}^{3}}+\ldots+\frac{\mathrm{f}_{\mathrm{n}} \times \mathrm{wt}_{\mathrm{n}}}{\mathrm{f}_{\mathrm{n}} \times \mathrm{cm}^{3}}=\frac{\left(\mathrm{f}_{1} \times \mathrm{wt}_{1}\right)+\ldots+\left(\mathrm{f}_{\mathrm{n}} \times \mathrm{wt}_{\mathrm{n}}\right)}{1 \mathrm{~cm}^{3}}
\end{gathered}
$$

where,

$\mathrm{f}_{\mathrm{n}}$ is the fraction by volume of the mixture component $\mathrm{n}$ and $\mathrm{wt}_{\mathrm{n}} / \mathrm{cm}^{3}$ is the particle density of component $\mathrm{n}$.

A two-way ANOVA was to be conducted where each of soil porosity, moisture content and salinity was considered the blocking factor. Each two-way ANOVA determined whether there was a blocking effect, which would indicate the relevance of soil porosity, salinity and moisture on the fit of the model describing the electric field's effectiveness at repelling earthworms. The data were analyzed by comparing residuals between the theoretical and measured electric field effectiveness for each treatment. The $\mathrm{R}^{2}$ value for all treatments (or each significantly different treatment group) was also calculated. 


\begin{tabular}{|c|c|c|c|c|}
\hline Soil Mix & 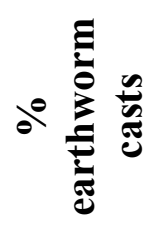 & ○゚ & 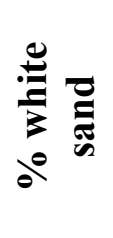 & 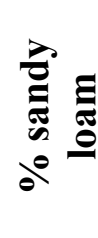 \\
\hline $1^{\mathrm{a}}$ & 0 & 55 & 15 & 30 \\
\hline 2 & 100 & 0 & 0 & 0 \\
\hline 3 & 0 & 90 & 10 & 0 \\
\hline 4 & 50 & $27.5^{b}$ & $7.5^{b}$ & $15^{b}$ \\
\hline
\end{tabular}

${ }^{a}$ Same soil mix as in the experiments used to develop the model for electric field effectiveness

${ }^{\mathrm{b}}$ These percentages represent $50 \%$ of an existing soil mix.

Table 5.3. Soil mixes created to evaluate the effect of soil properties on the effectiveness of the electric field at containing earthworms. The percentages are by volume.

\subsection{The effect of direct or alternating current on the effectiveness of an electric field at repelling earthworms}

In this experiment the effect of the type of electric current used on the effectiveness of the electric field at repelling earthworms is evaluated. Two treatments consisted of either direct current or alternating current. The experimental setup was the same as that used to derive the model for electric field effectiveness, with a $2.8 \mathrm{~cm}$ spacing and $7.5 \mathrm{~cm}$ depth for electrodes, and the soil mix 1 as a medium (see Table 5.3). Voltage level (at stable current output) was determined by maximizing the output in the AC treatment and recording the voltage. This same voltage was replicated in all AC and DC treatment replicates. The earthworm species $E$. foetida was used, the control was $0 \mathrm{~mA}$ and each treatment was replicated three times. As in the previous similar experiments the control was used to calculate the effectiveness of the electric field but not in the analysis of 
variance. The experimental design was a completely randomized design. An ANOVA was run to compare the value predicted by the theoretical model for electric field effectiveness (at repelling earthworms); the effectiveness measured in the AC treatment and the one measured in the DC treatment. A significant difference between the value as predicted by the model and the measured one would indicate the absence of fit to the model.

\subsection{The effect of current level on the location of threshold current in earthworm casts}

In this experiment spatial voltage diffusion from an electric field created between two electrodes was measured in a grid as shown in Figure 5.7. The surface area of the grid was $2.8 \mathrm{~cm}$ wide and $24 \mathrm{~cm}$ long. The soil slab was $7.5 \mathrm{~cm}$ deep and filled with earthworm casts (mix 2 in Table 5.3). Treatments consisted of a combination of three voltages generated between two electrodes placed at the center of the length of the slab, 5,12 , and 30 volts, and of 12 locations across the voltage distribution grid as shown in Figure 5.7. For each treatment (meaning each voltage level / location combination) both voltage drop and resistance across the $7.5 \mathrm{~cm}$ depth were measured, and the current at the given location was calculated accordingly. An ANOVA determined if there was a treatment effect, meaning if current levels varied due to location and also due to voltage level generated between electrodes. Once a treatment effect was determined current levels were plotted vs. location for each of the voltage levels, and a model of this relationship was derived. A target threshold current was determined and based on the derived model the location of this target threshold current was derived for each voltage. 
A second model was derived to describe the distance of the threshold current from the generated electric field, as a function of the voltage drop across this electric field.

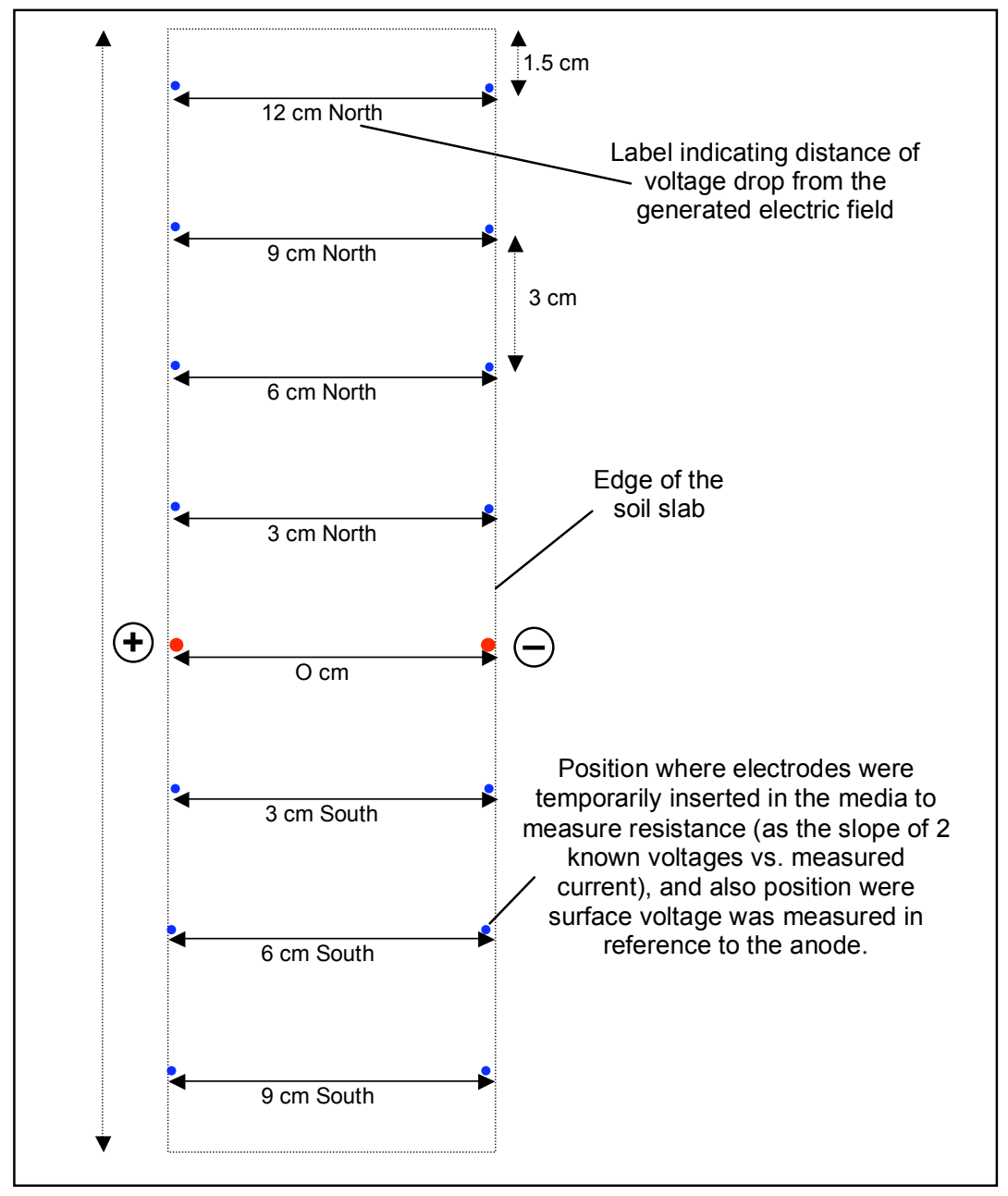

Figure 5.7. Top view of the rectangular soil slab used to measured voltage diffusion; layout of the voltage drop measurements (represented by the labeled segments) at the surface of the soil slabs used to evaluate voltage diffusion. The large dots represent the two soil electrodes (cathode and anode) across which the electric current is generated. The small dots represent the surface locations where voltage was measured in reference to the anode. 


\section{CHAPTER 6}

\section{RESULTS and DISCUSSION}

\subsection{Mobility studies, no electric field}

The first two trials on surface migration of E. foetida showed that migration rate increased with time (Figure 6.1). Results also showed freshly mailed earthworms migrate less than earthworms which had been incubating in an organic mix in the lab for two weeks prior to testing. This information is pertinent to future research on the subject. Significant migration also occurred in the third trial, where subsoil migration was made possible by the perforated container. That study showed that migration occurs in the absence of containment, even with lower stocking density for individual species. In the trial where only E. hortensis was used, migration increased little after two days of incubation, showing that E. foetida is more prone to migration than E. hortensis. Overall, the results show that without containment, earthworms of both species would migrate even in the presence of an optimal feed to earthworm ratio. 


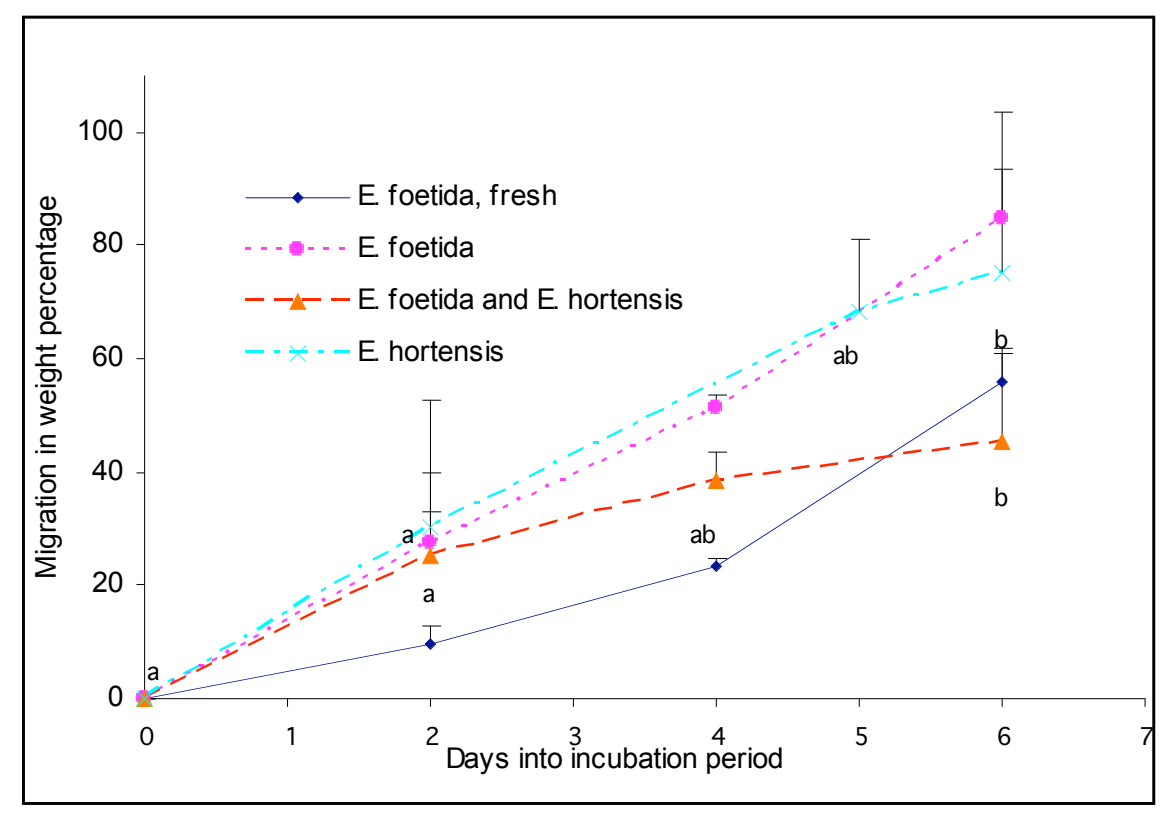

Figure 6.1. Earthworm migration in the absence of containment is expressed in percentage weight of earthworms which exited a nutrient-rich container. Significant treatment differences at the 5\% level using Tukey's test between treatment means are indicated by differing letters.

\subsection{Mobility studies, with electric field}

Phase 1. Movement of E. foetida away from an electric field over a 10 minutes test period is shown in Figure 6.2. For current levels of $3 \mathrm{~mA}$ and higher the position of the earthworm from the vertical plane connecting the electrodes was significantly different. However, there was no statistical difference in the position of the E. foetida earthworm for current levels higher than $3 \mathrm{~mA}$. This can be due to the fact that soil resistance in the 5 sided-container (four lateral sides, bottom) was high enough to limit the lateral diffusion of electric current and dampen the effect of increasing current levels. This can also be due to the fact that earthworms move a certain distance at the onset of discomfort (from electric shock) regardless of the level of discomfort. 


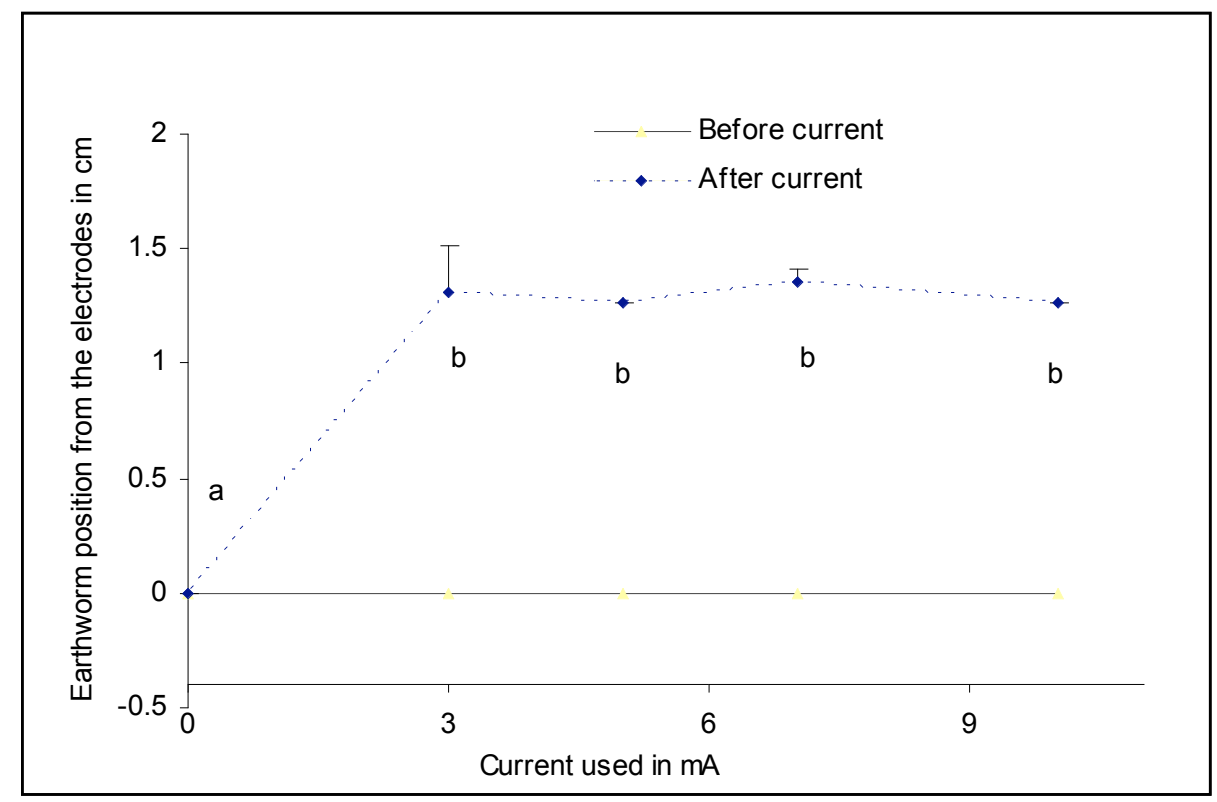

Figure 6.2. Earthworm displacement due to an electric field. The treatments were 0, 3, 5, 7 , and $10 \mathrm{~mA}$. Significant treatment difference $(\mathrm{p}<0.05)$ was found between $0 \mathrm{~mA}$ current and all the other treatments, but not among the other treatments.

Phase 2. In phase 2 the containment of earthworms by an electric field was investigated. Approximately 1000 earthworms of both species $(0.45 \mathrm{~kg}$ E. foetida and $0.45 \mathrm{~kg}$ E. hortensis) were used and their migration across the field and into traps was measured. Results are shown in Figure 6.3. Generating $5 \mathrm{~mA}$ current across the electrodes for about 12 hours caused earthworms, which were probably located between the electric field and the side of the box, to exit the box. This indicated that a $5 \mathrm{~mA}$ electric field does have a repelling effect. Results also showed the electric field combined with the surface light generated by LED contained $E$. hortensis at an efficiency of $94 \%$ and E. foetida at $85 \%$ (calculated from Figure 6.3). The electric field alone contained both species at a calculated efficiency of $42 \%$. Each of the $5 \mathrm{~mA}$ treatments, 
with and without LED was significantly different from the $0 \mathrm{~mA}$ control. However, there was no significant treatment difference between the $5 \mathrm{~mA}$ treatments with and without LED. Nonetheless, since the results show that about half of the migration occurs on the surface, adding a light source to the electric field would result in higher containment efficiency. The results show a higher sensitivity to light in E. hortensis, or a stronger attraction of $E$. foetida to a nutrient gradient. Results indicate an electric field and light source combination will contain $90 \%$ more of the earthworms in a given volume, as opposed to no containment.

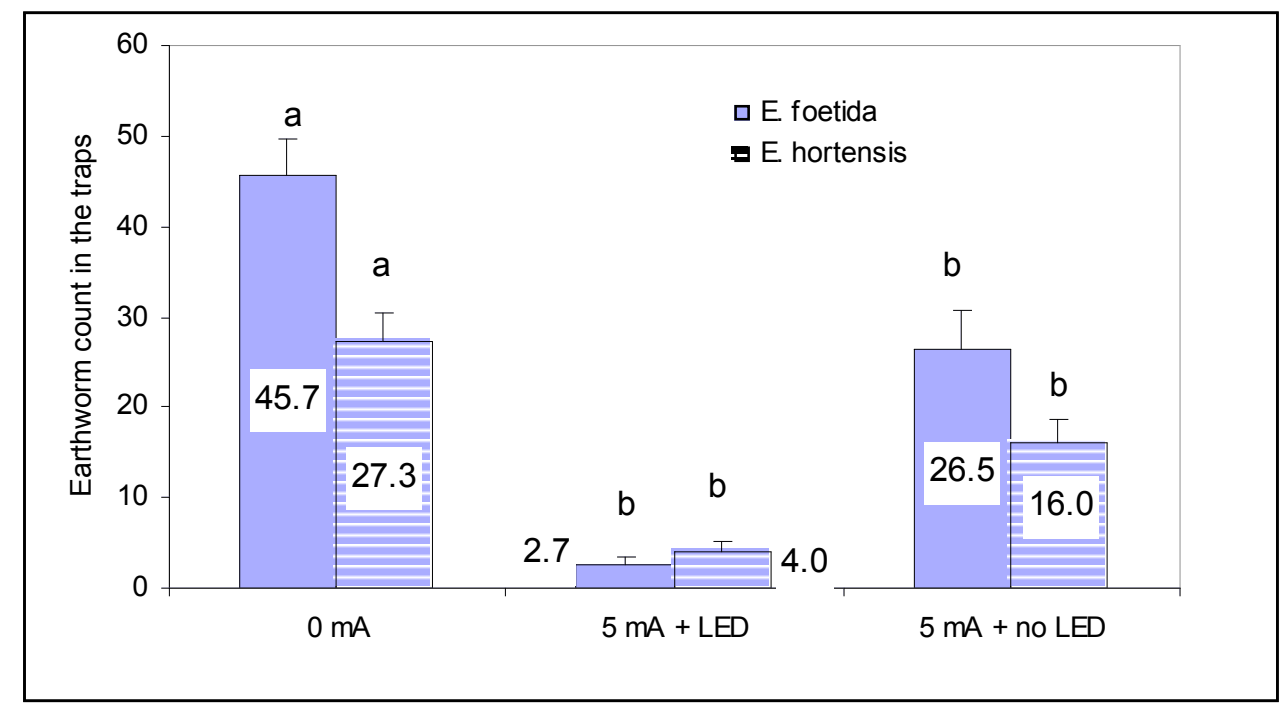

Figure 6.3. Earthworm migration across an electric field generated on one side of a 1x1 $\mathrm{m}$ surface area container is expressed in earthworm count. Significant treatment differences at the 5\% level using Tukey's test between treatment means are indicated by differing letters.

Phase 3. In phase 3 of this experiment, where electrode spacing and electric current level were varied an average of 129 E. foetida and 40 E. hortensis migrated into the traps for the control of $0 \mathrm{~mA}$ (Figure 6.4). For this study the density of E. hortensis was similar 
to the first electric field experiment while that of $E$. foetida was about three times higher. For the cases of an electric current the count of earthworms crossing the electric field, relative to the control was significantly decreased. The difference among direct current levels $>0$, however, wasn't significant. Efficiency in containing E. foetida varied between 49 and $67 \%$, and between 89 and $98 \%$ for E. hortensis. Even though the difference between treatments wasn't significant, results were used to derive the following preliminary models for each of the light conditions at the surface, and for each species. These preliminary mathematical models were used to design the next experiment. In case of a covered surface:

24.18 (current in $\mathrm{mA})-6.7$ (spacing in $\mathrm{cm})=\%$ decrease in $E$. foetida count 23.12 (current in $\mathrm{mA})-4.45$ (spacing in $\mathrm{cm})=\%$ decrease in $E$. hortensis count In case of a lit surface:

29.25 (current in $\mathrm{mA})-8.28$ (spacing in $\mathrm{cm})=\%$ decrease in $E$. foetida count 32.28 (current in $\mathrm{mA})-7.44($ spacing in $\mathrm{cm})=\%$ decrease in E. hortensis count 


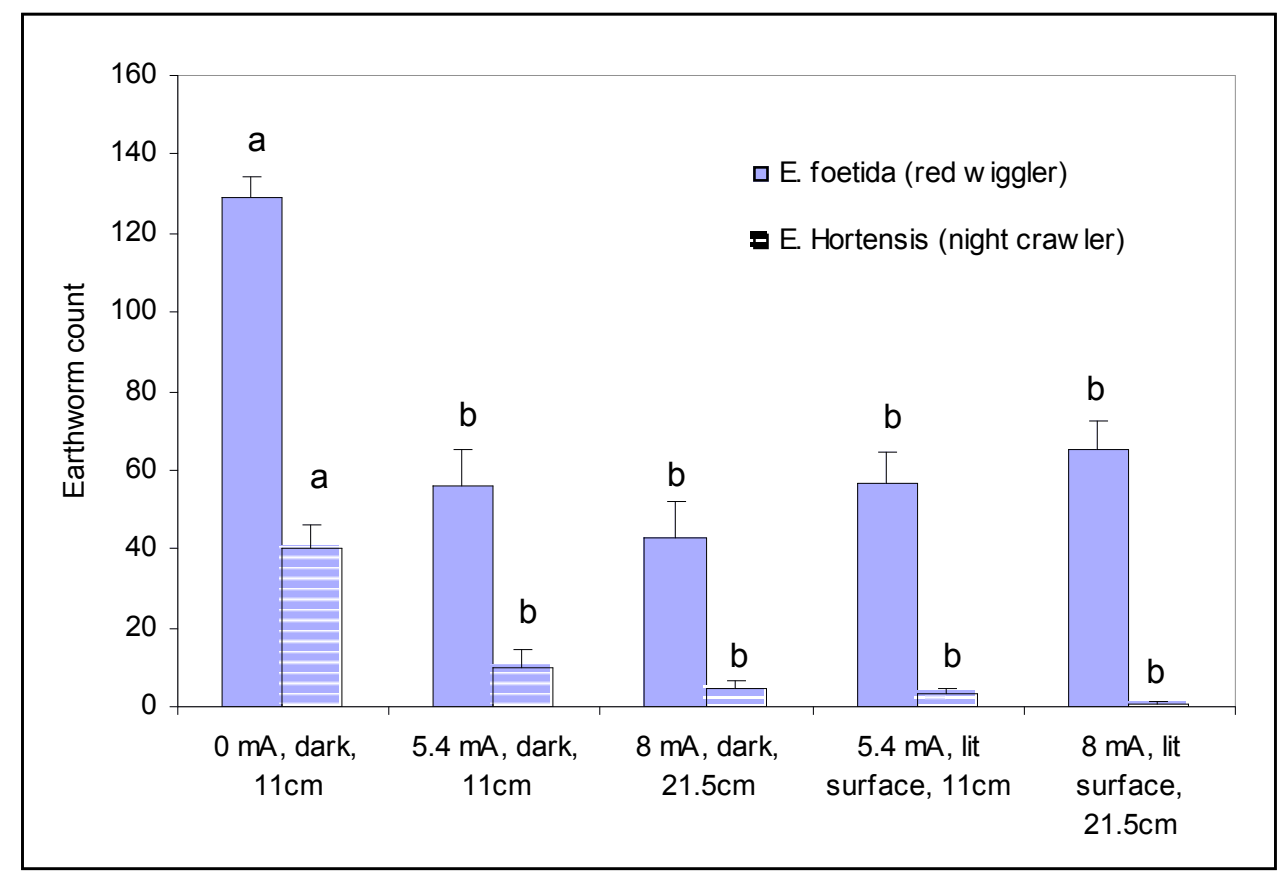

Figure 6.4. Earthworm migration across an electric field generated at the border of a 37 $\mathrm{cm}$ diameter container is expressed in earthworm count. Significant treatment differences at the 5\% level using Tukey's test between treatment means are indicated by differing letters.

The results show that electric current level has a higher impact on the effectiveness of the electric field at containing earthworms than does the spacing between electrodes. An increase in electric current increased the field's effectiveness at containing earthworms and an increase in electrode spacing decreased this effectiveness. Also the presence of light at the surface inhibited earthworm migration. 


\subsection{Testing and developing the theoretical model for effectiveness of an electric field at repelling earthworms}

\subsubsection{Earthworm diameter and resistance}

Resistance values (Table 6.1) determined for the two species, E. foetida and $E$. hortensis were not significantly different, but their diameter values were. As a result the $\mathrm{RD}^{2}$ term for the larger species (E. hortensis) is approximately three times greater that of E. foetida. The $\mathrm{RD}^{2}$ term is one of variables in the theoretical model expressing electric field effectiveness.

\begin{tabular}{|c|c|c|c|c|c|}
\hline $\begin{array}{c}\text { Earthworm } \\
\text { species }\end{array}$ & $\begin{array}{c}\text { Average } \\
\text { diameter } \\
\text { in cm }\end{array}$ & $\begin{array}{c}\text { \% Standard } \\
\text { error for } \\
\text { diameters }\end{array}$ & $\begin{array}{c}\text { Average } \\
\text { resistance } \\
\text { in Ohms }\end{array}$ & $\begin{array}{c}\text { \% Standard } \\
\text { error for } \\
\text { resistance }\end{array}$ & RD $^{2}$ \\
\hline E. foetida & $0.27^{\mathrm{a}}$ & 10.6 & $299800^{\mathrm{a}}$ & 6.96 & 21860 \\
\hline E. hortensis & $0.40^{\mathrm{b}}$ & $6.59 \mathrm{E}-07$ & $364200^{\mathrm{a}}$ & 5.28 & 58270 \\
\hline
\end{tabular}

Table 6.1. Diameter (D) and resistance (R) of two earthworm species, the corresponding standard error and the $\mathrm{RD}^{2}$ term to be used in modeling electric field effectiveness. Significant treatment differences at the 5\% level using Tukey's test between treatment means are indicated by differing letters

\subsubsection{Deriving threshold resistance and electric current}

Threshold current impacts $\varepsilon_{\mathrm{f}}$ (i.e., a ratio describing the electric field's effectiveness at containing earthworms) and is a function of the voltage created across earthworms. To calculate threshold current by $\mathrm{V} / \mathrm{R}$, the values for resistance at the edge of each type of soil slab (based on depth and electrode spacing) was derived. Resistance was derived as the slope of the trend line of the known voltage (12 and 24 volts) vs. the measured 
current. In actually, the regression line was derived over three points, since zero was chosen as an intercept. The results shown in Figure 6.5 indicate low variability within each voltage level/soil slab type for $\mathrm{R}$. The $\mathrm{R}$ for the three types of soil slab ranged from 0.52 to $1.46 \mathrm{kOhms}$.

At the 24 volts level all treatments had significantly different soil resistance values, but not at the 12 volts level. In treatments with a $2.8 \mathrm{~cm}$ electrode spacing the voltage drop at the edge of the slab was linear, and could be combined into one value. In the treatments where two current loops where generated across three soil electrodes the voltage drop was not linear and the current had to be calculated across each one separately.
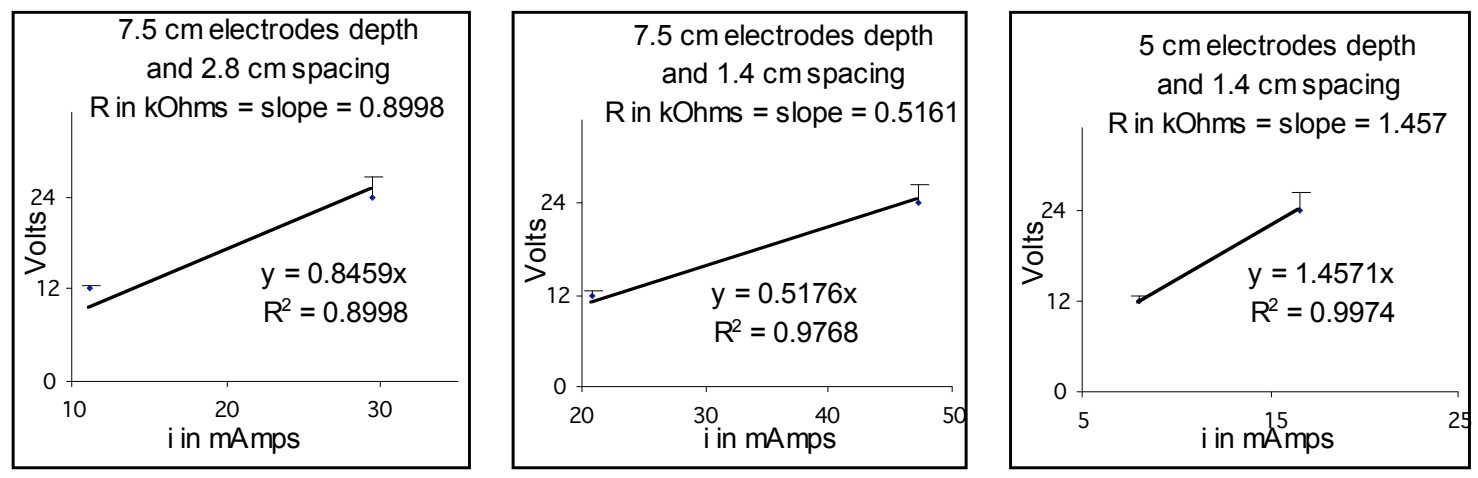

Figure 6.5. Voltage vs. electric current at the edge of the soil slabs with 7.5, 7.5, and 5 $\mathrm{cm}$ depth and 2.8, 1.4, and $1.4 \mathrm{~cm}$ electrode spacing respectively. The voltage drop across the corresponding spacing values was used to derive the threshold current in subsequent calculations. At the 24 volts level all treatments were significantly different at the $5 \%$ level using Tukey's test.

The average threshold current was calculated for each replicate by dividing the measured voltage drops at the edge of the soil slab by the resistance value derived for each category of soil slab/electrode spacing. Voltage drops at the threshold of the soil 
slab were averaged within each replicate. For the $2.8 \mathrm{~cm}$ and $1.4 \mathrm{~cm}$ electrode spacing the $\%$ standard error $(100 \mathrm{x} \mathrm{s} / \mu)$ within replicates ranged between 0.3 and $18 \%$ and between 8.7 to $40.8 \%$, respectively. The $\%$ standard error in voltage drops at the edge of the soil slab across all treatments was $51.9 \%$, higher than the highest variation within treatments. This indicates the expected treatment effect had an acceptable level of variation within replicates. The variation was higher within the replicates with $1.4 \mathrm{~cm}$ spacing between electrodes, possibly due to the higher margin of error when placing a third electrode in the middle of the soil slab and not against the side of the mold used to create the soil slab.

The voltage drop and resistance values used for calculating the threshold current corresponded to the same electrode spacing $(1.4 \mathrm{~cm}$ or $2.8 \mathrm{~cm})$ as at the center of the soil slab. While the current generated through the electrodes at the center of the soil slab was directly controlled, threshold current was only indirectly controlled and measured. For this reason threshold current had to be evaluated as a controlled variable before it could be used in the model for $\varepsilon_{\mathrm{f}}$. This was done by comparing the ratio of current across electrodes over threshold current, across treatments. The results in Figure 6.6 show that this ratio is consistent across all treatments with the same electrode spacing (no significant treatment difference). The treatment difference among different electrode spacings is due to the change in voltage diffusion pattern as the distance between electrodes is reduced. The results imply that for a given electrode spacing, threshold current can be considered a controlled variable with the same reliability as the prescribed current generated from a power supply across the electrodes. 
While the first two treatments in Figure 6.6 are significantly different from the other treatments as to soil resistance across the soil slab's center line, these same treatments are statistically similar to the others with the same electrode spacing $(2.8 \mathrm{~cm})$ as to the ratio of electric currents in the center and at the threshold of the soil slab. The reason is that a constant current power supply adjusts for variation in resistance by changing the applied voltage to maintain the prescribed current. This fact suggests use of a current source eliminates soil resistance as a variable controlling $\varepsilon_{\mathrm{f}}$ at repelling earthworms.

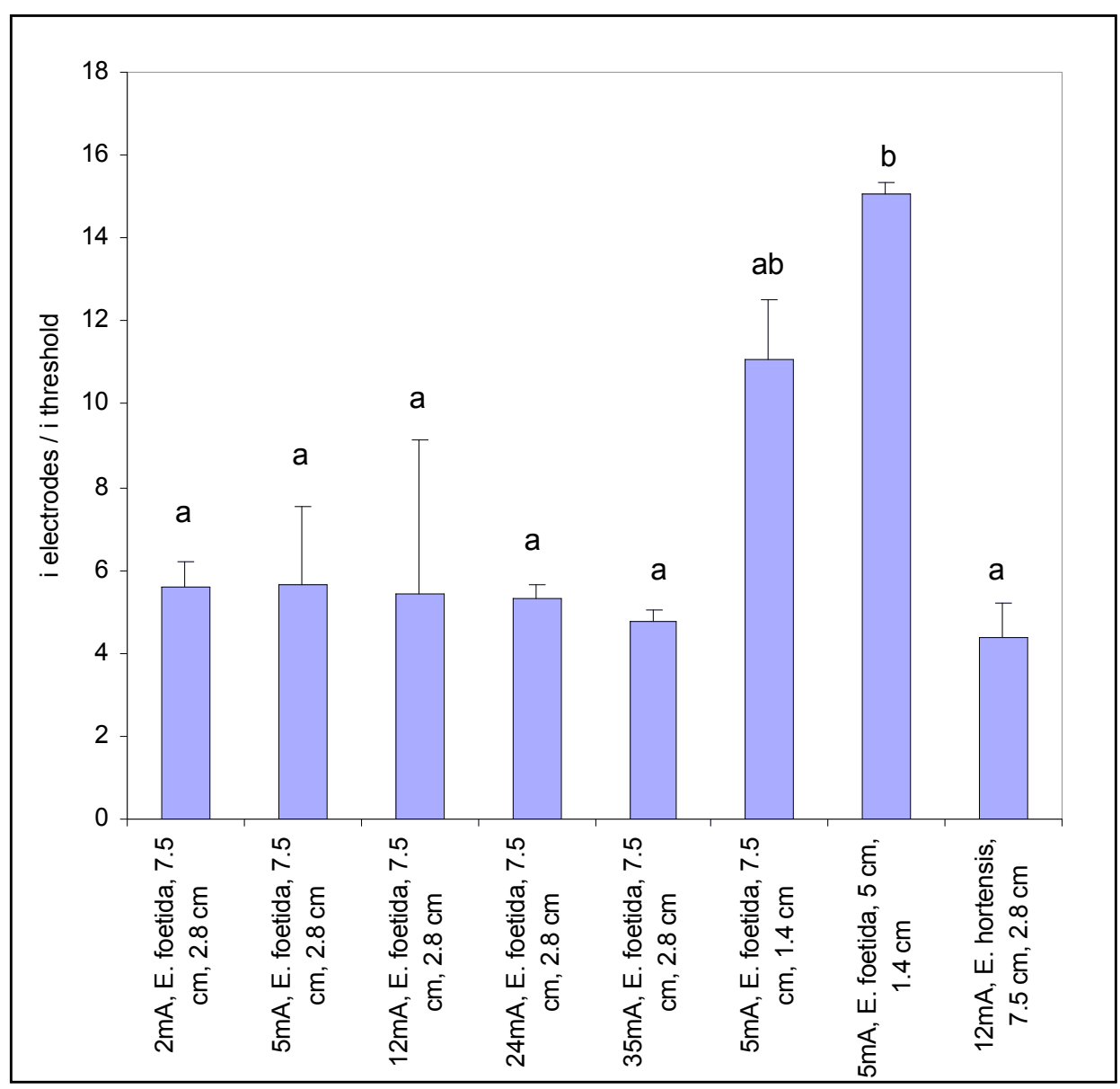

Figure 6.6. The ratio [electric current between electrodes/threshold electric current of the soil slab] vs. different treatments. Significant treatment differences at the $5 \%$ level are indicated by differing letters. 


\subsubsection{Evaluating the effect of each variable on electric field effectiveness}

Treatments used to evaluate $\varepsilon_{\mathrm{f}}$ were blocked into four pre-incubation time periods and evaluated using ANOVA. A two-way ANOVA determined that there was no incubation time effect $(\mathrm{p}=0.6882>0.005)$. Results for the one-way ANOVA on various treatments, as classified, are shown in Figure $6.7 \mathrm{a}$, where $\varepsilon_{\mathrm{f}}$ was expressed as a ratio from 0 to 1 . The peak $\varepsilon_{\mathrm{f}}$ was reached at $12 \mathrm{~mA}$ between electrodes for both earthworm species. All treatments except the $35 \mathrm{~mA}$ were significantly higher in $\varepsilon_{\mathrm{f}}$ than the $2 \mathrm{~mA}$ treatment, where average $\varepsilon_{\mathrm{f}}$ was 0.028 . At $35 \mathrm{~mA}, \varepsilon_{\mathrm{f}}$ was statistically similar to the $2 \mathrm{~mA}$ due to the high mortality rate (see Figure 6.10). 
Figure 6.7. Electric field effectiveness at repelling earthworms a) in all treatments and b) in treatments where one factor was varied between each treatment pair. Significant treatment differences at the 5\% level using Tukey's test between treatment means are indicated by differing letters. 

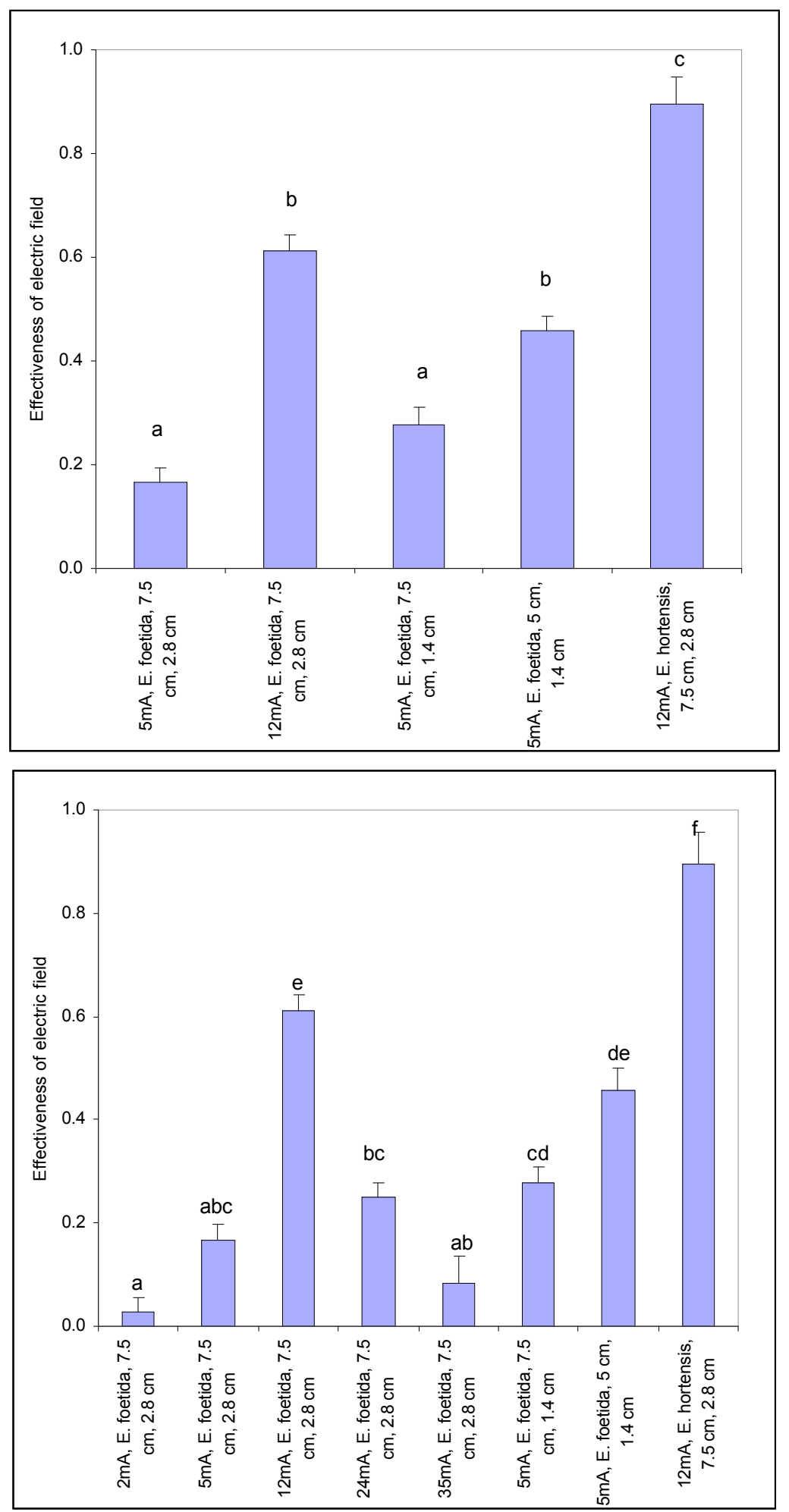
Figure $6.7 \mathrm{~b}$ shows the set of treatments where only one of the factors affecting $\varepsilon_{\mathrm{f}}$ was varied within each pair of treatments. The comparison of means shows that each of the factors; electrode depth, spacing, earthworm diameter and resistance, and current level, had a significant effect on $\varepsilon_{\mathrm{f}}$.

\subsubsection{Developing the model for electric field effectiveness at repelling earthworms}

From visual observation it would seem that different sets of data followed different trends (Figure 6.8). In order to derive a model of the electric field from these trends four sets of data were considered. The data sets were: electrode spacing of $1.4 \mathrm{~cm}$ and electrode spacing of $2.8 \mathrm{~cm}$ at current levels below the earthworm mortality threshold; and the same data set but for electric current levels beyond the current value where earthworm mortality occurs. The latter data set included only E. foetida as the earthworm species. Treatment differences are not shown in Figure 6.8 but are the same as that in Figure 6.7. Also, the $\mathrm{x}$ axis in Figure $6.8 \mathrm{is}^{2} / \mathrm{ds}$ compared to the treatment labels in Figure 6.7. As shown in Figure 6.8 electric field effectiveness increases logarithmically with a value proportional to the voltage created across earthworms ( $i \mathrm{RD}^{2} / \mathrm{ds}$ or $\mathrm{V}_{\mathrm{w}} / \mathrm{k}$ ) for a given electrode spacing, regardless of the earthworm species. The resulting equation is

$$
\varepsilon_{\mathrm{f}}=0.3048 \ln \left(\mathrm{iRD}^{2} / \mathrm{ds}\right)+0.2894
$$




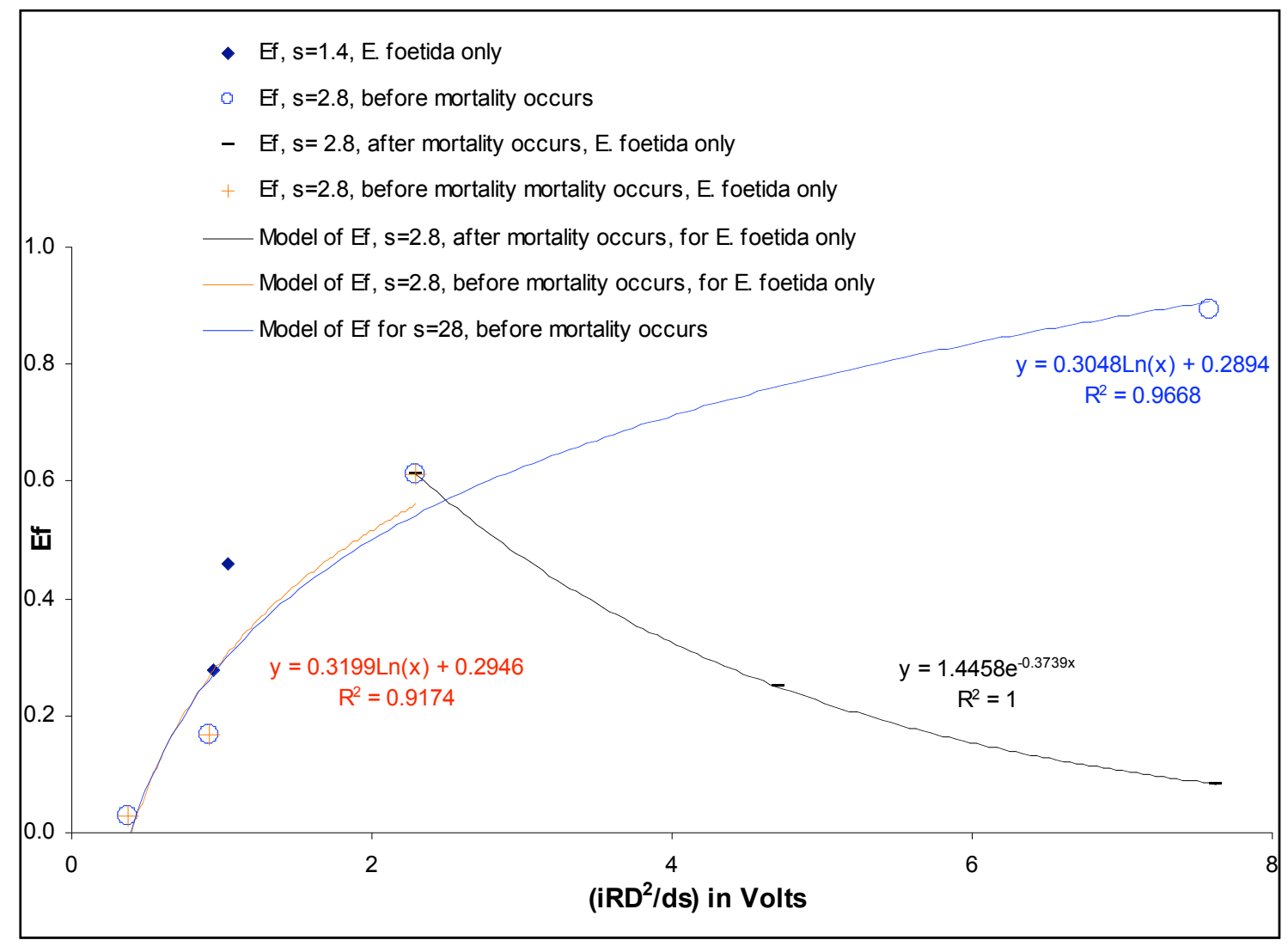

Figure 6.8. Electric field effectiveness at repelling earthworms vs. a value proportional to the voltage created across earthworms $\left(\mathrm{V}_{\mathrm{w}} / \mathrm{k}\right)$.

The logarithmic curves in Figure 6.8 fits treatments with the electrode spacing of 2.8 $\mathrm{cm}$, but not $1.4 \mathrm{~cm}$. This implies that different coefficients are to be used in models which predict the electric filed effectiveness at different electrode spacings. This also implies that the current model does not account for some indirect effects of electrode spacing.

This first curve in Figure 6.8 is intercepted by a curve showing a decrease in effectiveness at $V_{w} / k$ levels high enough to cause mortality (Figure 6.10). The mortality curve is considered specific to E. foetida since no mortality occurred in the treatment 
where E. hortensis was used. This indicates that while the suggested model predicts effectiveness of the electric field at $V_{\mathrm{w}} / \mathrm{k}$ values below the mortality threshold regardless of earthworm species it does not account for a species-specific effect on the mortality rate at high $\mathrm{V}_{\mathrm{w}} / \mathrm{k}$ levels. As a result a species-specific model is needed to predict the decline in electric field effectiveness after the mortality threshold is reached. The intersection point between the mortality curve and the 'before mortality curve', at approximately $\mathrm{V}_{\mathrm{w}} / \mathrm{k}=18$, is the mortality threshold level of $\mathrm{V}_{\mathrm{w}} / \mathrm{k}$ for E. foetida earthworms at a $2.8 \mathrm{~cm}$ electrode spacing.

\subsection{5. $t_{100 \%}$ : Time required to repel all potential earthworms}

Figure 6.9 shows that for an electrode spacing of $2.8 \mathrm{~cm}$, the time period required to repel all E. foetida earthworms from the soil slab $\left(\mathrm{t}_{100 \%}\right)$ increases exponentially with $\mathrm{V}_{\mathrm{w}} / \mathrm{k}$ (Voltage across earthworms divided by proportionality constant). These results indicate an increase in field effectiveness (Figure 6.8) until the mortality threshold value is reached. After the earthworm mortality threshold is reached $t_{100 \%}$ decreases exponentially with the increase in $V_{w} / k$, These results show that peak $t_{100 \%}$, coincides with the onset of earthworm mortality for a given species. Treatments including the $E$. hortensis species or $1.4 \mathrm{~cm}$ electrode spacing are excluded from this analysis because as shown in Figure 6.9 different electrode spacing responds to different trends, and the treatment including the $E$. hortensis earthworm falls beyond the mortality onset for $E$. foetida (Figure 6.9). These results along with the effectiveness model in Figure 6.8 indicate that peak $t_{100 \%}$, and the onset of mortality might occur at a higher $V_{w} / k$ value for the larger earthworm species. 
Figure 6.9. a) Time elapsed in minutes before the maximum potential number of earthworms exiting the soil slab is reached $\left(\mathrm{t}_{100 \%}\right)$, in each treatment. Significant treatment differences at the 5\% level using Tukey's test between treatment means are indicated by differing letters. b) $t_{100 \%}$ vs. a value proportional to the voltage created across earthworms $\left(\mathrm{V}_{\mathrm{w}} / \mathrm{k}\right)$. 

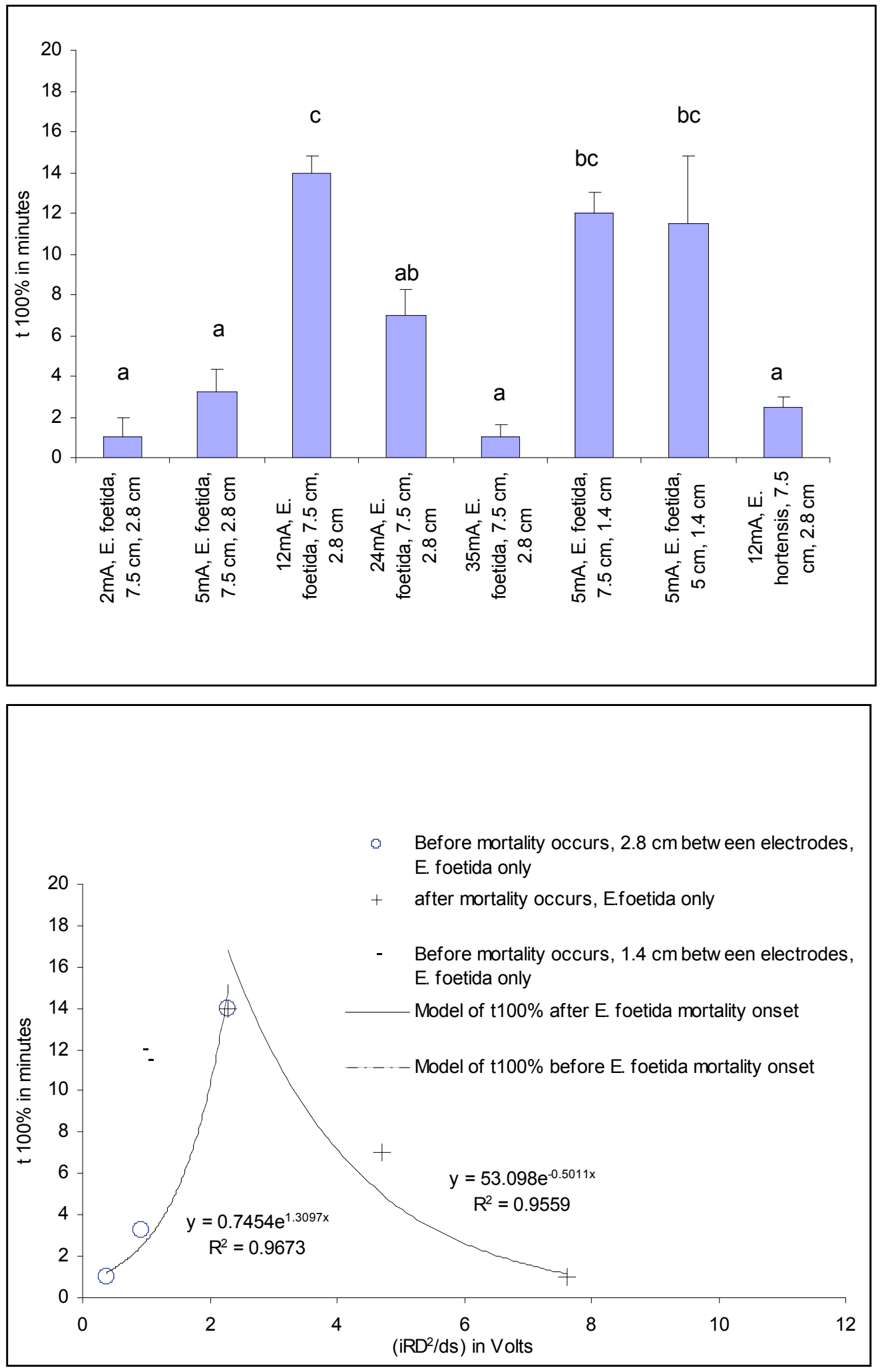


\subsubsection{Earthworm mortality}

Earthworm mortality (Figure 6.10) is considered specific to earthworm species since the one E. hortensis data point does not fit on the curve for E. foetida. While the suggested model predicts effectiveness of the electric field at $V_{w} / k$ values below the mortality threshold regardless of earthworm species it does not account for a speciesspecific effect above the threshold. As a result a species-specific model is needed to

predict the decline in electric field effectiveness after the mortality threshold is reached as was discussed earlier in section 6.3.4. 

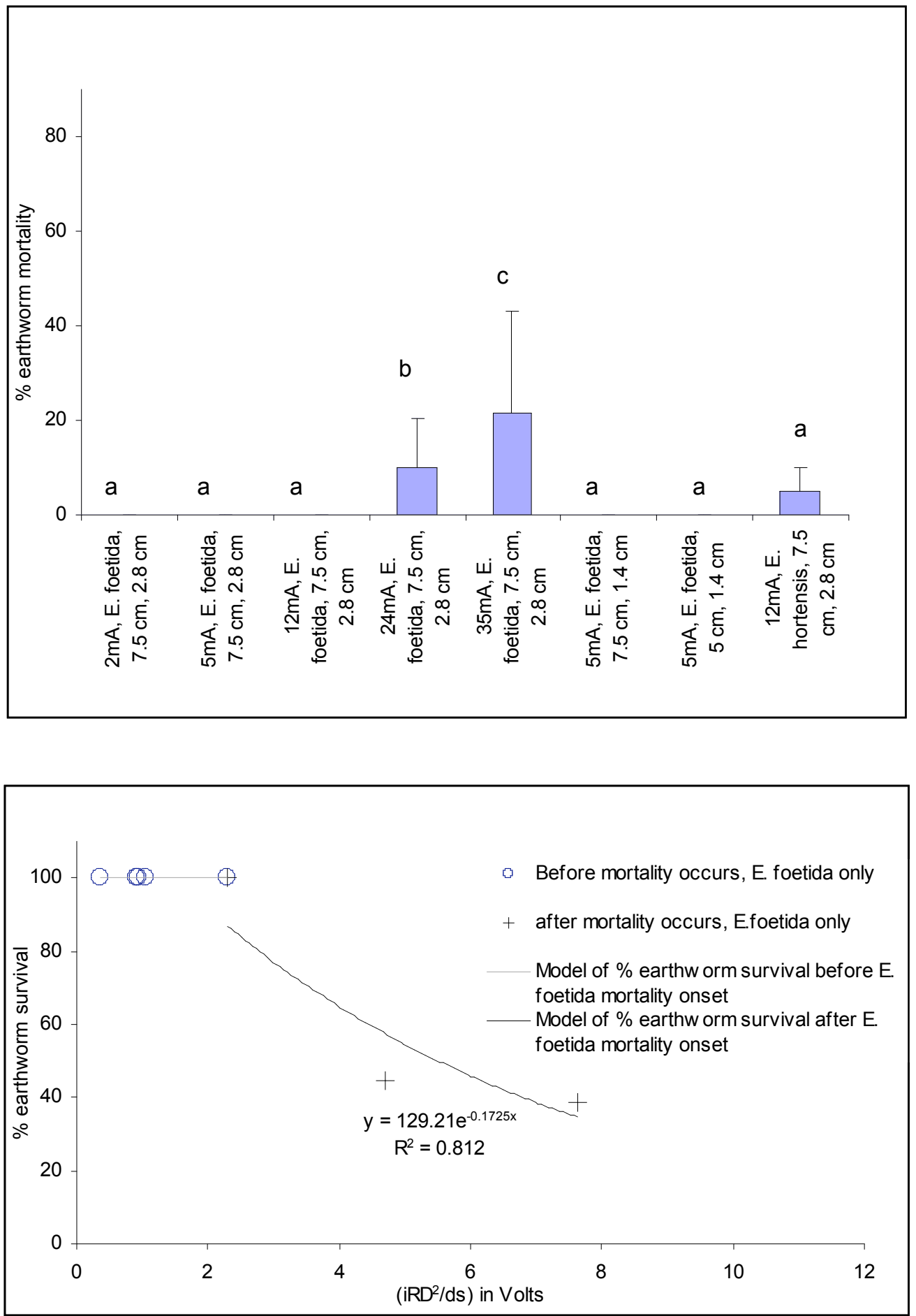

Figure 6.10. a) Percentage earthworm mortality in each treatment. Significant treatment differences at the 5\% level using Tukey's test between treatment means are indicated by differing letters. b) Percentage earthworm survival vs. a value proportional to the voltage created across earthworms. 


\subsubsection{Replicability of the soil slab preparation technique}

Replicability of the soil slabs was evaluated through soil resistance values at the center of the soil slab and through soil moisture values. Soil resistance was calculated by dividing the measured voltage drop by the current applied across electrodes from the power supply. In the case of the $1.4 \mathrm{~cm}$ spacing between electrodes, three electrodes were used creating two current loops. In this case the resistance of the soil slab was the $\mathrm{R}_{\mathrm{eq}}$ of the two parallel resistors consisting of soil between each pair of electrodes.

$$
R_{\text {eq }}=\frac{R_{1} R_{2}}{R_{1}+R_{2}}
$$

The results (Figure 6.11) showed that soil resistance was consistent (no significant treatment difference) across all treatments except for the $2 \mathrm{~mA}$ and $5 \mathrm{~mA}$ treatments. This could be due to the presence of a higher count of live earthworms in these treatments and the earthworms having less resistance than the equivalent volume of soil mix. Results support the assumption that all soil slabs had similar resistance. 


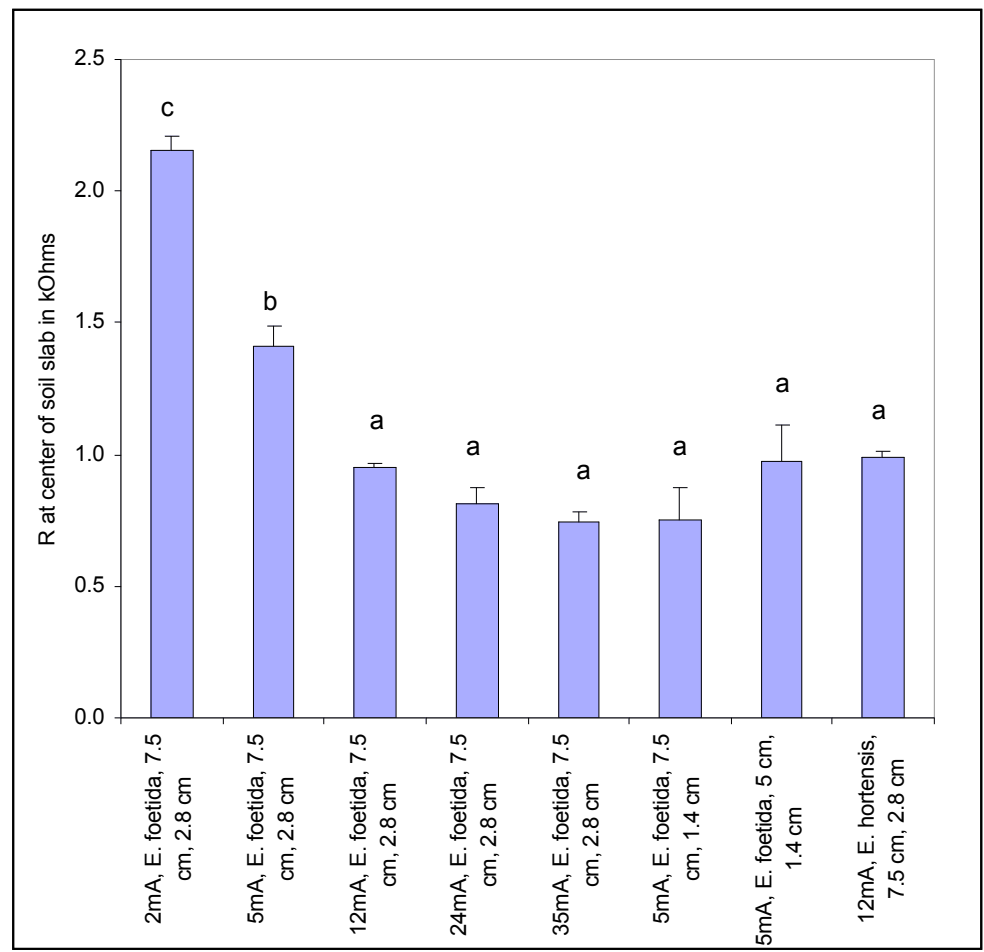

Figure 6.11. Soil resistance at the center of the soil slab, based on resistance measured between electrodes. Significant treatment differences at the 5\% level using Tukey's test between treatment means are indicated by differing letters.

Moisture was also measured in all soil slabs and the average value was $28.7 \%$ on dry basis, with a relatively low $1.3 \%$ standard error. This indicates that neither soil moisture level nor consequently moisture resistance were a source of variability in the effectiveness of the electric field at repelling earthworms. 


\subsection{Test the model for electric field effectiveness in media with different levels of soil salinity, moisture content or bulk density levels}

The porosity, salinity and moisture levels of the four media used in this experiment were analyzed and found to be significantly different between the media (Table 6.2). This indicates that these parameters were effectively varied, and that the blocking factors in the RCBD design used were valid. Figure 6.12 shows the electric field effectiveness values calculated for the four soil mixes as compared to the theoretical model for the electric field effectiveness. A two-way ANOVA conducted on the square of the residuals between the calculated and theoretical values for electric field effectiveness showed the following; there was no blocking effect due to the different mixes $(p=0.38263>0.05)$ nor a treatment effect $(p=0.97582>0 / 05)$ on the values of the residuals. This indicates that the fit of the model was not affected by the soil mix used. This also implies that soil moisture level, salinity and porosity are accounted for by soil resistance, which is indirectly expressed in the electric current term in the model predicting electric field effectiveness. The $\mathrm{R}^{2}$ values indicating the fit of the data to the model, for each soil mix (Table 6.2) for mixes 1,2 and 3 ranged from 0.312 to 0.411 . In the case of mix 4 the $\mathrm{R}^{2}$ value was relatively high at 0.707 , which is due to the fact that it was derived from two treatment values as opposed to the three treatments used for the other mixes. One of the treatments in this block, the $5 \mathrm{~mA} /$ E. foetida treatment had an $\mathrm{x}$ value below the boundary of the model for the electric field effectiveness and was therefore discarded from the $\mathrm{R}^{2}$ analysis. Mix 4 was also dropped from the regression analysis on the soil mixes properties. The relationship for the three soil properties are shown in Figure 6.13, Figure 
6.14 and Figure 6.15. The data suggest that these soil properties do not affect the model's fit.

\begin{tabular}{|c|c|c|c|c|c|c|c|c|}
\hline 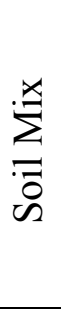 & 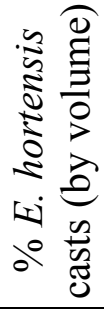 & 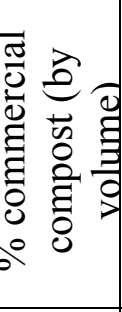 & 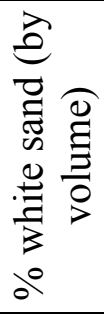 & 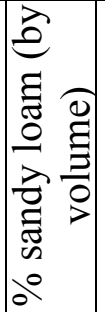 & 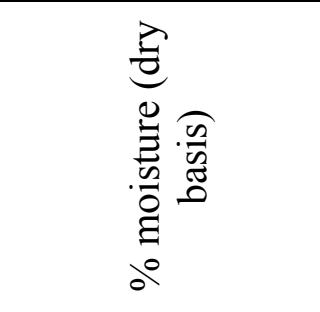 & 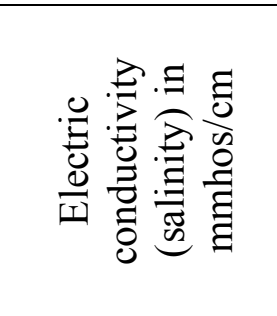 & $\begin{array}{l}\frac{2}{0} \\
0 \\
0 \\
0 \\
2 \\
0\end{array}$ & 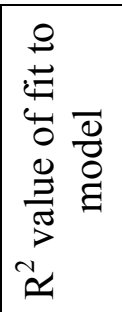 \\
\hline 1 & 0 & 55 & 15 & 30 & $28.44^{\mathrm{a}}+/-0.004$ & $0.82^{\mathrm{a}}+/-0.012$ & $44.26^{\mathrm{a}}$ & 0.312 \\
\hline 2 & 100 & 0 & 0 & 0 & $158.99^{d}+/-0.033$ & $3.72^{\mathrm{d}}+/-0.060$ & $76.03^{d}$ & 0.316 \\
\hline 3 & 0 & 90 & 10 & 0 & $70.26^{\mathrm{c}}+/-0.016$ & $3.10^{\mathrm{c}}+/-0.058$ & $57.63^{c}$ & 0.411 \\
\hline 4 & 50 & 27.5 & 7.5 & 15 & $50.27^{b}+/-0.015$ & $2.23^{b}+/-0.037$ & $47.29^{\mathrm{b}}$ & $0.707^{* *}$ \\
\hline
\end{tabular}

** This value was calculated based on two data points only because the third treatment in the block (soil mix) had an (x) value outside of the model's range; the predicted effectiveness value for the point was negative.

Table 6.2. Properties of the four soil mixes used in testing the model for electric field effectiveness at repelling earthworms, and the $\mathrm{R}^{2}$ values of showing the fit of each soil mix to the model. Significant treatment differences at the 5\% level using Tukey's test between treatment means are indicated by differing letters. 


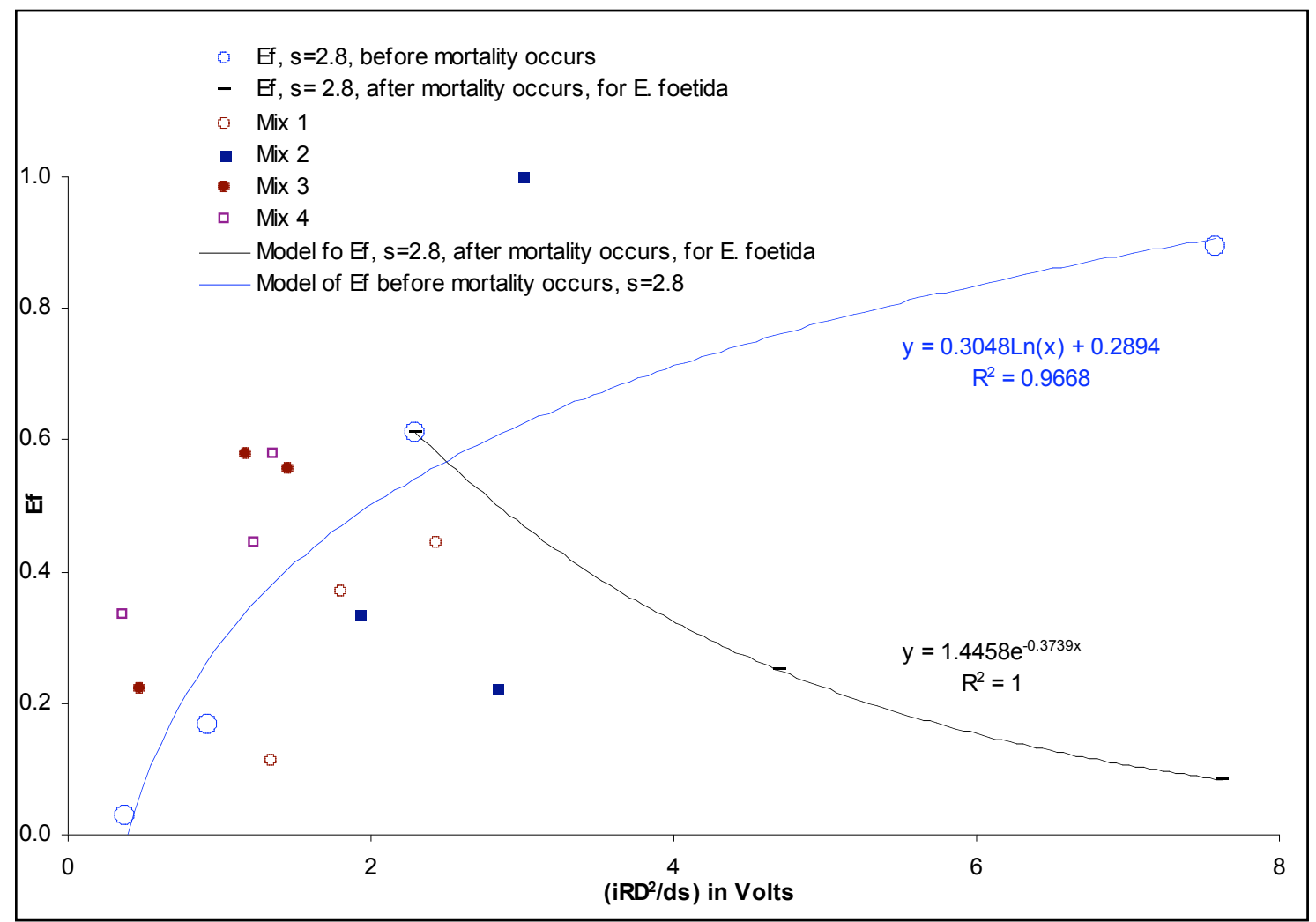

Figure 6.12. Testing the model for electric field effectiveness by plotting against it field effectiveness values derived from four soil mixes as described in Table 6.2 


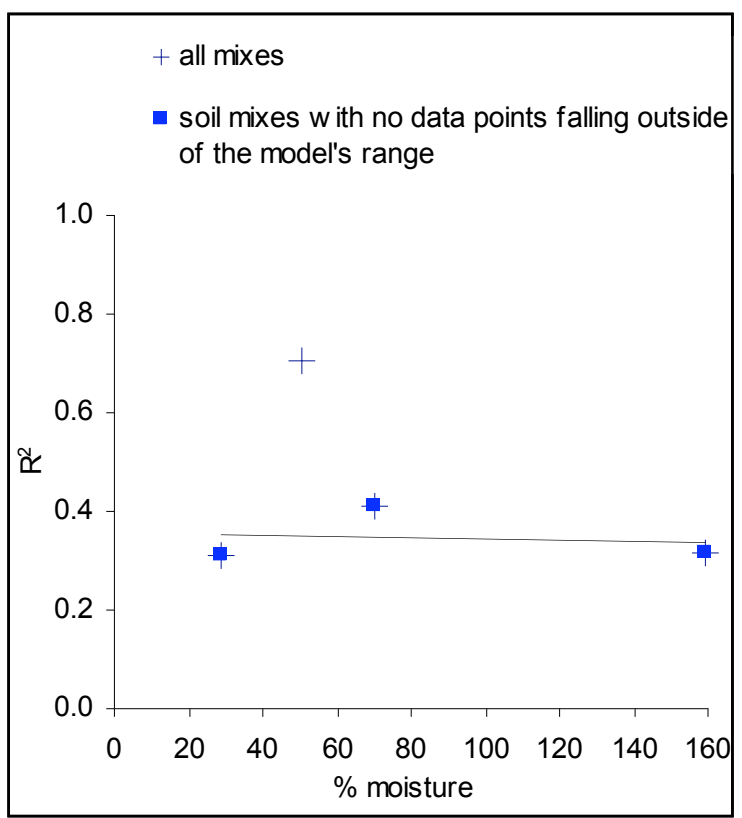

Figure 6.13. The $\mathrm{R}^{2}$ values indicate the fit of the electric field effectiveness recorded in four soil mixes, to the theoretical model. It is shown here in relation to the moisture level of used mixes. In this completely random blocked design, one of the blocks (mix 4) included a treatment with an $\mathrm{x}$ value beyond the range of the theoretical model. The trend line shown here excludes this mix (mix 4). 


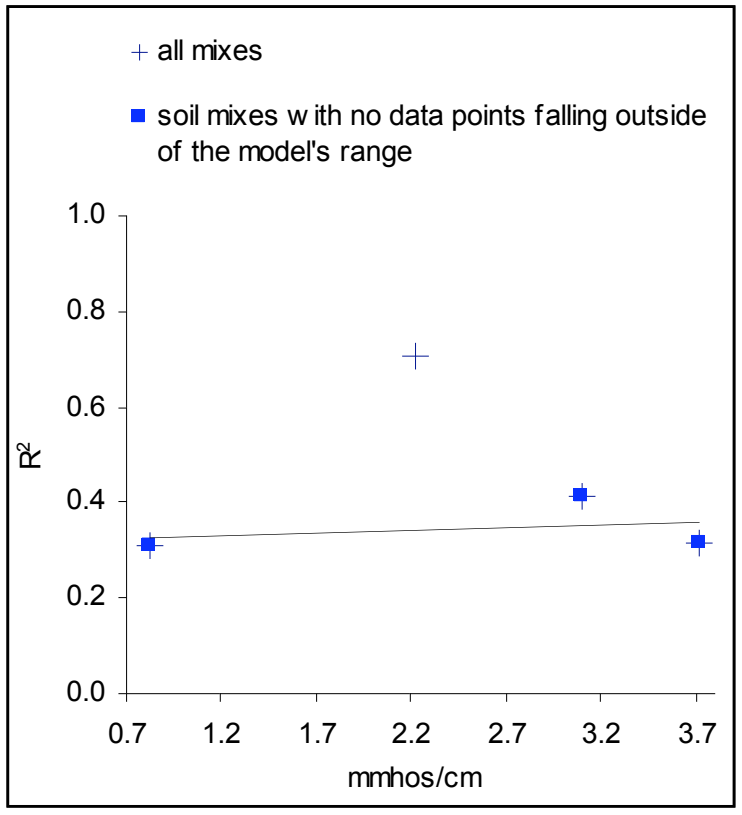

Figure 6.14. The $\mathrm{R}^{2}$ values indicate the fit of the electric field effectiveness recorded in four soil mixes, to the theoretical model. It is shown here in relation to the conductivity (salinity) level of used mixes. In this completely random blocked design, one of the blocks (mix 4) included a treatment with an $\mathrm{x}$ value beyond the range of the theoretical model. The trend line shown here excludes this mix ( $\operatorname{mix} 4)$. 


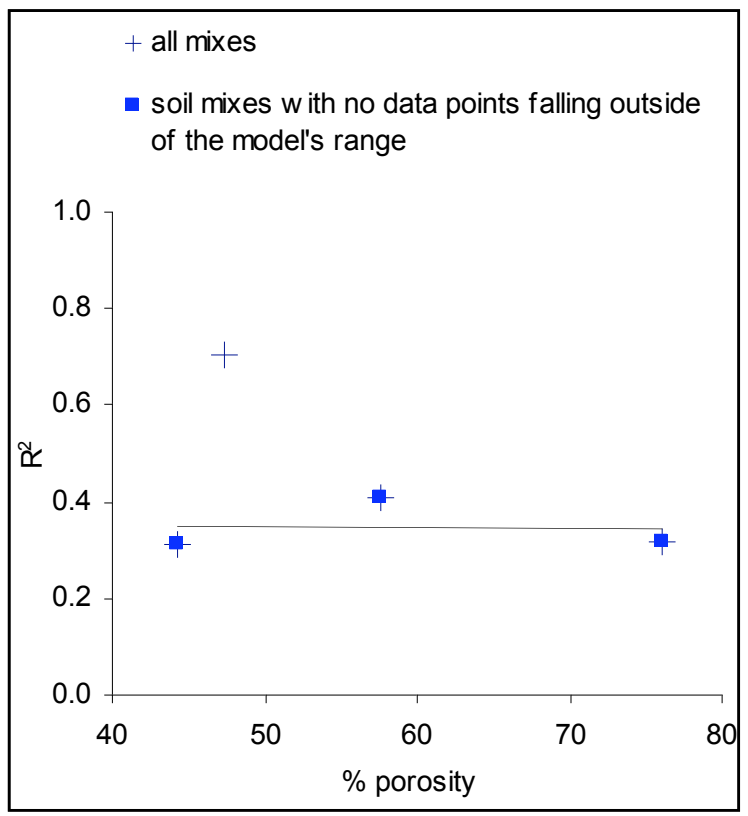

Figure 6.15. The $\mathrm{R}^{2}$ values indicate the fit of the electric field effectiveness recorded in four soil mixes, to the theoretical model. It is shown here in relation to the $\%$ porosity of used mixes. In this completely random blocked design, one of the blocks (mix 4) included a treatment with an $\mathrm{x}$ value beyond the range of the theoretical model. The trend line shown here excludes this mix (mix 4).

\subsection{The effect of direct or alternating current on the effectiveness of an electric field at repelling earthworms}

The maximum average voltage output when using an $\mathrm{AC}$ function generator to create an electric field across a $7.5 \mathrm{~cm}$ deep soil slab filled with mix 1 (Table 6.2), and with an electrode spacing of $2.8 \mathrm{~cm}$ was 5.43 volts. This voltage was replicated (at stable current levels) in the DC treatment and resulted in a current of 5.43 mAmps across the center of the soil slab. Figure 6.16 shows that the alternating current gave an electric field effectiveness of 0.81 , a level significantly higher than 0.21 , the one predicted by the model. Using direct current resulted in an effectiveness level statistically similar to the 
one predicted by the model. This indicates that the model's fit does depend on the type of current used. Since direct current leads to muscle tetanus and alternating current causes fibrillation (Surbrook and Schrandt, 2005), it may be that $5 \mathrm{~mA}$ of direct current generated across a soil slab causes the earthworms to freeze, while an alternating current of the same magnitude causes discomfort but still allow earthworms the move away from the electric pulse.

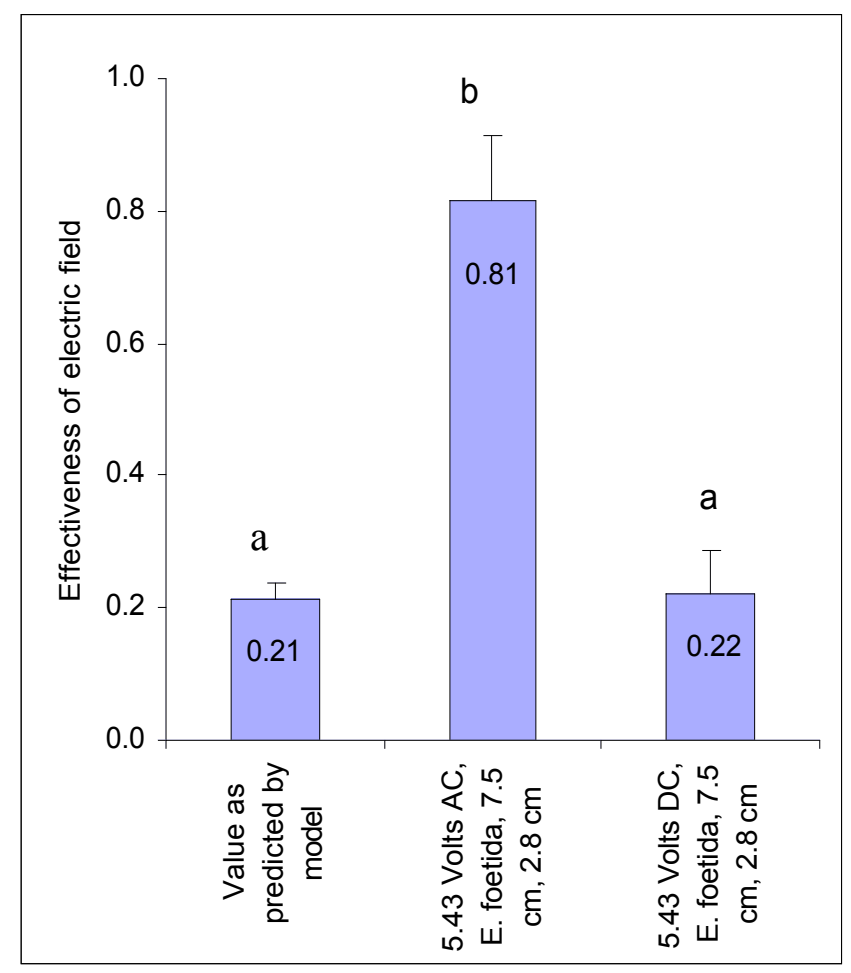

Figure 6.16. Electric field effectiveness at repelling earthworms when alternating or direct current is used, and also in comparison to the theoretical effectiveness value predicted by the model. Significant treatment differences at the 5\% level using Tukey's test between treatment means are indicated by differing letters. 


\subsection{The effect of current level on the location of threshold current in earthworm casts}

The E. hortensis earthworm casts slab used here has a $75.3 \%$ porosity and $159 \%$ moisture content (db). Results shown in Table 6.3 and Figure 6.17 show that across the voltage levels, the current level derived from the measured voltage drops and resistance values, becomes negligible beyond a $3 \mathrm{~cm}$ distance from the electric field. For this reason only the current values within a $3 \mathrm{~cm}$ range from the electric field were used to model electric current levels in terms of distance from the field, from electric field of different voltage values. These models are used in Table 6.4 to derive an expression of the distance in $\mathrm{cm}$ from an electric field in terms of the targeted electric current. This allows evaluating at which location a targeted threshold current will be found. Based on Figure 6.8 , one targeted threshold current for the species E. foetida is $2.2 \mathrm{~mA}$, in $7.5 \mathrm{~cm}$ deep soil slab and at a $2.8 \mathrm{~cm}$ electrode spacing, since this is the level at which the electric field's effectiveness at repelling earthworms peaks. In Table 6.4 the distance from the electric field at which the targeted current level is found is calculated based one of each of the two symmetrical models with the best fit to the data (expressed as $\mathrm{R}^{2}$ ). The resulting values indicate (Figure 6.18) the functional relationship between the distances at which the targeted current is found and the voltage level is an exponential. The value for this distance however does converge to around $3 \mathrm{~cm}$. This distance is close to the $2.8 \mathrm{~cm}$ spacing between electrodes, which implies that the largest distance at which an electric current diffuses, and potential at which a threshold current can be targeted, could be similar to the spacing between electrodes used. 


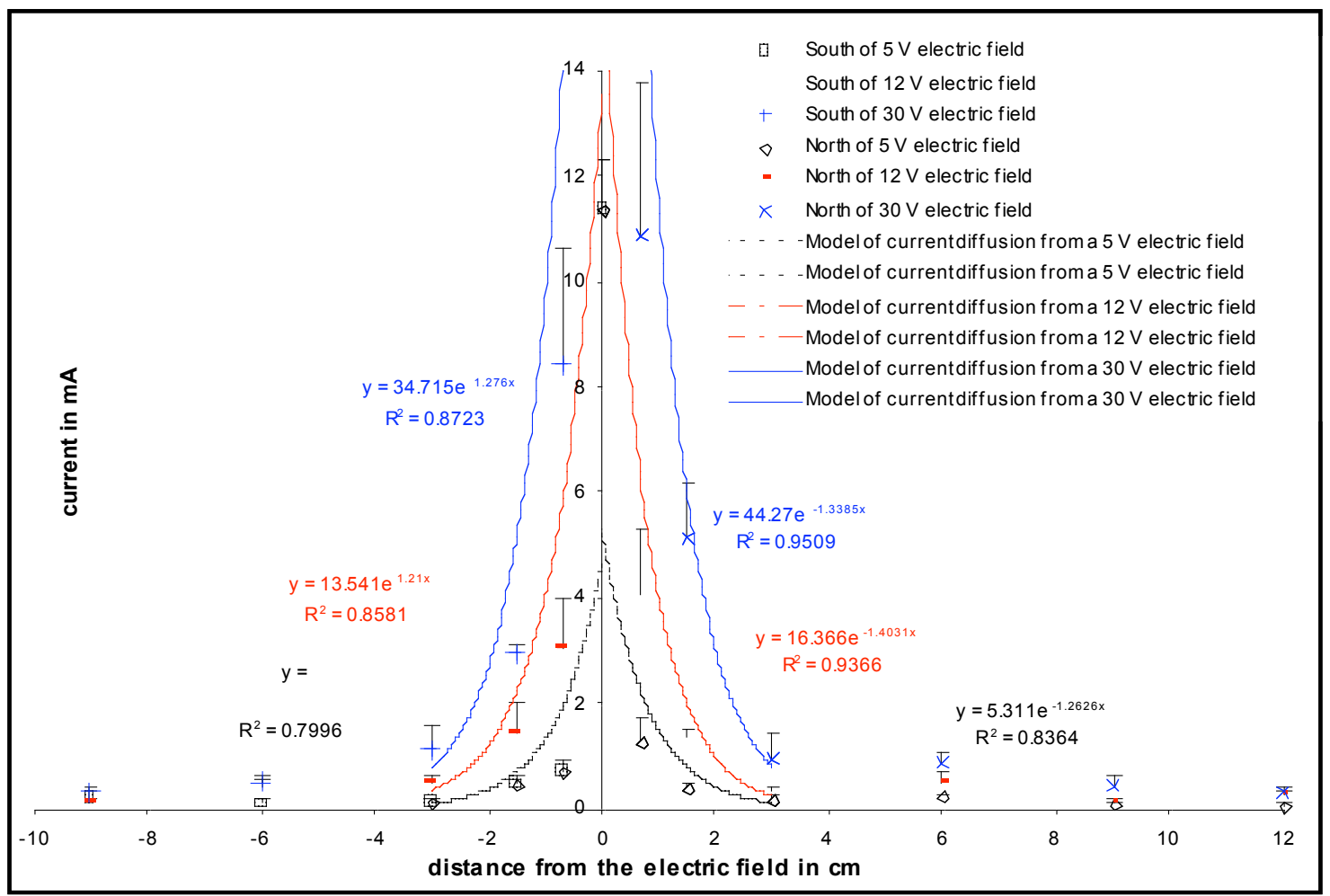

Figure 6.17. Models of electric current values in function of the voltage created across an electric field and the distance of the current from the electric field (within $3 \mathrm{~cm}$ from the field). These values apply to a slab of earthworm casts that is $7.5 \mathrm{~cm}$ deep, with a porosity of $75.3 \%$ and a moisture level of $159 \%(\mathrm{db})$. 
Table 6.3. The mean electric current values at increasing distances from an electric field generated between two electrodes, in a $7.5 \mathrm{~cm}$ deep soil slab, with a $2.8 \times 24 \mathrm{~cm}$ surface area. Significant treatment differences at the 5\% level using Tukey's test between treatment means are indicated by differing letters. Shown in bold are the significantly different values used to model the electric field's diffusion (in Figure 6.17), all within a 3 $\mathrm{cm}$ range from the electric field. Values beyond this range we not significantly different from those at $+/-3 \mathrm{~cm}$ from the electric field. 


\begin{tabular}{|c|c|c|c|c|}
\hline \multirow[b]{2}{*}{$\begin{array}{l}\text { Voltage generated } \\
\text { across the electric field } \\
\text { and distance from the } \\
\text { electric field at which } \\
\text { electric current is } \\
\text { recorded (as V drop/R) }\end{array}$} & \multirow[b]{2}{*}{$\begin{array}{l}\text { Average } \\
\text { electric } \\
\text { current in } \\
\mathrm{mA}\end{array}$} & \multirow[b]{2}{*}{$\begin{array}{l}\text { Standard } \\
\text { error in } \\
\text { electric } \\
\text { current }\end{array}$} & \multicolumn{2}{|c|}{ Separation of means } \\
\hline & & & $\begin{array}{l}\text { Including the } \\
\text { electric current } \\
\text { value through the } \\
\text { electric field }\end{array}$ & $\begin{array}{l}\text { Excluding the } \\
\text { electric current } \\
\text { value through the } \\
\text { electric field }\end{array}$ \\
\hline $5 \mathrm{~V}, 12 \mathrm{~cm}$ & 0.059 & 0.047 & $\mathrm{a}$ & $\mathrm{a}$ \\
\hline $5 \mathrm{~V}, 9 \mathrm{~cm}$ & 0.122 & 0.041 & $\mathrm{a}$ & $\mathrm{a}$ \\
\hline $5 \mathrm{~V}, 6 \mathrm{~cm}$ & 0.238 & 0.061 & $\mathrm{a}$ & $\mathrm{a}$ \\
\hline $5 \mathrm{~V}, 3 \mathrm{~cm}$ & 0.192 & 0.048 & $\mathbf{a}$ & $\mathbf{a}$ \\
\hline $5 \mathrm{~V}, 1.5 \mathrm{~cm}$ & 0.408 & 0.090 & $\mathbf{a}$ & $\mathbf{a}$ \\
\hline $5 \mathrm{~V}, 0.7 \mathrm{~cm}$ & 1.260 & 0.447 & $\mathbf{a}$ & b \\
\hline $5 \mathrm{~V}, 0 \mathrm{~cm}$ & 11.366 & 0.929 & b & \\
\hline $5 \mathrm{~V},-0.7 \mathrm{~cm}$ & 0.743 & 0.166 & $\mathbf{a}$ & ab \\
\hline $5 \mathrm{~V},-1.5 \mathrm{~cm}$ & 0.491 & 0.168 & $\mathbf{a}$ & $\mathbf{a b}$ \\
\hline $5 \mathrm{~V},-3 \mathrm{~cm}$ & 0.156 & 0.073 & $\mathbf{a}$ & $\mathbf{a}$ \\
\hline $5 \mathrm{~V},-6 \mathrm{~cm}$ & 0.123 & 0.068 & $\mathrm{a}$ & $\mathrm{a}$ \\
\hline $5 \mathrm{~V},-9 \mathrm{~cm}$ & 0.224 & 0.102 & $\mathrm{a}$ & $\mathrm{a}$ \\
\hline $12 \mathrm{~V}, 12 \mathrm{~cm}$ & 0.295 & 0.040 & $\mathrm{a}$ & $\mathrm{a}$ \\
\hline $12 \mathrm{~V}, 9 \mathrm{~cm}$ & 0.129 & 0.042 & $\mathrm{a}$ & $\mathrm{a}$ \\
\hline $12 \mathrm{~V}, 6 \mathrm{~cm}$ & 0.506 & 0.171 & $\mathrm{a}$ & $\mathrm{ab}$ \\
\hline $12 \mathrm{~V}, 3 \mathrm{~cm}$ & 0.324 & 0.077 & $\mathbf{a}$ & $\mathbf{a}$ \\
\hline $12 \mathrm{~V}, 1.5 \mathrm{~cm}$ & 1.362 & 0.116 & $\mathbf{a}$ & ab \\
\hline $12 \mathrm{~V}, 0.7 \mathrm{~cm}$ & 4.037 & 1.301 & $\mathbf{a}$ & c \\
\hline $12 \mathrm{~V}, 0 \mathrm{~cm}$ & 27.278 & 2.230 & b & \\
\hline $12 \mathrm{~V},-0.7 \mathrm{~cm}$ & 3.069 & 0.898 & $\mathbf{a}$ & bc \\
\hline $12 \mathrm{~V},-1.5 \mathrm{~cm}$ & 1.443 & 0.590 & $\mathbf{a}$ & abc \\
\hline $12 \mathrm{~V},-3 \mathrm{~cm}$ & 0.515 & 0.146 & $\mathbf{a}$ & $\mathbf{a b}$ \\
\hline $12 \mathrm{~V},-6 \mathrm{~cm}$ & 0.408 & 0.161 & $\mathrm{a}$ & $\mathrm{a}$ \\
\hline $12 \mathrm{~V},-9 \mathrm{~cm}$ & 0.150 & 0.055 & $\mathrm{a}$ & $\mathrm{a}$ \\
\hline $30 \mathrm{~V}, 12 \mathrm{~cm}$ & 0.328 & 0.090 & $\mathrm{a}$ & $\mathrm{a}$ \\
\hline $30 \mathrm{~V}, 9 \mathrm{~cm}$ & 0.430 & 0.217 & $\mathrm{a}$ & $\mathrm{ab}$ \\
\hline $30 \mathrm{~V}, 6 \mathrm{~cm}$ & 0.890 & 0.193 & $\mathrm{a}$ & $\mathrm{ab}$ \\
\hline $30 \mathrm{~V}, 3 \mathrm{~cm}$ & 0.958 & 0.447 & $\mathbf{a}$ & $\mathbf{a b}$ \\
\hline $30 \mathrm{~V}, 1.5 \mathrm{~cm}$ & 5.129 & 1.080 & ab & c \\
\hline $30 \mathrm{~V}, 0.7 \mathrm{~cm}$ & 10.870 & 2.927 & $\mathbf{b}$ & d \\
\hline $30 \mathrm{~V}, 0 \mathrm{~cm}$ & 68.194 & 5.574 & c & \\
\hline $30 \mathrm{~V},-0.7 \mathrm{~cm}$ & 8.425 & 2.184 & ab & d \\
\hline $30 \mathrm{~V},-1.5 \mathrm{~cm}$ & 2.957 & 0.186 & ab & bc \\
\hline $30 \mathrm{~V},-3 \mathrm{~cm}$ & 1.122 & 0.474 & ab & ab \\
\hline $30 \mathrm{~V},-6 \mathrm{~cm}$ & 0.499 & 0.151 & $\mathrm{a}$ & $\mathrm{ab}$ \\
\hline $30 \mathrm{~V},-9 \mathrm{~cm}$ & 0.343 & 0.075 & $\mathrm{a}$ & $\mathrm{a}$ \\
\hline
\end{tabular}




\begin{tabular}{|c|c|c|c|c|c|c|c|}
\hline & \multicolumn{2}{|c|}{$\mathrm{R}^{2}$ value } & \multirow[b]{2}{*}{$\begin{array}{c}\text { Current in } \\
\text { terms of } \\
\text { distance in } \mathrm{cm} \\
\text { (x) }\end{array}$} & \multirow[b]{2}{*}{$\begin{array}{l}\text { Absolute value of } \\
\text { distance } \mathrm{x} \text { in } \mathrm{cm} \text { in } \\
\text { terms of current in } \mathrm{mA} \\
\text { (x) }\end{array}$} & \multirow[b]{2}{*}{ 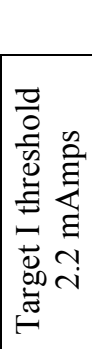 } & \multirow[b]{2}{*}{ 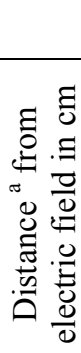 } \\
\hline $\begin{array}{l}\text { Distance } \\
\text { range from } \\
\text { electric field }\end{array}$ & 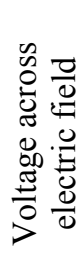 & 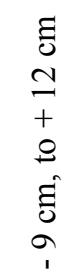 & $\begin{array}{c}\Xi \\
0 \\
m \\
+ \\
0 \\
0 \\
\Xi \\
0 \\
m \\
1\end{array}$ & & & & \\
\hline south $5 \mathrm{~V}$ & & 0.44 & 0.80 & $4.6205 \mathrm{e}^{1.2607 \mathrm{x}}$ & $|\ln (\mathrm{x} / 4.205) / 1.2607|$ & 2.2 & \\
\hline north $5 \mathrm{~V}$ & 5 & 0.66 & 0.84 & $5.311 \mathrm{e}^{-1.2626 \mathrm{x}}$ & $|\ln (y / 5.311) / 1.2626|$ & 2.2 & 0.70 \\
\hline south $12 \mathrm{~V}$ & & 0.74 & 0.86 & $13.541 \mathrm{e}^{1.21 \mathrm{x}}$ & $|\ln (\mathrm{x} / 13.541) / 1.21|$ & 2.2 & \\
\hline north $12 \mathrm{~V}$ & 12 & 0.59 & 0.94 & $16.366 \mathrm{e}^{-1.4031 \mathrm{x}}$ & $|\ln (\mathrm{x} / 16.366) / 1.4031|$ & 2.2 & 1.43 \\
\hline south $30 \mathrm{~V}$ & & 0.75 & 0.87 & $34.715 \mathrm{e}^{1.276 \mathrm{x}}$ & $|\ln (\mathrm{x} / 34.715) / 1.276|$ & 2.2 & \\
\hline north $30 \mathrm{~V}$ & 30 & 0.74 & 0.95 & $44.27 \mathrm{e}^{-1.3385 \mathrm{x}}$ & $|\ln (\mathrm{x} / 44.27) / 1.3385|$ & 2.2 & 2.24 \\
\hline
\end{tabular}

Table 6.4. Based on Figure 6.17, the following models express electric current in function of distance from an electric field and voltage, in an earthworm casts slab as described in (Figure 3.1), for each voltage level across the field. Models shown also express the distance at which a given current level is found from an electric field. 


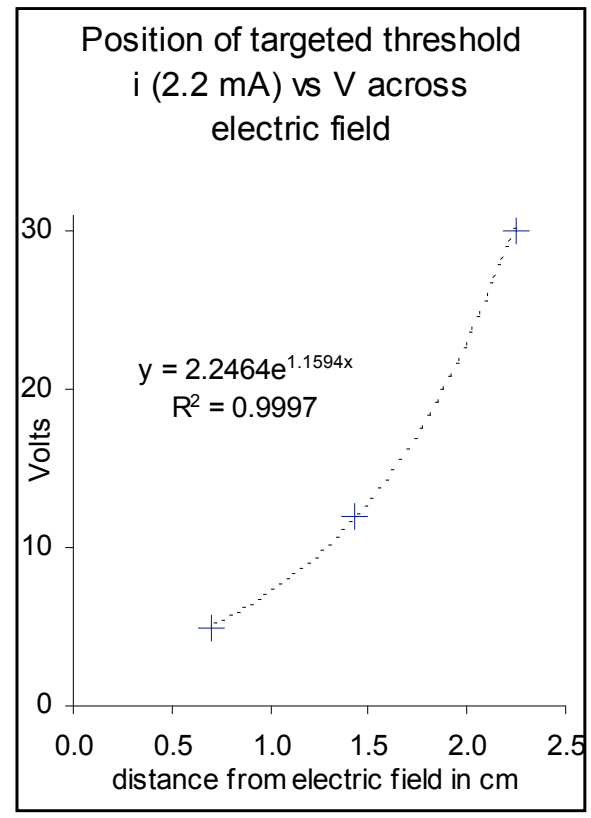

Figure 6.18. Distance from an electric field at which a targeted current of $2.2 \mathrm{~mA}$ is found, plotted against the voltage across the electric field. 


\section{CHAPTER 7}

\section{SUMMARY}

A preliminary earthworm mobility study showed that earthworms placed in a soil media at high count do migrate if not contained. Studies of earthworm mobility as affected by electric current showed that a current of $3 \mathrm{~mA}$ and more does repel earthworms, and that a combination of a $5 \mathrm{~mA}$ electric field and surface light is most effective at preventing earthworm migration along a nitrate gradient This same study also showed that the spacing and the electric current generated between soil electrodes affects the effectiveness of an electric field at preventing earthworm migration along a nitrate gradient.

A mathematical model was derived to express the effectiveness of an electric field at repelling earthworms based on voltage created across earthworms given by

$$
\mathrm{V}_{\mathrm{w}}=\mathrm{k} \cdot \mathrm{i} \cdot \mathrm{R} \cdot \mathrm{D}^{2} /(\mathrm{d} \cdot \mathrm{s})
$$

The electrode depth, spacing, earthworm species (and resulting diameter and resistance) and electric current level each have a significant effect on electric field effectiveness at repelling earthworms. The logarithmic relationship between field effectiveness and voltage across earthworms was

$$
\stackrel{\circ}{\mathrm{f}}_{\mathrm{f}}=0.3048 \ln \left(\mathrm{iRD} \mathrm{D}^{2} / \mathrm{ds}\right)+0.2894
$$


for values of voltage below that which causes earthworm mortality for a particular species. The model (equation) is specific to an electrode spacing of $2.8 \mathrm{~cm}$. This model is intercepted by an exponentially decreasing curve describing the decrease in electric field effectiveness due to earthworm mortality and is species specific. The intersection point between the two curves was the mortality threshold level of $V_{w} / k$ for a given species.

The low variability in soil resistance across replicates and treatments indicated that the method used in this study to create soil and earthworms slabs was consistent. Also the consistent ratio between the derived electric current value at the threshold of the soil slab and the prescribed current generated across soil electrodes confirm the measurement techniques used in this study and that current at the soil slab's threshold can be considered a controlled variable.

The time period required to repel all potential earthworms from a given species from a soil slab increases exponentially with the voltage created across earthworms, up to the mortality threshold, and then decreases exponentially.

Testing the mathematical model of electric field effectiveness at repelling earthworms on different soil types showed that a medium's salinity, porosity and moisture content are successfully accounted for by soil resistance, which is indirectly expressed in the electric current term found in the model. This implies that the model is applicable to all media types.

Using both alternating (AC) and direct current (DC) at the same level showed that $\mathrm{AC}$ is more effective at repelling earthworms (by about four fold) and that the derived model applies to DC current only. 
A derived model of electric current diffusion in earthworm casts suggests that as increasing voltage levels are used, the furthest distance from the electric field at which an optimal electric current level can be found (current level where repelling effectiveness peaks) converges to a value which seems to be equal to the distance between electrodes.

The results of this study provide future researchers with a method of assessing the effectiveness of an electric field at repelling earthworms. The results also indicate that soil properties do not need to be incorporated in a model of effectiveness at repelling earthworms since they are accounted for by soil resistance, which is used to calculate the electric current term in the model. Instead, soil resistance is simply measured. The presented results also suggest that it would be useful to repeat this study using an AC voltage source. A DC source was used here to in order to stabilize electric current, which was a controlled variable. In a study where AC is used, a stable voltage can be generated across the electric field and a margin of error in current level will need to be accounted for, due to fluctuation in the resistance of the medium.

Future studies modeling the location of the desired threshold current from an electric field, based on the resistance of the medium and electrode spacing / current level would be useful. Threshold current here indicates the electric current at the location beyond which earthworms will be repelled. Such a study would result in a more developed design model for an electric earthworm separator, or an underground electric earthworm fence to be placed at the edge of a plot inoculated with a high count of earthworms. 
Finally a study where the effect of an earthworm-repelling electric field on plant yield and soil microbial activity and available nutrients level would also be useful at investigating the benefits and disadvantages of containing earthworms at high counts in a plant / soil system. 


\section{BIBLIOGRAPHY}

Al Dahmani, J. H., Abbasi, P. A., Miller, S. A., and Hoitink, H. A. 2003. Suppression of bacterial spot of tomato with foliar sprays of compost extracts under greenhouse and field conditions. Plant Disease, 87 (8), 913-919.

Araujo, Y. and Lopez-Hernandez, D. 1999. Earthworm populations in a savannaagroforestry system of Venezuelan Amazonia. Biology and Fertility of Soils, 29 (4), 413-418.

Baker, G.H., Allsopp, P.G. (ed.), Rogers, D.J. (ed.) and Robertson, L.N. 1997. Influence of the introduced anecic earthworm Aporrectodea longa (Lumbricidae) on pasture production in southwestern Victoria. Soil invertebrates in 1997. Proceedings of the 3rd Brisbane Workshop on Soil Invertebrates, 21-25.

Barois, I. 1992. Mucus production and microbial activity in the gut of two species of Amynthas (Megascoledicae) from cold and warm tropical climates. Soil Biology and Biochemistry, 24 (12), 1507-1510.

Bar-Yosef, B. 1976. Effects of various trickle irrigation and fertilization regimes on nutrient and water distribution in two sandy soils, and nutrient uptake by tomato plants. Pamphlet, Agricultural Research Organization, 161.

Batte, M.T., Forster, D.L. and Hitzhusen, F.J. 1993. Organic agriculture in Ohio: an economic perspective. Journal of Production Agriculture, 6 (4), 536-542. 
Beetz, A. 1999. Worms for Composting (Vermicomposting). ATTRA Livestock technical notes.

Bergstrom, L. and Kirchmann, H. 1999. Leaching of total-N from 15N labeled poultry manure and inorganic fertilizer. Journal of Environmental Quality28, 12831290.

Binet, F., Hallaire, V., Curmi, P. and Edwards, C.A. 1997. Agricultural practices and the spatial distribution of earthworms in maize fields. Relationships between earthworm abundance, maize plants and soil compaction. 5th International symposium on earthworm ecology held in Columbus, Ohio, USA, 5-9 July 1994. Soil Biology and Biochemistry, 29 (3/4), 577-583.

Binet, F. and Trehen, P. 1992. Experimental Microcosm Study of the Role of Lumbricus Terrestris (Oligochatea: Lumbricadea) on Nitrogen Dynamics in Cultivated Soils. Soil Biology and Biochemistry, 13 (1), 39-42.

Black, C.A. 1965. Methods of Soil Analysis: Part I Physical and mineralogical properties. American Society of Agronomy, Madison, Wisconsin, USA

Bohlen, P.J. and Edwards, C.A. 1995. Earthworm effects on N dynamics and soil respiration in microcosms receiving organic and inorganic nutrients. Soil Biology and Biochemistry, 27 (3), 341-348.

Bohlen, P.J., Parmelee, R.W., Blair, Edwards, C.A., and Stinner, B.R. 1995. Efficacy of methods for manipulating earthworm populations in large-scale field experiments in agroecosytems. Soil Biology and Biochemistry, 27 (8), 993-999.

Borowski, E. 1995. Response of tomatoes to $\mathrm{NO}_{3}-\mathrm{N}$ or $\mathrm{NH}_{4}-\mathrm{N}$ applied to sand, loam, and soil substrate. Annales Universitatis Mariae Curie Sklodowska, 3, 111-118. 
Brown, G.C., Hendrix, P.F. and Beare, M.H. 1998. Earthworms (Lumbricus rubellus) and the fate of N-15 in surface-applied sorghum residues. Soil Biology and Biochemistry, 30, 1701-1705.

Buck, J., Walcott, R. and Beuchat., L R. 2003. Recent trends in microbiological safety of fruits and vegetables, in Plant Health Progress.

Buckerfield, J.C., Lee, K.E., Davoren, C.W., Hannay, J.N. 1997. Earthworms as indicators of sustainable production in dryland cropping in southern Australia. Soil Biology and Biochemistry, 29 (3/4), 547-554.

Buckingham, P.W. 1931. Dimensional Analysis. New Haven: Yale University Press.

Burrows, L. A. and Edwards, C. A. 2002. The use of integrated soil microcosms to predict effects of pesticides on soil ecosystems. European Journal of Soil Biology, 38, 245-249.

Calderon, F.J., Jackson, L.E., Scow, K.M. and Rolston, D.E. 2001. Short-term dynamics of nitrogen, microbial activity, and phospholipid fatty acids after tillage. Soil Science Society of America Journal, 65 (1), 118-126.

Cameron, K.C. and Wild, A. 1984. Potential aquifer pollution from nitrate leaching following the plowing of temporary grassland. J. Environ. Qual., 13, 274-278.

Cassman, K.G. 1999. Ecological intensification of cereal production systems: yield potential, soil quality, and precision agriculture. Proceedings of the National Academy of Sciences of the United States of America, 96 (11), 5952-5959. 
Cavero, J., Plant, R.E., Shennan, C. and Friedman, D.B. 1996. Effect of nitrogen source and crop rotation on the growth and yield of processing tomatoes. Nutrient Cycling in Agroecosytems, 47 (3), 271-282.

Chan, K.Y. and Heenan, D.P. 1995. Occurrence of enchytraeid worms and some properties of their casts in an Australian soil under cropping. Australian Journal of Soil Research, 33 (4), 651-657.

Clapperton, M.J., Miller, J.J., Larney, F.J. and Lindwall, C.W. 1997. Earthworm populations as affected by long-term tillage practices in southern Alberta, Canada. Soil Biology and Biochemistry, 29 (3/4), 631-633.

Decaens, T., Rangel, A.F., Asakawa, N. and Thomas, R.J. 1999. Carbon and nitrogen dynamics in ageing earthworm casts in grasslands of the eastern plains of Colombia. Biology and Fertility of Soils, 30 (1/2), 20-28.

Delgado, J.A., Ristau, R.J.D, Dillon, M.A., Duke, H.R., Stuebe, A., Follett, R.F., Shaffer, M.J., Riggenbach, R.R., Sparks, R.T. and Thompson, A. 2001. Use of innovative tools to increase nitrogen use efficiency and protect environmental quality in crop rotations. Communications in Soil Science and Plant Analysis, 32 (7/8), 1321-1354.

Dickey, J.B. and Kladivko, E.J. 1989. Sample unit sizes and shapes for quantitative sampling of earthworm populations in crop lands. Soil Biology and Biochemistry, 21 (1), 105-111.

Edwards CA, Bohlen PJ. 1996. The Biology and Ecology of Earthworms. $3^{\text {rd }}$ ed. Chapman and Hall. London

Edwards CA, ed. 1998. Earthworm Ecology. St. Lucie Press. Boca Raton, FL. 
Edwards, C.A. and Lofty, J. R. 1972. Biology of earthworms. Chapman and Hall, Ltd. Available from John Wiley, New York.

FAO, 1999. Organic farming, Demand for organic products has created new export opportunities for the developing world. Agriculture 21, [http://www.fao.org/ag/magazine/9901sp3.htm] Accessed: 12-11-2004.

Fieldson, R.S. 1988. The economic viability of earthworm culture on animal wastes, in Earthworms in waste and environmental management. C. Edwards, and Neuhauser, F., Editors. The Hague, 145-156.

Finola, M., Rodrigues, C. and Beoletto, V. 1995. Gastrointestinal bacteriology of the earthworm Eisenia foetida grown in composted broiler litter. Rev. Argent Microbiol., 27, 210-213.

Frederickson, J. and Howell G. 2004. Large-scale vermicomposting: emission of nitrous oxide and effects of temperature on earthworm populations. Pedobiologia, 47 $(5 / 6), 724-730$

Freijer, J.I. 1996. Mineralization of hydrocarbons in soils under decreasing oxygen availability. Journal of Environmental Quality, 25 (2), 296-304.

Friis, K., Damgaard, C. and Holmstrup, M. 2004. Sublethal soil copper concentrations increase mortality in the earthworm Aporrectodea caliginosa during drought. Ecotoxicololgy and Environmental Safety, 57, 65-73.

Garcia, F., Cruse, R.M., and Blackmer, A.M. 1988. Compaction and nitrogen placement effect on root growth, water depletion, and nitrogen uptake. Soil Sci Soc Am J, $52(3), 792-798$. 
Gregory, N.G., Wilkins, L.J. and Wotton, S.B. 1991. Effect of electrical stunning frequency on ventricular fibrillation, downgrading and broken bones in broilers, hens and quails. British Veterinary Journal, 47 (1), 71-77.

Gundale, M.J. 2002. The influence of exotic earthworms on the soil organic horizon and the rare fern Botrychium mormo. Conservation Biology 16, 1555 -1561.

Haimi, J., Huhta, V. and Boucelham, M. 1992. Growth Increase of Birch Seedlings under the Influence of Earthworms - a Laboratory Study. Soil Biology and Biochemistry, 24 (12), 1525-1528.

Hata, T.Y., Hara, A.H. and Hu, B.K.S. 1997. Molluscicides and mechanical barriers against slugs, Vaginula plebeia Fischer and Veronicella cubensis (Pfeiffer) (Stylommatophora: Veronicellidae).Crop Protection, 16 (6), 501-506.

Hendrix, P. F. and Bohlen, P. J. 2002. Exotic Earthworm Invasions in North America: Ecological and Policy Implications. BioScience, 52 (9), 801-811.

Hendrix, P.F. 1998. Earthworms in agroecosytems: a summary of current research, in Earthworm ecology, 259-269.

Hinrich L.B., Ben-Asher, J., Tabbara, H.S. and Marwan, M. 1982. Theories and tests of electrical conductivity in soils. Soil Science Society of America Journal, 46, $1143-1146$

Hubbard, V.C., Jordan, D. and Stecker, J.A. 1999. Earthworm response to rotation and tillage in a Missouri claypan soil. Biology and Fertility of Soils, 29 (4), 343-347. 
Jongmans, A.G., Pulleman, M.M., Balabane, M., van Oort, F. and Marinissen, J. C. Y. 2003. Soil structure and characteristics of organic matter in two orchards differing in earthworm activity. Applied Soil Ecololgy, 24, 219-232.

Kim, H.H., Choo, H.Y., Lee, H.S., Cho, S.R., Shin, H.Y., Park, C.G. and Choo, Y.M. 2000. Occurrence and damage of Bradysia agrestis Sasakawa (Diptera: Sciaridae) in propagation house. Korean Journal of Applied Entomology, 39 (2), 89-97.

Knight, D., Elliott, P.W., Anderson, J.M. and Scholefield, D. 1992. The role of earthworms in managed, permanent pastures in Devon, England. Soil Biology and Biochemistry, 24 (12), 1511-1517.

Kolz, L. 1995. Electroshock repulsion of waterfowl, aquatic animals, and small mammals. United States Department of Agriculture Patents. $(5,460,123) 1$ p.

Kravcov, P.V. 1962. The effect of supplementary electricity on the intensification of microbiological processes in the rhizosphere of plants and fallow soil. Agrobiologia (2), 253-257.

Kurstjens, D.A.G. and Weide, R.Y.van. der. 2000. Adaptation of cultivation and mechanization: solution for labour problem during weed control. Landbouwmechanisatie, 51 (5), 20-21.

Lattaud, C., Zhang, B.G., Locati, S., Rouland, C. and Lavelle, P. 1997. Activities of the digestive enzymes in the gut and in tissue culture of a tropical geophagous earthworm, Polypheretima elongata (Megascolecidae). Soil Biology and Biochemistry, 29 (3/4), 335-339. 
Lipson, M. 1997. Searching for the "O-Word": analyzing the USDA current research information system for pertinence to organic farming. Organic Farming research foundation, Policy program.

Lui, S. X., Xiong, D. Z. and Wu, D. B. 1991. Studies on the effect of earthworms on the fertility of red-arid soil. Advances in management and conservation of soil fauna, Proceedings of the 10th International Soil Zoology Colloquium, held at Banglador, India, August 7-13.

Marininssen, J.C.Y. and Hillenaar, S.I. 1997. Earthworm-induced distribution of organic matter in macro-aggregates from differently managed arable fields. Soil Biology and Biochemistry, 29 (3/4), 391-395.

McInerney, M. and Bolger, T. 2000. Temperature, wetting cycles and soil texture effects on carbon and nitrogen dynamics in stabilized earthworm casts. Soil Biology and Biochemistry, 32 (3), 335-349.

McSpadden-Gardener, B. and Fravel, D. 2002. Biological control of plant pathogens: Research, commercialization, and application in the USA. Online. Plant Health Progress doi:10.1094/PHP-2002-0510-01-RV.

Ndegwa, P.M. and Thompson, S.A. 2000. Effects of C-to-N ratio on vermicomposting of biosolids. Bioresource Technology, 75, 7-12.

Ndegwa, P.M., Thompson, S.A., Das, K.C., 1999. Effects of stocking density and feeding rate on vermicomposting of biosolids. Bioresource Technology, 71 (1), $5-1$.

Orozco, F.H. Cegarra, J., Trujillo, L.M. and Roig, A. 1996. Vermicomposting of coffee pulp using the earthworm Eisenia fetida: effects on $\mathrm{C}$ and $\mathrm{N}$ contents and the availability of nutrients. Biology and Fertility of Soils, 22 (1/2), 162-166. 
Pang, X.P. and Letey, J. 2000. Organic farming: challenge of timing nitrogen availability to crop nitrogen requirements. Soil Science Society of America Journal, 64 (1), 247-253.

Parmelee, R.W. and Crossley, D.A. Jr. 1988. Earthworm production and role in the nitrogen cycle of a no-tillage agroecosystem on the Georgia piedmont. Pedobiologia, 32 (5/6), 355-361.

Pashanasi, B., Lavelle, P., Alegre, J. and Charpentier, F. 1996. Effect of the endogeic earthworm, Pontoscolex corethrurus on soil chemical characteristics and plant growth in a low-input tropical agroecosystem. Soil Biology and Biochemistry, 28 (6), 801-808.

Pashanasi, B., Melendez, G. Szott, L. and Lavelle, P. 1992. Effect of inoculation with the endogeic earthworm Pontoscolex corethrurus (Glossocolecidae) on N availability, soil microbial biomass and the growth of three tropical fruit tree seedlings in a pot experiment. Soil Biology and Biochemistry, 24 (12), 16551659 .

Phillips, V.R. 1988. Engineering problems in the breakdown of animal wastes by earthworms, in Earthworms in waste and environmental management. C. Edwards, and Neuhauser, F., Editors. The Hague, 111-118.

Picek,T., Simek, M. and Santruckova, H. 2000. Microbial responses to fluctuation of soil aeration status and redox conditions. Biology and Fertility of Soils, 31 (3/4), 315-322.

Poole, D.W., Western, G. and McKillop, I.G. 2004. The effects of fence voltage and the type of conducting wire on the efficacy of an electric fence to exclude badgers (Meles meles). Crop protection, 23 (1), 27-33. 
Pozdnyakova, L. 1999. Electrical properties of Soils. Unpublished PhD dissertation, U of Wyoming, Laramie.

Rayleigh, Lord. 1915. The principle of similitude. Nature, 95, 66-68.

Reinecke, S.A ., Helling, B. and Reinecke, A.J. 2002. Lysosomal response of earthworm (Eisenia fetida) coelomocytes to the fungicide copper oxychloride and relation to ecologically relevant endpoints. Environmental Toxicology and Chemistry, 21, 1026-1031.

Rhoades, J. D. 1996. Salinity: Electrical conductivity and total dissolved solids. p. 417435. In: Methods of Soil Analysis, Part 3, Chemical Methods. Soil Science Society of America, Madison, WI, USA.

Riskowski, G.L., Chang, A.C., Steinberg, M.P. and Day, D.L. 1991. Methods for evaluating odor from swine manure. Applied Engineering in Agriculture, 7 (2), 248-253.

Robb, D.H.F., O'Callaghan, M., Lines, J.A. and Kestin, S.C. 2002. Electrical stunning of rainbow trout (Oncorhynchus mykiss): factors that affect stun duration. Aquaculture, 205 (3/4), 359-371.

Rodriguez-Aragones, C. and Martinez-Leiva-M-de-los, A.M. 2001. Earthworm communities (Annelida: Oligochaeta) of a dairy waste channel in a pastoral area in Cuba. Revista Biologia Habana, 15 (1), 37-44.

Rossi, J.P., Lavelle, P. and Albrecht, A.1997. Relationships between spatial pattern of the endogeic earthworm Polypheretima elongata and soil heterogeneity Soil Biology and Biochemistry, 29 (3/4), 485-488. 
Rushton S.P. and Luff, M.L. 1984. A new electrical method for sampling earthworm populations. Pedobiologia, 27 (1), 15-19.

Ruz-Jerez, B.E. Ball, P.R. and Tillman, R.W. 1992. Laboratory assessment of nutrient release from a pasture soil receiving grass or clover residues, in the presence or absence of Lumbricus rubellus or Eisenia foetida. Soil Biology and Biochemistry, 24 (12), 1529-1534.

Santamaria-Romero, S, Ferrera-Cerrato, R, Almaraz-Suarez, J.J., Galvis-Spinola, A. and Barois-Boullard, I. 2001. Dynamics and relationships among microorganisms, $\mathrm{C}$-organic and N-total during composting and vermicomposting. Agrociencia Montecillo, 35(4), 377-384.

Schmidt, O, Curry, J.P., Hackett, R.A., Purvis, G. and Clements, R.O. 2001. Earthworm communities in conventional wheat monocropping and low-input wheat-clover intercropping systems. Annals of Applied Biology, 138 (3), 377-388.

Scholl, D.G. 1978. A two-element ceramic sensor for [soil water] matric potential and salinity measurements. Soil Science Society of America Journal, 42 (3), 429432.

Schonholzer, F., Hahn, D. and Zeyer, J. 1999. Origins and fate of fungi and bacteria in the gut of Lumbricus terrestris L. studied by image analysis. FEMS Microbiology Ecology, 28 (3), 235-248.

Shipitalo, M.J. 1987. Soil structure formation and stabilization by earthworms and tillage effects on soil porosity. PhD University of Guelph Canada.

Slowik, T.J., Thorvilson, H.G. and Green, B.L. 1996. Red imported fire ant (Hymenoptera: Formicidae) response to current and conductive material of active electrical equipment. Journal of Economical Entomology, 89 (2), 353-358. 
Spurgeon, D.J., Svendsen, C., Kille, P., Morgan, A.J. and Weeks, J.M. 2004. Responses of earthworms (Lumbricus rubellus) to copper and cadmium as determined by measurement of juvenile traits in a specifically designed test system. Ecotoxicology and Environmental Safety, 57, 54-64.

Stephens, P.M. and Davoren, C.W. 1997. Influence of the earthworms Aporrectodea trapezoides and $A$. Rosea on the disease severity of Rhizoctonia solani on subterreanean clover and ryegrass. Soil Biology and Biochemistry, 29 (3/4), 511 516.

Stephens, P.M., Davoren, C.W., Ryder, M.H., Doube, B.M. and Correll, R.L. 1994. Field evidence for reduced severity of Rhizoctonia bare-patch disease of wheat, due to the presence of the earthworms Aporrectodea rosea and Aporrectodea trapezoides. Soil Biology and Biochemistry, 26 (11), 1495-1500.

Surbrook., T. and Schrandt, J.M. A review of stray voltage research. Michigan Agricultural Electric Council, Michigan State University. Website; Available: [http://www.egr.msu.edu/age/MAEC/review.html] Accessed: 30-8-2005.

Szczech, M. and Smolinska, U. 2001. Comparison of suppressiveness of vermicomposts produced from animal manures and sewage sludge against Phytophthora Breda de Haan var. nicotianae. Phytopath Z., 149 (2), 77-82.

Szczech, M., Rondomanski, W., Brzeski, M.W., Smolinska, U. and Kotowski, J. 1993. Suppressive effect of a commercial earthworm compost on some root infecting pathogens of cabbage and tomato. Biological Agriculture and Horticulture, 10 (1), 47-52.

Tebrugge, F. and During, R.A. 1999. Reducing tillage intensity - A review of results from a long-term study in Germany. Soil and Tillage Research, 53 (1), 15-28. 
The national organic program, Economic research service, USDA 2000.

[http://www.ams.usda.gov/nop/regtext.htm]. Accessed: 12-11-2004.

Tomati, U., Grapelli, A. and Galli, E. 1987. The hormone-like effect of earthworm casts on plant growth. Biology and Fertility of Soils, 5 (4), 288-294.

Tomlin, A.D., McCabe, D. and Protz, R. 1992. Species composition and seasonal variation of earthworms and their effect on soil properties in southern Ontario, Canada. Soil Biology and Biochemistry, 24 (12), 1451-1457.

USDA Agricultural Marketing Services. 2000. Program Standards [http://www.ams.usda.gov/nop/NOP/standards/Intro.html]. Accessed: 12-112004.

Varshney, P., Kanwar, R.S., Baker, J.L. and Anderson, C.E. 1993. Tillage and nitrogen management effects on nitrate-nitrogen in the soil profile. Transactions of the ASAE, 36 (3), 783-789.

Weindorf, D.C. and Wittie, R. 2003. Determining Particle Density in Dairy Manure Compost. The Texas Journal of Agriculture and Natural Resource, 16, 60-63.

Wszelaki, A.L., Walker, S.D., Steiner C.P. and Miller, S.A. 2003. Evaluation of alternatives for the control of foliar and fruit diseases of organic processing tomatoes, 2002. Biological and Cultural Tests for Control of Plant Diseases (Online). Report 18:PT008. DOI:10.1094/BC18.

Zhao, S.W. and Huang, F.Z. 1988. The nitrogen uptake efficiency from 15N labeled chemical fertilizer in the presence of earthworm manure (cast). Advances in management and conservation of soil fauna, Proceedings of the 10th International Soil Zoology Colloquium, held at Banglador, India, August 7-13. 


\section{APPENDIX A}

The effect of aeration on feed ingestion by earthworms 
In this experiment the effect of mechanical aeration on the rate of feed incorporation into the soil by earthworms was evaluated. Pots with a $3.9 \mathrm{~cm}$ diameter were filled with $300 \mathrm{~g}$ moist soil mix (55\% commercial compost, $30 \%$ sandy loam and $15 \%$ commercial fine white sand) up to a volume of $390 \mathrm{ml}$, resulting in a soil bulk density of $0.77 \mathrm{~g} / \mathrm{cm}^{3}$. A quantity of E. hortensis earthworms equivalent to $16 \mathrm{~g}+/-$ $0.3 \mathrm{~g}$ was placed in each pot. Soil moisture was successfully maintained through three capillary tubes (Fisher catalog \# 22-260-943) immersed in a water cup placed underneath the pot. The capillary tubes were glued to the bottom of the pot, with half a centimeter protruding into the pot. Two trials were conducted; the total air flow in the first one was $25 \mathrm{cc} /$ minute $(2.78 \mathrm{cc}$ per tube, nine tubes) and $18 \mathrm{cc}$ in the second trial $\mathrm{c}(3 \mathrm{cc}$ per tube, 6 tubes). The first trial consisted of two treatments and a control (no airflow); one where one airflow-conducting tube was placed at $3.5 \mathrm{~cm}$ soil depth, and another where two tubes were placed $2 \mathrm{~cm}$ apart along the pot's surface center line, at $1.5 \mathrm{~cm}$ soil depth each. The second trial consisted of a control and one treatment, where two airflowconducting tubes were placed at $2.5 \mathrm{~cm}$ soil depth. In all treatments feed was added on the surface of the pots in the form of a blue paste consisting of 1:3 corn flour: bluecolored water ratio (using food colorant). Feed covers made from duct tape were added over the feed to create dark conditions and allow surface earthworm feeding. Pots were monitored several times a day and the time when all blue feed was incorporated into the soil was recorded. Results shown in Figure A.1 indicate that when tubes delivered airflow into the soil (the equivalent of $5.56 \mathrm{cc} /$ minute in trial 1 , and $6 \mathrm{cc} /$ minute in trial 2), the time required until complete incorporation of the feed into the soil was 
significantly decreased. This implies that aeration could increase the rate at which earthworms process organic matter.
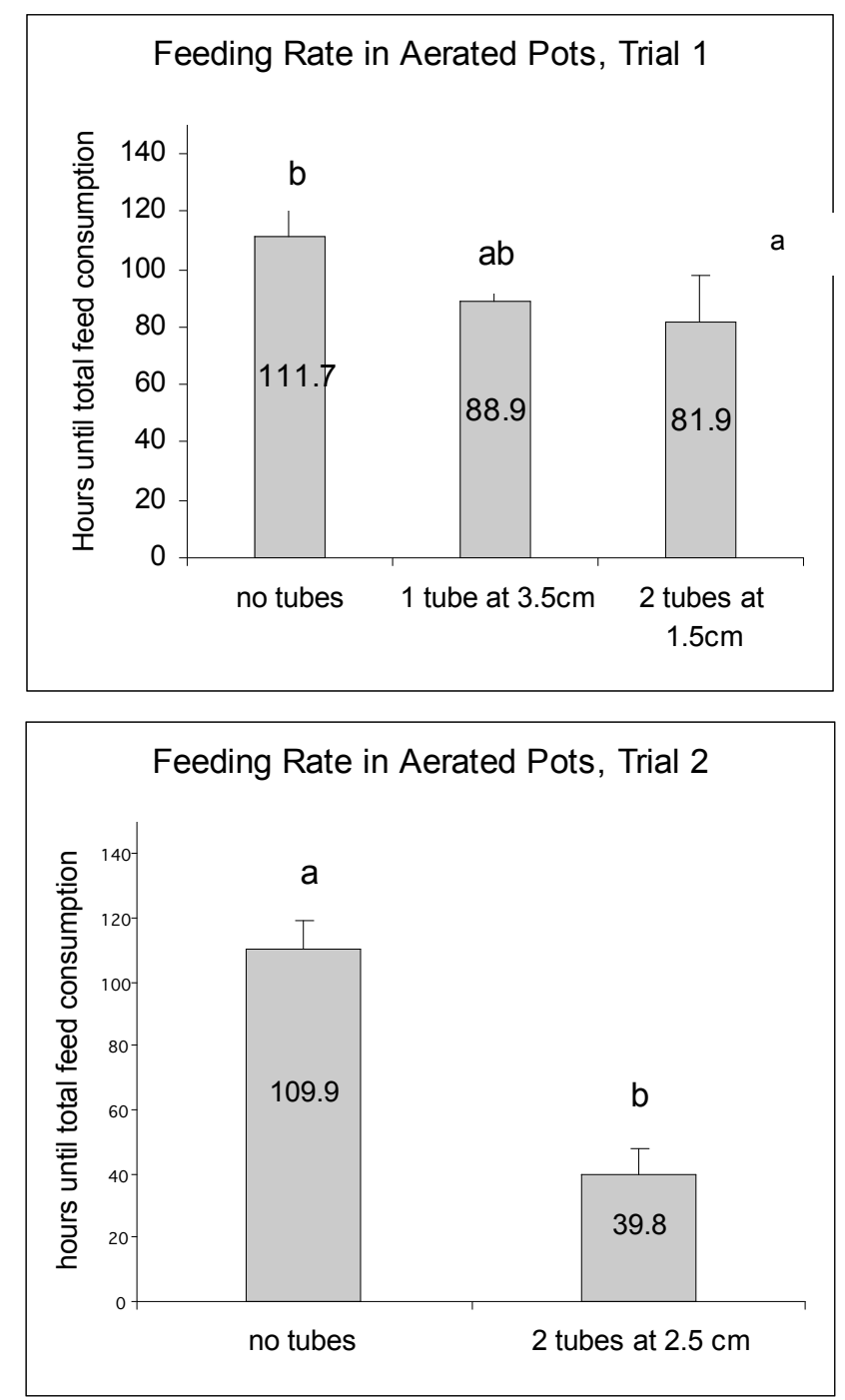

Figure A.1. a) Trial 1 and b) Trial 2 of a study showing the effect of mechanical aeration on earthworm feeding rate, shown in hours until full incorporation of feed into the soil (Significant treatment differences at the 5\% level using Tukey's test between treatment means are indicated by differing letters). 


\section{APPENDIX B}

The effect of species distribution on the rate of feed ingestion by earthworms 
Determining the most efficient earthworm species distribution could potentially lower the amount of earthworms to be invested in plots. This experiment evaluates the effect of earthworm species distribution on the rate of feed ingestion by earthworms. $1 \mathrm{ml}$ of semiliquid blue-colored feed (a 1:3 weight ratio of corn flower and blue-colored water) was added on top of earthworm casts, per gram of fresh earthworm weight. The treatments were $0,33,66$, and $100 \%$ E. foetida by weight in the E. foetida and $E$. hortensis species distribution. Each treatment was replicated three times and each replicate consisted of a $175 \mathrm{ml}$ flask with around 4 grams of earthworms and the corresponding volume of feed. Two trials were conducted with $20 \mathrm{~g}$ of media in the first and $7 \mathrm{~g}$ in the second. Replicates were monitored every 6 hours and a picture taken to evaluate feed consumption, based on the disappearance of the blue puddle created by the feed. Results are shown in Figure 2.2 and discussed in section 2.3. Results showed that an E. foetida / E. hortensis species mix containing 100 to $66 \%$ E. foetida is estimated to be the most efficient at incorporating feed from the surface. As shown in Figure B.1, there was no significant difference between the $100 \%$ and $66 \%$ levels of $E$. foetida as to the speed of feed incorporation, but both are significantly more efficient at incorporating feed than populations with $0-33 \%$ E. foetida in the species distribution. 


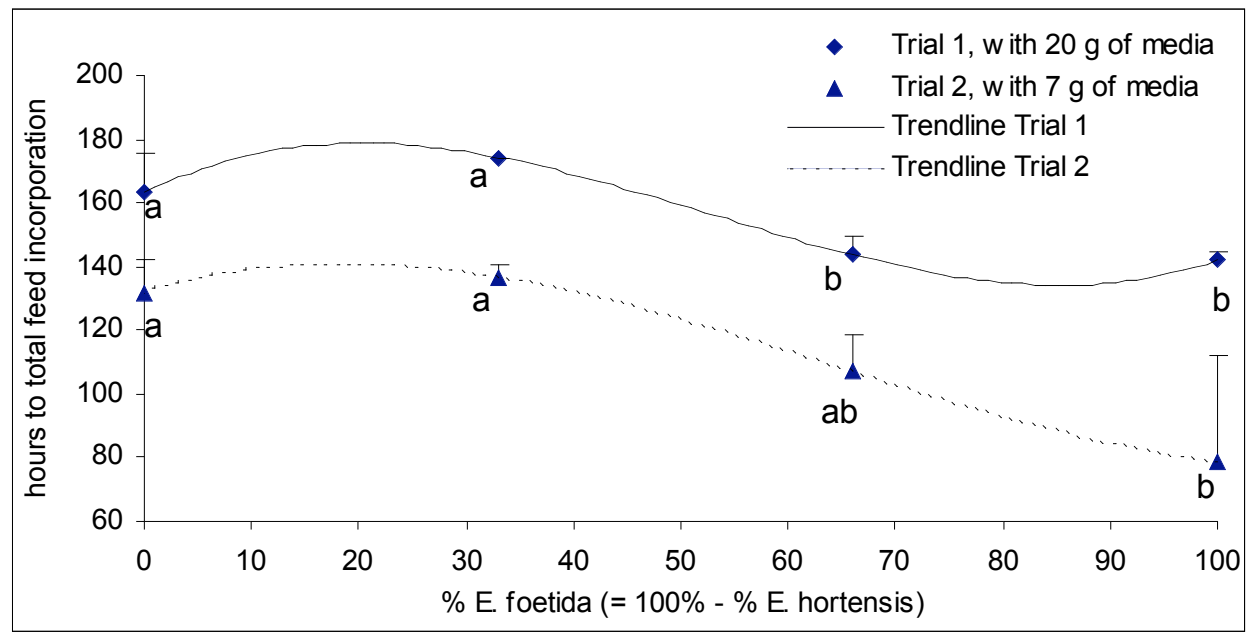

Figure B.1. Elapsed time for feed incorporation in hours vs. the percentage of E. foetida in the distribution of endogeic and epigeic species. Each trial was analyzed for significant treatment differences separately and significant treatment differences at the 5\% level using Tukey's test are indicated by differing letters. 